
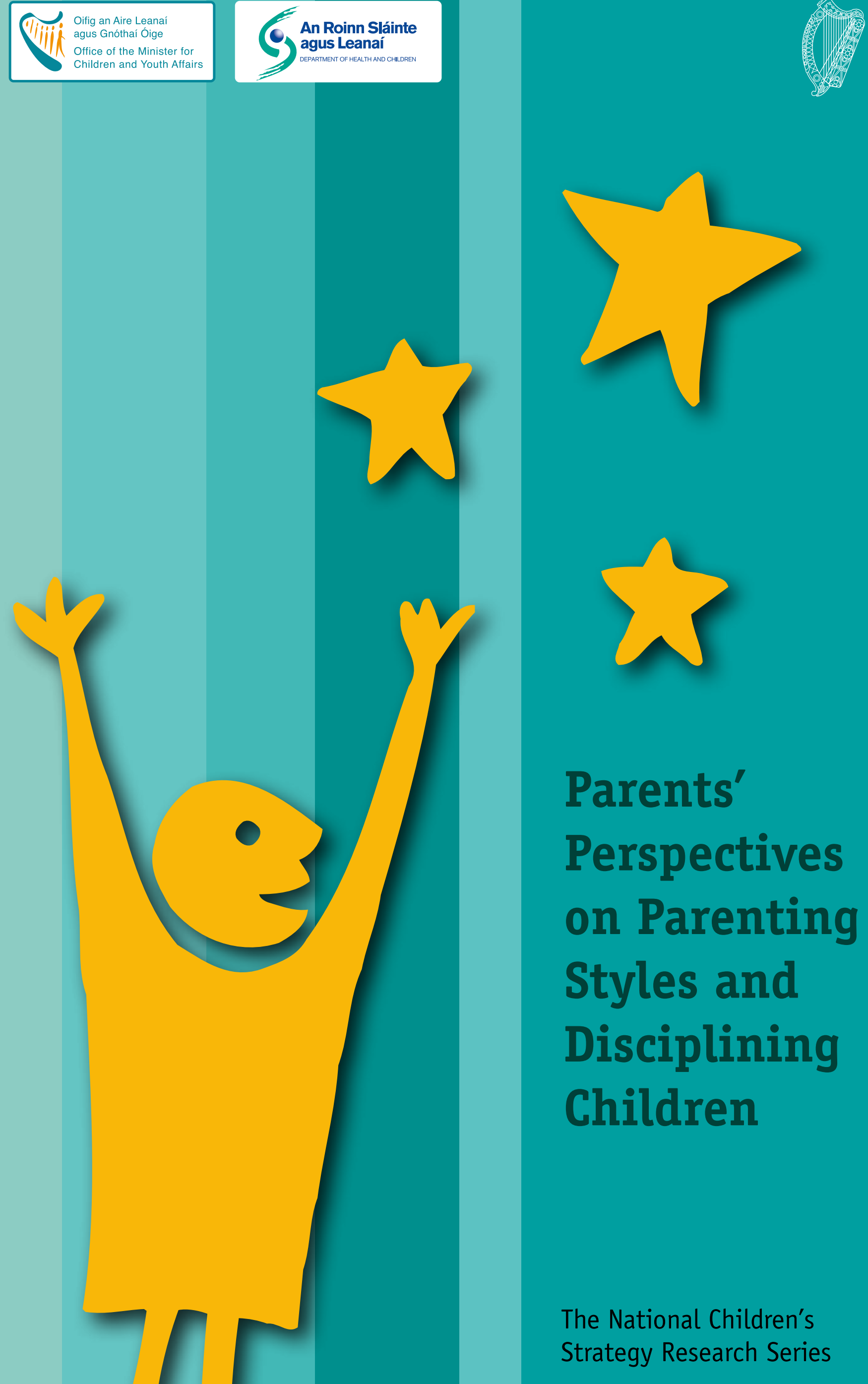



\section{Parents' Perspectives on Parenting Styles and Disciplining Children}




\section{The authors of this report are:}

Ann Marie Halpenny, School of Social Sciences \& Law and Centre for Social and Educational Research, Dublin Institute of Technology; Elizabeth Nixon, School of Psychology and Children's Research Centre, Trinity College, Dublin; and

Dorothy Watson, Economic and Social Research Institute.

Copyright () Minister for Health and Children, 2010 Office of the Minister for Children and Youth Affairs Department of Health and Children

Hawkins House

Hawkins Street

Dublin 2

Tel: +353 (0)1 6354000

Fax: $+353(0) 16743223$

E-mail: omc@health.gov.ie

Web: www.omcya.ie

Published by The Stationery Office, Dublin

All rights reserved. No part of this publication may be reproduced, stored in a retrieval system, or transmitted, in any form or by any means, electronic, mechanical, photocopying, recording or otherwise, without the prior permission in writing of the copyright holder.

For rights of translation or reproduction, applications should be made to the Head of Communications, Office of the Minister for Children and Youth Affairs, Hawkins House, Hawkins Street, Dublin 2, Ireland. 


\section{Contents}

ACKNOWLEDGEMENTS vi

$\begin{array}{lr}\text { EXECUTIVE SUMMARY } & 1\end{array}$

$\begin{array}{lr}\text { Study overview } & 1\end{array}$

Methodology 1

Key findings

General views on parenting $\quad 2$

Parental discipline practices $\quad 2$

Parental use of physical punishment 2

Intergenerational transmission of discipline strategies $\quad 3$

Parenting styles $\quad 3$

Parental attitudes to physical punishment $\quad 3$

Awareness and understanding of legislation on physical punishment 3

Conclusions

1. INTRODUCTION AND OVERVIEW 5

Contemporary perspectives on parenting 6

$\begin{array}{ll}\text { Changing family contexts in Ireland } & 7\end{array}$

Defining discipline and physical punishment $\quad 8$

Prevalence of physical punishment $\quad 8$

Legislative context $\quad 9$

$\begin{array}{lr}\text { Irish legislative context } & 10\end{array}$

$\begin{array}{ll}\text { Study aims and objectives } & 10\end{array}$

$\begin{array}{ll}\text { Research approach } & 11\end{array}$

2. LITERATURE REVIEW 13

$\begin{array}{lr}\text { Theoretical frameworks } & 14\end{array}$

$\begin{array}{lr}\text { Factors influencing parental discipline strategies } & 16\end{array}$

$\begin{array}{ll}\text { Child characteristics } & 16\end{array}$

$\begin{array}{ll}\text { Parent characteristics } & 18\end{array}$

$\begin{array}{ll}\text { Contextual factors } & 19\end{array}$

Effects of physical punishment on children $\quad 20$

$\begin{array}{ll}\text { Conclusion } & 23\end{array}$

3. DESIGN AND METHODS 25

Research instruments $\quad 26$

$\begin{array}{lr}\text { Standardised measures } & 27\end{array}$

$\begin{array}{ll}\text { Pilot study } & 28\end{array}$

Interviewer training $\quad 28$

Sampling and recruitment $\quad 28$

Sample for Monthly Consumer Survey $\quad 29$

Sample size and response rates to Monthly Consumer Survey 29

Willingness to be re-contacted for Parenting Survey 30

Re-weighting the data $\quad 32$

Ethical issues $\quad 33$

$\begin{array}{ll}\text { Data analysis } & 34\end{array}$

$\begin{array}{ll}\text { Study limitations } & 34\end{array}$ 
Profile of parents $\quad 38$

$\begin{array}{ll}\text { Profile of households } & 39\end{array}$

$\begin{array}{lr}\text { Profile of children } & 40\end{array}$

$\begin{array}{lr}\text { Summary } & 41\end{array}$

5. PRESSURES, PRIORITIES AND PLEASURES IN PARENTING 43

$\begin{array}{ll}\text { Changing parenting contexts } & 44\end{array}$

$\begin{array}{ll}\text { Perceived pressures on parenting } & 45\end{array}$

$\begin{array}{ll}\text { Support from spouse/partner } & 46\end{array}$

$\begin{array}{ll}\text { Parental values and expectations } & 47\end{array}$

$\begin{array}{ll}\text { Involving children in decisions } & 47\end{array}$

$\begin{array}{lr}\text { What parents enjoy most about parenting } & 48\end{array}$

Key findings $\quad 49$

$\begin{array}{ll}\text { Discussion } & 50\end{array}$

6. PARENTING STYLES AND DISCIPLINE PRACTICES 53

Discipline strategies adopted by parents $\quad 54$

Non-aggressive discipline strategies $\quad 55$

Psychologically aggressive discipline strategies $\quad 56$

$\begin{array}{ll}\text { Physical punishment discipline strategies } & 58\end{array}$

$\begin{array}{ll}\text { Physical punishment as an adjunct to other discipline strategies } & 61\end{array}$

$\begin{array}{ll}\text { Parental experience of discipline strategies in childhood } & 61\end{array}$

$\begin{array}{ll}\text { Non-aggressive discipline strategies } & 61\end{array}$

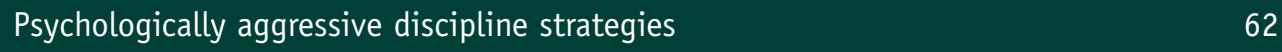

$\begin{array}{ll}\text { Physical punishment } & 63\end{array}$

Intergenerational transmission of physical punishment $\quad 64$

$\begin{array}{ll}\text { Parenting styles } & 64\end{array}$

$\begin{array}{ll}\text { Discipline strategies and child behaviour } & 67\end{array}$

Comparison of findings with UK-based studies $\quad 68$

$\begin{array}{ll}\text { Key findings } & 69\end{array}$

$\begin{array}{ll}\text { Discussion } & 70\end{array}$

7. PHYSICAL PUNISHMENT - ATTITUDES, CONTEXT AND RATIONALES 73

$\begin{array}{ll}\text { Attitudes towards smacking } & 74\end{array}$

$\begin{array}{ll}\text { Social class } & 75\end{array}$

$\begin{array}{ll}\text { Education level of parent } & 75\end{array}$

$\begin{array}{ll}\text { Age of parent } & 76\end{array}$

$\begin{array}{ll}\text { Parental use of physical punishment } & 76\end{array}$

$\begin{array}{ll}\text { Effectiveness of smacking } & 76\end{array}$

$\begin{array}{ll}\text { Rationales for using physical punishment } & 77\end{array}$

$\begin{array}{ll}\text { Contexts in which physical punishment occurs } & 79\end{array}$

Child behaviour as a context for physical punishment $\quad 80$

Parents' emotional responses following the use of physical punishment 82

Parents' understanding of Irish law in relation to physical punishment 82

Key findings $\quad 86$

Discussion $\quad 86$ 
8. DISCUSSION AND CONCLUSIONS

Parenting and discipline in context

Parenting styles and discipline strategies

Intergenerational continuity and change in discipline strategies

Physical punishment as an adjunct to other discipline strategies

Attitudes, acceptance and behaviours

Summary

Conclusions

REFERENCES 


\section{Acknowledgements}

We would like to express our sincere thanks to the Office of the Minister for Children and Youth Affairs for providing funding for this study.

We also wish to thank the many parents who agreed to participate in the survey. Our special thanks go to Carly Cheevers from the Economic and Social Research Institute (ESRI) and the team of interviewers who worked on the study.

Finally, for their support and advice, our thanks to Professor Noirín Hayes of the Centre for Social and Educational Research, Dublin Institute of Technology; Professor Sheila Greene of the Children's Research Centre, Trinity College, Dublin; and Dr. Deborah Ghate, formerly of the UK Policy Research Bureau.

Ann Marie Halpenny, DIT,

Elizabeth Nixon, TCD and Dorothy Watson, ESRI 


\section{Executive Summary}

\section{Study overview}

Families represent the primary setting in which most children's lives are shaped and determined. Central to the process of the socialisation of children are the parenting behaviours and discipline responses which children experience within family settings. Within these family contexts, children gradually internalise social standards and expectations, which facilitate, in turn, greater selfregulation skills and responsibility. Knowledge of the range of disciplinary tactics used by parents and of parental beliefs and attitudes to discipline strategies is, therefore, essential in order to promote and support effective and constructive parental discipline responses with children and young people.

The present study sought to investigate the parenting styles and parental use of disciplinary strategies with children in Ireland, with a particular focus on attitudes to and uses of physical punishment. A further aim of the research was to identify parental attitudes to the legislative position in relation to physical punishment and children. The study adopted a telephone survey methodology, involving interviews with 1,353 women and men, with at least one child younger than 18 years of age, living in private households.

Specifically, the following questions were addressed:

- What parenting goals and expectations for their children do parents in Ireland have today?

- What are parents' perspectives on Irish society as a context for parenting and what pressures do parents experience?

- What parenting styles and discipline strategies do parents use? To what extent do parents use physical punishment as a method of discipline?

- Under what circumstances do parents employ certain approaches to discipline?

- What are parents' attitudes towards physical punishment?

- Are parents aware of the current legislative position on physical punishment?

- What are parents' perspectives on potential legislative change?

- How do child-rearing goals, parenting styles and approaches to discipline and attitudes towards physical punishment vary according to the age, gender and social class of parents and children?

\section{Methodology}

A telephone survey methodology was adopted in the present study and data collection was carried out by the Economic and Social Research Institute. The design was a three-stage clustered sample: the first stage involved the selection of the primary sampling unit from the GeoDirectory; the second stage involved the selection of the household within each of 200 sampling units; and the third stage involved the selection of the actual individual within the household who completed the questionnaire. A total of 1,353 parents participated in the survey. Parents ranged in age from 21 to 69 years (mean $=40.45$ years; s.d. $=7.98$ ), with $79 \%$ of them being married and/or living with their spouses.

The survey questionnaire was developed to explore the parenting styles and discipline strategies typically adopted by parents and the factors underpinning parental behaviour. More specifically, the questionnaire covered the following topics:

- details of household and randomly selected child;

- general views on parenting in Ireland, attitudes towards smacking and the contexts in which it occurs;

- discipline strategies experienced by parents in childhood; 
- parenting styles and discipline strategies adopted by parents with their children, including a focus on physical punishment;

- attitudes to and awareness of legislation on physical punishment of children in Ireland.

Standardised measures of temperament, child behaviour and parenting style were adapted for use in the present study.

\section{Key findings}

\section{General views on parenting}

- Most parents expressed the view that parenting had changed substantially when compared with parenting 20 years ago. Degrees of parental responsibility and pressure on parents were viewed as having increased, while a decrease in levels of parental control was highlighted.

- Key pressures for parents were concerns about the physical and psychological well-being of their children, concerns about their educational outcomes and worries about financial issues. Over three-quarters of parents asserted that their own work responsibilities impacted substantially on bringing up their children, while, at the same time, perceived levels of spousal/partner support were high.

- In the child-rearing goals of parents, characteristics related to pro-social behaviours, selfdirection and autonomy were emphasized as being most important to teach children, while just one-third of respondents prioritised including children in decision-making with regard to family issues.

- Enjoyment of the parental role was associated with the sense of fulfilment and achievement parents experienced as a result of the healthy and successful development of their children. Additional pleasures included spending time in activities with children and family members; engaging with care-giving tasks on a daily basis; reciprocal affections, friendship and companionship in relationships; and positive child outcomes.

\section{Parental discipline practices}

- Discipline strategies adopted by parents ranged from inductive, non-aggressive strategies to more coercive strategies, including physical punishment.

- Almost all parents reported using inductive discipline strategies, such as reasoning or discussing an issue with a child. Other non-aggressive discipline strategies, such as making a child take time-out, threatening to ground them or actually grounding them, were highlighted by approximately half the parents interviewed. Age differences were apparent in the parents' approach, with time-out and grounding being used more frequently with children in middle childhood, while setting a chore to complete was more likely to be used with older children in adolescence.

- Psychologically aggressive strategies were not used frequently with children. Shouting, yelling or swearing at a child was most commonly used within this category of response, with just under half of parents reporting that they used this strategy. Other psychologically aggressive strategies included threatening to smack or hit a child (reported by $25 \%$ of parents) and calling a child stupid or lazy (reported by approximately $20 \%$ of parents). Love-withdrawal strategies were the least common behaviours reported by parents within this category of psychologically aggressive responses.

\section{Parental use of physical punishment}

- Approximately one-quarter of all parents reported using physical punishment with their child in the past year. The most common forms of physical punishment reported were slapping a child on the bottom or on the hands, legs or arms, and shaking, grabbing or pushing a child. Child age effects were identified in the use of physical punishment, with children aged 2-9 experiencing physical punishment more frequently than children of other ages. 
- A relationship between parenting behaviours and child behaviour difficulties was apparent, with the proportion of parents who used physical punishment in the past year being highest among families with children classified as having hyperactivity or conduct difficulties. Parents of children with conduct problems engaged more frequently in authoritarian parenting behaviours and levels of verbal hostility were highest in families of children with emotional or conduct problems.

\section{Intergenerational transmission of discipline strategies}

- Parents' recollections of discipline strategies experienced in their own childhood indicated a decrease in psychologically aggressive and physical punishment strategies over time. While there was a strong association between current use of physical punishment and past experience of certain physical punishment responses, the majority of parents who had experienced physical punishment in their childhood did not use physical punishment with their own children.

\section{Parenting styles}

- Parents scored higher on all aspects of authoritative parenting, characterised by warmth and reasoning, compared with authoritarian parenting, characterised by high levels of control. Parents also scored higher on warmth and involvement, induction and reasoning than on democratic participation. Within the authoritarian domain, parents scored higher on verbal hostility and non-reasoning punitive scales than on the corporal punishment sub-scale.

- Older parents were more likely to use democratic participation in their parenting than younger parents, while younger parents were more likely to score higher on corporal punishment. Similarly, parents of younger children scored lower on democratic participation and induction and reasoning. Overall, parents of young children (0-4 years) engaged less frequently in authoritative parenting behaviours than parents of older teenagers (15-17 years).

\section{Parental attitudes to physical punishment}

- There was no clear consensus in terms of parents' attitudes towards smacking. With regard to attitudes towards the potential effects of physical punishment, on the one hand, the majority of parents believed that the odd smack does not do a child any harm. On the other hand, the majority of parents also believed that it is not necessary to use smacking to bring up a wellbehaved child. Similarly, approximately equal proportions of parents agreed and disagreed that smacking can damage the parent-child relationship, that smacking can be necessary as a last resort, and that children who are smacked are likely to be more aggressive.

- Little consensus emerged on the extent to which parents believed in the effectiveness of physical punishment as a discipline strategy. Half the parents expressed the view that physical punishment is effective in stopping misbehaviour at the time, while a slightly lower proportion believed in its effectiveness in preventing later misbehaviour. However, there was a clear association between beliefs in the effectiveness of physical punishment and parental use of physical punishment in the past year: those who believed in the effectiveness of physical punishment were more likely to have used physical punishment in the past year.

- Clearer patterns of consensus emerged with regard to justifications for physical punishment. The majority of parents rejected rationales underpinned by notions of domination or coercion, such as letting off steam, acting without thinking or letting a child know who is boss. Contexts of danger were most strongly endorsed as rationales for the use of physical punishment with children, mainly with the motive of stopping bad behaviour quickly and, to a lesser degree, emphasizing the seriousness of child misbehaviour.

- Negative emotions were reported by parents following their administration of physical punishment. Specifically, feelings of guilt and remorse were most common and only a minority of parents professed that they felt better after using physical punishment.

\section{Awareness and understanding of legislation on physical punishment}

- A lack of clear understanding about the status of Irish law in relation to physical punishment was evident in interviews with parents. Similar proportions of parents believed that it was illegal or not illegal to smack a child. Some parents believed that the illegality of smacking 
depended on the age of the child. The majority of parents believed that children younger than 5 were too young to be smacked, while almost two-thirds of parents felt that children aged 10 and older were too old to be smacked.

- Clear support for a proposed outright ban on physical punishment did not emerge. Just over one-third of parents (34\%) felt that smacking should remain legal. Almost one-quarter (24\%) stated that whether smacking is made illegal should depend on the age of the child, while $42 \%$ said that smacking should be made illegal. Parents who had used physical punishment in the past year were more likely to reject a proposed ban on physical punishment.

\section{Conclusions}

A key message to emerge from the present study is the need to consider parental discipline strategies within the broader context of parenting and the specifics of the disciplinary incident. Overall, the incidence of physical punishment among parents in Ireland is low compared to findings in similar UK-based studies. Furthermore, physical punishment is typically used in combination with other non-physical discipline strategies. These findings, therefore, highlight the potential to build on parents' existing skills and competencies in order to reinforce the effectiveness of non-aggressive strategies that parents actually use in contemporary family contexts.

It is also worth noting the increased propensity for parents to use physical punishment when they are stressed, anxious about their child's safety or in situations where they feel that they lack control. Some children are also more vulnerable to physical punishment than others - children who are younger and children who display difficult behaviours. These parents may, therefore, require extra support to reduce their reliance on physical punishment and to enable them to develop alternative discipline strategies.

A further point worth highlighting is that although the incidence of physical punishment was relatively low in the present study, many parents did not see the harm in it and believe they have the right to use it as a discipline strategy. Ambivalence in parental attitudes to the use of physical punishment needs to be investigated further and highlights the challenges that a legislative ban on physical punishment would bring to the Irish context. In contrast to discipline strategies involving physical punishment, little emphasis has been placed on the potential effects of psychologically coercive discipline strategies. Despite the low incidence of these strategies being reported in the present study, the potential negative effects of such strategies on children should not be neglected. 
1 INTRODUCTION
AND OVERVIEW 
The profound influence of parenting practices on children's development has been widely documented. A large body of research literature in the UK, USA and Australia has focused on the links between parenting styles, parental discipline responses, child behaviour and children's psychological well-being (Smith et al, 2005; Gershoff, 2002; Parke, 2002; Eisenberg et al, 2001). In Ireland, however, there is little available information on the prevalence of different parental discipline responses or on parental beliefs about and attitudes towards the use of physical chastisement as a form of discipline with children. The present study aims to address these gaps in the Irish research context through an investigation of the parental use of disciplinary strategies with children, with a particular focus on attitudes to and uses of physical punishment. A further aim of the research is to identify parental attitudes to the legislative position in relation to the physical punishment of children. The study adopted a telephone survey methodology involving interviews with 1,353 women and men, with at least one child under 18 years of age, living in private households.

Systems of influence surround family experiences and parenting behaviours are, to a large extent, shaped by social norms and expectations. Potential influences on family and parenting behaviours include community and cultural values, and the associated social and legal policies in which they are embedded. In the following sections, we focus on setting the context in terms of gaining insight into parenting against a broader international background; next, we review the changing settings in which parenting occurs in contemporary Irish society; and, finally, we provide a brief outline of the legislative developments, nationally and internationally, that have informed and guided the present research.

\section{Contemporary perspectives on parenting}

A recent report on parenting in contemporary Europe (Daly, 2007) highlights the following key insights with regard to parenting. Firstly, a strong social component to parenting is emphasized, while at the same time acknowledging that parenting is a private affair, which occurs in a specific family context, imbued with the emotional ties that bind specific family members together. Secondly, parenting is an activity that needs support, with some families having additional needs, as, for example, parents bringing up children alone or in the context of coping with adversity. Thirdly, the importance of recognising that there is no standardised correct approach to parenting is highlighted, but rather a plural approach is advocated, given the increasing diversity in contemporary family experience. Finally, the value of recognising that parenting involves both parents and children is underscored by pointing out the mutually reinforcing nature of child-parent relationships, in which the benefits of positive parenting operate to the mutual advantage of both.

Barber et al (2005) have identified three dimensions of parenting that appear to characterise parental influence across multiple cultural samples, both in industrialised and non-industrialised countries. Parental support, which refers to varied behaviours with 'affective, nurturant or companionate' qualities, is especially relevant to the older child and adolescent's degree of social initiative (ibid, p. 139). Psychological control refers to parents' actions that attempt to change the child's thoughts or feelings, ignores or dismisses the child's views and withdraws love or affection; such parental behaviour has been associated with the development of depressive symptoms later in a child's life. Finally, behavioural control refers to parents' monitoring and knowledge of children's activities and is relevant to the extent of the child's anti-social behaviour.

Differing parental values and needs are associated with variations in child-rearing styles and the discipline responses of parents to their children (Goodnow and Collins, 1990; Pinderhughes et al, 2000). One of the overarching goals of effective parenting is to support children's development - from dependency and external control to internalisation, the ability to take initiative and to be socially responsible (Smith et al, 2005). Within family contexts, children gradually internalise social standards and expectations, a process that facilitates greater self-regulation skills and responsibility for their own behaviours. 
While there is no unique model for effective parenting that can be generalised to all societies and situations, research findings clearly point to parenting practices which are associated with more positive outcomes. These strategies will be reviewed in more depth in Chapter 2. For the moment, it is worth highlighting four parenting activities that have been identified as facilitating more positive parenting experiences (Pecnic, 2007). Nurturing behaviour refers to activities that respond to the child's needs for emotional security, such as the provision of warmth and sensitivity within the relationship. Structure refers to setting boundaries and guiding the child's behaviour through modelling of positive behaviours, without physical or psychological coercion. Recognition refers to the child's need to be respected and acknowledged by parents and to foster the potential for mutual understanding and influence to develop. Finally, empowerment refers to combining a sense of personal control with the ability to affect the behaviour of others; this is conceptualised as a process that necessitates ongoing parental adjustment to the changing developmental tasks of children as they grow older.

As previously outlined, parental discipline strategies are generated within specific socio-cultural contexts. Perceptions about the appropriateness of physical punishment for children are rooted in personal attitudes and values about what is acceptable in the way children should be treated. These attitudes, in turn, are linked to the views and values of the social and cultural context that surrounds the individual (Gracia and Herrero, 2008; Gershoff, 2002). It is, therefore, worthwhile reflecting upon some of the key changes to family contexts in Irish society in order to gain insight into potential factors influencing contemporary parenting beliefs and practices.

\section{Changing family contexts in Ireland}

The increasing pressure that families experience in terms of negotiating the parental role has been highlighted in a recent report focusing on key aspects of changes in Irish family experience (Daly, 2004). A significant challenge identified by most parents was finding the right balance between control and consultation in their parenting interactions with children. Guiding children was, furthermore, viewed by parents to be increasingly more difficult in a society where rules and values were subject to constant fluctuation and parental authority was no longer so clearly supported by society. It is also worth noting that parenting in Irish society frequently occurs within a family routine which involves both parents working, thus creating additional stressors for parenting. Humphreys et al (2000) emphasize that one of the dominant issues facing family life in modern Ireland is the challenge posed by reconciling the growing demands of work with caring responsibilities outside the workplace.

Further changes to family contexts in Irish society involve increasing diversity in family structure and form, which is also likely to impact considerably on parenting values and practices in the Irish context. Rapid growth in the variation of family forms, most notably over the last decade, has contributed to a profile of family type where, according to the latest Census of Population in 2006, fewer than one in five households in Dublin City are now made up of the traditional family unit of husband, wife and children. This decline in traditional family households is also reflected nationwide, although less dramatically so (Central Statistics Office, 2007). The number of divorced persons increased by almost 70\% between 2002 and 2006, making it the fastest growing marital status category. Similarly, the number of lone parents is up $80 \%$ since 1986 , with 190,000 lone parents now resident in the country.

Cultural diversity, in terms of different beliefs, values and practices as they relate to parenting behaviour, is a significant feature of the recent transformation in Irish family life experiences (One Family, 2004). Irish society has seen a substantial increase in the diversity of ethnic origin of parents, with non-nationals now constituting $10 \%$ of the overall population (Central Statistics Office, 2007). These parents are likely to be faced with the challenge of re-assessing their parenting goals and values, and adjusting their child-rearing practices to adapt to the demands of a new cultural environment. A review of international migration patterns has indicated that the majority of the world's families are headed by parents who are raising their children in cultural environments other than those in which they themselves were raised (Timur, 2000). 
Changes in family contexts are likely to impact on parenting practices and these, in turn, will be reflected more broadly in children and young people's behaviours and attitudes beyond the home. In a recent report on student behaviour in secondary schools in Ireland, dramatic social changes and alterations in lifestyle patterns in contemporary Ireland were highlighted (Department of Education and Science, 2006). More specifically, changes were noted in the power attributed to authority figures and altered perspectives on the status granted to young people.

\section{Defining discipline and physical punishment}

Discipline is the process of teaching children the values and normative behaviours of their society (Wissow, 2002). A distinction has been drawn between power-assertive disciplinary methods (i.e. physical punishment, threats or withdrawal of privileges), love-withdrawal disciplinary methods (i.e. withholding attention, affection or approval, or expressing disappointment or disapproval) and inductive discipline (i.e. reasoning, reminding children of rules and explaining the impact of children's behaviour on others). Inductive discipline has been found to be more effective in terms of promoting children's internalisation of moral and social values (Kerr et al, 2004). Holden (2002) further draws a distinction between discipline and punishment, highlighting the important role that discipline plays in emphasizing instruction about what is valuable and the consequences of actions. Durrant (2005, p. 49) defines corporal or physical punishment as 'an action taken by a parent, teacher or caregiver that is intended to cause physical pain or discomfort to a child. It is the application of punishment to the body'.

Debates have been ongoing as to whether it is possible to draw a distinction between physical punishment and physical abuse (Durrant, 2005). Some researchers assert that there are common, everyday types of physical punishment that are qualitatively different from abusive acts (Larzelere, 1993; Baumrind, 1997). On the other hand, others argue that physical punishment and physical abuse are better understood as points on a continuum of violence and that it is impossible to draw a line that distinguishes where punishment ends and abuse begins (Cawson et al, 2000; Graziano, 1994). This debate is further confounded by legal definitions. In Ireland, the UK and a number of other countries, the common law defence 'reasonable chastisement' exists. This is not clearly defined and is, therefore, open to broad interpretation. Durrant (2005) draws attention to using criteria of physical injury alone when defining physical punishment. According to the author, such a definition ignores the psychological dimension of physical punishment and the emotional distress and humiliation it can induce. Furthermore, some physical punishments are aimed specifically at inducing fear, disgust or loss of dignity, rather than inducing pain. Gershoff (2002) considers the nature of the disciplining act itself, classifying behaviours that do not risk significant physical injury (smacking and slapping) as corporal punishment and behaviours that risk injury (punching, kicking, burning) as physical abuse.

\section{Prevalence of physical punishment}

Prevalence estimates of physical punishment are typically based on questionnaires or face-to-face surveys (Cawson et al, 2000). It is possible, therefore, that the prevalence of such a discipline response will be underestimated since parents may be reluctant to self-report, in particular where physical punishment has a low cultural approval level. Durrant (2006) further emphasizes the complexity of measurement due to the wide variety of methods which have been used to estimate the prevalence of physical punishment, yielding a wide range of estimates. Furthermore, all acts of physical punishment are not equivalent in severity and it is useful to look at more customary physical punishment (Larzelere, 2000) in the context of severe and abusive acts of violence against children. An in-depth, comprehensive global study on violence against children was undertaken in 2004 with the aim of reporting on the scale of violence against children across five settings home and family, schools, care and justice systems, the workplace and the community (Pinheiro, 2006). According to the report, almost 53,000 children are estimated to have died worldwide in 2002 as a result of homicide. In some industrialised countries, infants under one year faced three times the risk of homicide than children aged 1-4 years. Such violence was most frequently at the hands of parents. The report also highlighted the fact that discipline through physical 
punishment, bullying and sexual harassment is frequently perceived as normal, particularly when there are no visible or lasting physical effects. With specific reference to corporal punishment, up to $80 \%-90 \%$ of children experience physical punishment in the home, with one-third or more experiencing severe physical punishment resulting from the use of implements. Arising from the recommendations outlined in Pinheiro's 2006 report, the year 2009 has been set as the target date for achieving universal abolition of corporal punishment of children.

More specifically, and closer to the Irish context, studies in the UK show that $58 \%$ of parents reported having used 'mild' forms of physical punishment with children in the past year in England, while $16 \%$ of parents reported ever having used 'severe' physical punishment with their children (Ghate et al, 2003). ${ }^{1}$ These findings were based on a national survey involving 1,250 parents of children aged 0-12 years. In Scotland, a survey of 692 parents indicated that the most common forms of punishment tend to be non-physical (Anderson et al, 2002). Nevertheless, about half the parents interviewed said that they had used some form of physical chastisement within the past year; this figure rose to $77 \%$ of parents of children aged 3-5 years. One-fifth of all parents of children under 5 years said they had used some form of physical chastisement in the past week. In Northern Ireland, $87 \%$ of parents of children aged 4-7 years reported having ever used mild physical punishment with their children (Murphy-Cowan and Stringer, 1999); it is important to note that this study included a relatively small sample size of 371 parents.

\section{Legislative context}

In 1979, Sweden became the first country in the world to prohibit all corporal punishment of children. A primary objective of this prohibition was altering public attitudes and acknowledging children as autonomous individuals (Durrant, 1996; Freeman, 1999; Smith et al, 2005). As pointed out by Smith et al (2005), the emphasis of this change in legislation in the Swedish context was firmly on educating parents about the importance of good parenting practices and, to this end, a major public education campaign accompanied the reform process.

To date, corporal punishment of children is prohibited in all settings (home, schools, penal systems and alternative care) in 18 out of the 47 Member States of the Council of Europe: Austria, Bulgaria, Croatia, Cyprus, Denmark, Finland, Germany, Greece, Hungary, Iceland, Latvia, Netherlands, Norway, Portugal, Romania, Spain, Sweden and the Ukraine (Council of Europe, 2008). In May 2007, the New Zealand Parliament passed - by an overwhelming majority - new legislation effectively prohibiting corporal punishment of children by parents.

The European Court of Human Rights has challenged the concept of 'reasonable chastisement' by parents (Council of Europe, 2007). In September 1998, the European Court unanimously found in the case 'A $v$. United Kingdom' that the corporal punishment of a young English boy by his stepfather was degrading punishment, in breach of Article 3 of the European Convention on Human Rights (European Court of Human Rights, 1998). Prosecution of the stepfather in a UK court had failed on the grounds that the punishment was 'reasonable chastisement'. The European Court found that the UK Government was responsible because the domestic law allowing a defence of 'reasonable chastisement' failed to provide children with adequate protection, including 'effective deterrence'. In the UK, public consultation exercises, incorporating law reform options, have been undertaken in Scotland, Northern Ireland, England and Wales (Smith et al, 2005). The Criminal Justice (Scotland) Act 2003 abandoned a proposed prohibition on the use of physical punishment with children under the age of 3, and instead introduced the concept of 'justifiable assault' of children. Section 51 of the Criminal Justice (Scotland) Act 2003 bans the use of implements to hit children, as well as shaking and blows to the head.

Mild corporal punishment was defined in these studies as smacking, pinching or hitting, slapping on arm, leg, hand or buttocks; did not involve the use of implements; no physical injury sustained. Severe corporal punishment was defined in these studies as repeated, prolonged, or involving the use of implements; causing likely or actual harm; punching, kicking, shaking, knocking down, burning, scalding, threatening with a knife or gun. 


\section{Irish legislative context}

In 1994, the Law Reform Commission in Ireland examined the common law immunity allowing parents to use 'reasonable chastisement' in the correction of their children. The Commission considered it premature to abolish the immunity immediately and recommended that education of parents and the public about the discipline of children could facilitate law reform in due course (Smith et al, 2005).

While the UN Convention on the Rights of the Child does not explicitly mention corporal punishment or physical discipline, several of its Articles are pertinent to the issue of physical punishment (UN, 1989). Most notably, Article 19(1) states that children must be protected from 'all forms of physical or mental violence'. However, physical punishment of children within the home is currently permitted in Ireland by the existence of the common law defence 'reasonable chastisement', which is not clearly defined legally and which is, therefore, open to broad interpretation. According to Shannon (2005), the Irish law on chastisement by parents and corporal punishment is contained in the Irish Non-Fatal Offences Against the Person Act (1997). Parental chastisement is a defence to both a criminal prosecution and a civil claim. The only defence specifically excluded by the Act can be found in Section 24, which abolishes any rule of law giving a teacher immunity from criminal prosecution in respect of any physical chastisement of a pupil.

In June 2005, the European Committee of Social Rights confirmed that Ireland is in breach of its human rights obligations under the European Social Charter as a result of its failure to prohibit all corporal punishment of children. The European Committee found that Article 17 of the Charter requires a prohibition in legislation against any form of violence against children, whether at school, in other institutions, in their home or elsewhere. Reflecting a commitment to the aim of supporting alternative discipline strategies with children, the National Children's Strategy (Department of Health and Children, 2000, p. 74) states: 'Quality parenting programmes are to be made available to all parents. As part of a policy of ending physical punishment, parenting courses will focus on alternative approaches to managing difficult behaviour in children.'

To date, however, a gap still remains in Ireland in our understanding of the styles of parenting, including discipline and punishment approaches that parents adopt. The current study aims to address this gap by identifying the main parenting styles and forms of discipline used by parents in Ireland today.

\section{Study aims and objectives}

The primary aim of this research is to identify the main parenting styles and forms of discipline used in Ireland by parents with children up to the age of 18 , with a particular focus on attitudes to and use of physical punishment. A further aim of the research is to identify parental attitudes to the legislative position in relation to physical chastisement and children. Specifically, the following questions are addressed:

- What parenting goals and expectations for their children do parents in Ireland have today?

- What are parents' perspectives on Irish society as a context for parenting and what pressures do parents experience?

- What parenting styles and discipline strategies do parents use? To what extent do parents use physical punishment as a method of discipline?

- Under what circumstances do parents employ certain approaches to discipline?

- What are parents' attitudes towards physical punishment?

- Are parents aware of the current legislative position on physical punishment?

- What are parents' perspectives on potential legislative change?

- How do child-rearing goals, parenting styles and approaches to discipline and attitudes towards physical punishment vary according to the age, gender and social class of parents and children? 


\section{Research approach}

A telephone survey methodology was adopted in the present study and data collection was carried out by the Economic and Social Research Institute (ESRI) between December 2007 and April 2008 (see Chapter 3 for full details of survey). A total of 1,353 parents participated in the survey. Parents ranged in age from 21 to 69 years (mean $=40.45$ years; s.d. $=7.98$ ), with $79 \%$ of them being married and/or living with their spouses.

The survey questionnaire was developed to explore the parenting styles and discipline strategies typically adopted by parents and the factors underpinning parental behaviour. More specifically, the questionnaire covered the following topics:

- details of household and randomly selected child;

- general views on parenting in Ireland, attitudes towards smacking and the contexts in which it occurs;

- discipline strategies experienced by parents in childhood;

- parenting styles and discipline strategies adopted by parents with their children, including a focus on physical punishment;

- attitudes to and awareness of legislation on physical punishment of children in Ireland.

Standardised measures of temperament, child behaviour and parenting style were adapted for use in the present study. 


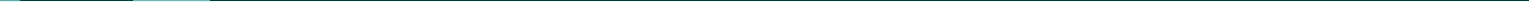




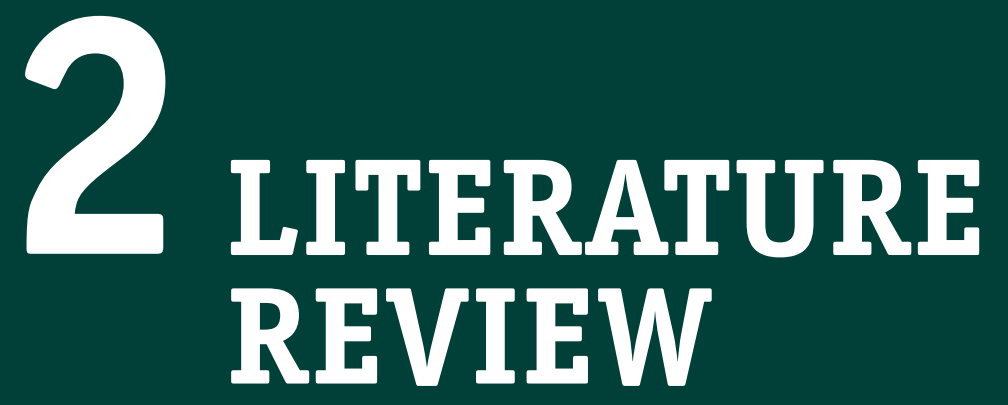


A broad overview of the literature is provided here, focusing on a range of issues salient to parenting and parental discipline strategies. Knowledge of factors influencing different parental discipline responses and the effects of these discipline strategies on children's development can help us to gain insight into how best to develop effective ways to solve children's discipline problems and, thus, encourage more positive family climates. First, a brief review of theoretical concepts is given against which parenting and discipline can best be understood. The focus then moves to outlining key factors influencing parental choice of discipline strategies. With specific reference to the physical punishment of children, factors influencing parental use of physical punishment and its effects are outlined and discussed in the final section.

\section{Theoretical frameworks}

The study of parental disciplinary practices and their impact on children's development can be considered within a variety of theoretical and conceptual frameworks, including learning and social learning theory, the theory of moral internalisation, the parenting styles approach, and ecological/systemic approaches.

One overarching theoretical perspective underpinning parental discipline is that of learning and social learning theory. Within this approach, mechanisms of reinforcement (or reward) and punishment are central to learning and socialisation. Learning theory suggests that the consequences of behaviour strengthens or weakens behaviour in the future: behaviours that are rewarded continue in the child's repertoire, while behaviours that are punished drop out (Eisenberg and Valiente, 2002). Punishment is defined as the presentation of an aversive stimulus or the removal of a positive stimulus. According to principles of learning, punishment following a specific behaviour is likely to lessen the likelihood of that behaviour being repeated. Punishment can be an effective agent for behavioural change, but in order for punishment to effectively suppress undesirable behaviour permanently, it must be immediately and intensely administered after every transgression (Domjan, 2000). Thus, according to learning principles, physical punishment must be administered severely enough to ensure that it is a negative consequence for the child, in order for it to successfully suppress behaviour. This, according to some, may become a recipe for physical abuse and injury, rather than effective discipline (Holden, 2002). In modern social learning theory, children learn through observation and imitation of models in their environment (Bandura, 1986). Parents provide important information to children about behaviour expectations and possible consequences for various behaviours; parents model relevant behaviour, and reinforce and punish children for different actions (Eisenberg and Valiente, 2002). One argument commonly used against physical punishment draws on social learning theory to argue that parents who use physical punishment with their children model aggressive behaviour for their children (Straus, 1991).

Of course, discipline is not synonymous with punishment. Other theoretical perspectives and much of the research on parental discipline have been concerned with the long-term goal of how children acquire the motives, values and behaviour of their parents and of society through the process of internalisation (Grusec and Goodnow, 1994). Hoffman's (2000) theory of moral internalisation attempts to address how societal norms and parental values, which are initially motivated by external forces (e.g. fear of sanction), eventually come to acquire an internal motivational force. He argues that disciplinary encounters with parents are central to this process of moral internalisation and what happens in a disciplinary encounter is likely to influence whether or not children internalise norms and subsequently behave in a way that is consistent with these norms (Hoffman, 2000). As children internalise norms of behaviour, the need for external control of behaviour through mechanisms such as reward and punishment is lessened (Smith et al, 2005). Grusec and Goodnow (1994) suggest that the use of punishment or other power-assertive techniques is less effective than the processes of reasoning or induction in promoting internalisation.

Hoffman (1983 and 2000) proposed that power-assertive techniques - such as physical force, deprivation of privileges or possessions, direct commands or threats - are detrimental to socialisation because they arouse fear and anxiety in the child, provide a model of aggression to the child, heighten the child's view that the moral standard is external to the self, and direct the 
child's attention to the consequences of the behaviour for the self rather than for other people. In contrast, parents who use inductive techniques point out the effect of the child's behaviour on others and may suggest reparative actions. Hoffman (1970 and 1983) argues that such otheroriented inductions promote internalisation because they develop the child's empathic capacities and induce negative feelings from which the child cannot escape even when the parent is no longer present; also, inductions are unlikely to produce high levels of anxiety or fear, and so the child is more available to attend to and process the information embedded in the parent's inductive statement.

Disciplinary strategies should promote a moderate level of arousal in the child (Smith et al, 2005). Too much arousal may result in fear and anxiety, which will direct attention away from the parent's message to the consequence for the self. In contrast, too little arousal may result in the child not attending to the parental message at all. As Kochanska and Thompson $(1997$, p. 68) explain, 'Power-oriented, forceful discipline elicits very high anxiety or arousal in the child and it interferes with the effective processing of the parental message about behavioural standards and thus undermines internalisation'. While some researchers, including Hoffman himself, do argue that an appropriate combination of power-assertive and inductive disciplinary techniques can be successful in promoting internalisation, if the goal of discipline is to promote children's compliance and internalisation of parental and societal values, then effective instruction must be to the fore (Grusec and Goodnow, 1994).

Further work that has been influential in understanding effective discipline falls within the parenting styles paradigm, exemplified by the work of Baumrind (1971 and 1991) and Maccoby and Martin (1983). In studies of parenting styles, two dimensions of parenting behaviour have emerged: whether parents are high or low in control or demands, and whether parents are high or low in warmth or responsiveness. Depending on where parents lie along these dimensions, they can be categorised as:

- authoritative (high-control, high-responsive);

- authoritarian (high-control, low-responsive);

- permissive-indulgent (low-control, high-responsive);

- permissive-neglectful (low-control, low-responsive).

Studies on the impact of parenting styles have found that authoritative parenting has most commonly been associated with positive outcomes (Teti and Candelaria, 2002). A later development of this approach teased apart parenting practices (content) and parenting style (context) (Darling and Steinberg, 1993). Practices refer to specific parenting behaviours and goals for socialisation (such as slapping a child, requiring children to do their homework, taking an interest in children's activities). Style, on the other hand, refers to the emotional climate in which parenting practices take place (such as tone of voice, bursts of anger, displays of empathy). Thus, parenting practices (such as specific disciplinary strategies) can differ according to the style or emotional climate in which the message is transmitted to the child. Darling and Steinberg (1993) argue that parenting styles (such as authoritative, authoritarian) are best understood as a context that moderates the influence of specific parenting practices on the child. For example, the effect of a harsh disciplinary strategy may vary depending on whether it is delivered within the context of a warm or a rejecting relationship between the parent and child.

Shifts in thinking about parenting style as a context for parenting practice reflect the seeping influence of ecological and systemic approaches within the study of children's development. An ecological and systemic perspective on family represents an important theoretical framework within which parental discipline can be better understood (Lerner et al, 2002). As previously highlighted within the parenting styles literature (see above), the effect of discipline may vary depending on whether it is in the context of a warm and responsive parent-child relationship. Furthermore, parental discipline is nested within a wider system of relationships in the family, as well as overarching systems of social and economic influences, which may impede or facilitate effective parenting (Smith et al, 2005). Culture and ethnicity have also emerged as key influences on the consequences of different discipline practices. Differences between discipline practices 
across different ethnic groups have been well documented (Coll et al, 1995). Brody and Flor (1998) reported that African-American parents use high levels of control and physical punishment, along with high levels of affection and acceptance, while European-American parents use democratic parenting practices more often. Moreover, a significant positive correlation between harsh punishment and acting-out behaviour has emerged for African-American families, but not European-American ones, in the USA (Deater-Deckard and Dodge, 1997). Lerner et al (2002, p. 330) suggest that 'because the meaning of parents' behaviour is critical in determining its effect on the child and because community standards determine the meaning of parents' behaviour, physical punishment is likely to have very different consequences in different communities'.

An additional facet of this ecological and systemic approach is consideration of child effects on parenting. For example, an important, but relatively neglected aspect of parental discipline is the child's perception and acceptance of the parent's disciplinary message (Holden, 2002). Grusec and Goodnow (1994) suggest that successful internalisation is a function of the 'fit' between parental inductions and children's ability to take the parent's message on board. It is likely that children's reactions to disciplinary strategies are influenced by such characteristics as gender, age, temperament and the history of transactions between the child and parent (Holden, 2002). Much has been written about these transactional effects in families, where parents display high levels of physical punishment and children display high levels of aggression. Patterson and Fisher (2002) argue that harsh discipline is a prime example of a parenting practice that not only reflects parents as models of aggressive behaviour, but also reflects children as agents who evoke particular responses in their parents. In elucidating this process, Patterson (1982) developed a model of coercive family processes, which identified the bi-directional parent-child interactions that contribute to the development of aggressive behaviour in children. Coercive cycles may begin when children exhibit non-compliance to a troublesome degree, to which parents respond aversively but ineffectively. Parents' ineffective responses inadvertently reinforce the child's negative behaviour. As a result, a stable pattern of mutually coercive cycles of interaction become established over time (Kent and Peplar, 2003). Such transactional models may be best suited to capture the dynamic nature of discipline effects.

In conclusion, the study of parental discipline can usefully be informed by a range of theoretical perspectives, including learning and social learning theory, internalisation theory and the parenting styles paradigm. A further useful overarching paradigm is provided by the ecological and systemic approach, which embraces the idea that a range of factors within the individual (both parent and child), within the family setting and beyond the family impact on parenting. In the next section, the impact of a number of such factors on parental discipline strategies will be discussed.

\section{Factors influencing parental discipline strategies}

A broad and complex array of factors operates to shape and determine parenting behaviours. Specifically, these factors can be discussed under three broad categories: child characteristics, parent characteristics and contextual factors. Undoubtedly, specific parental discipline responses often occur as a result of the complex interplay of factors across these categories and it is, therefore, a demanding and challenging task to attempt to elucidate the precise nature of such influences.

\section{Child characteristics}

In contrast to the traditional view of parental attitudes as originating in the parent, over the past decade children's influence on their parents' attitudes has been emphasized. Such a concept is noteworthy because it approaches parental attitudes from the 'child effects' or 'two-way effects' perspective (Bugental and Goodnow, 1998, p. 389). With specific reference to parental attitudes to physical punishment of children, Holden et al (1997) found that $75 \%$ of mothers who reported a change in their attitude to physical punishment attributed it to the particular child's reaction to a discipline strategy or to child characteristics. Parental experiences in the family, therefore, appear to be linked to changes in parental attitudes and behaviours. 
A number of studies have examined the influence of child gender on parental use of physical punishment, although findings are somewhat inconsistent. In general, boys have been found to be at greater risk of physical punishment than girls and of it being administered more severely (Dietz, 2000; Kanoy et al, 2003). However, other studies have found no gender differences in parental use of physical punishment (Woodward and Fergusson, 2002; Holden et al, 1997). Smith et al (2005) report that severity of physical punishment has also been examined in relation to gender differences. A number of studies have found that parents were more likely to use harsh or severe discipline with sons than with daughters (Nobes et al, 1999; Simons et al, 1991). Historical changes in responses to child gender have also been noted with fathers in New Zealand: in the 1970s, they were more likely to use physical punishment with their daughters than with their sons, but no such differences were recorded in the 1990s (Ritchie, 2002).

The age of a child has also been implicated in parental discipline responses, with younger children tending to experience physical punishment more than older children (Dietz, 2000; Ghate et al, 2003). However, there is also evidence that older children are more likely to be the victims of more severe physical punishment than younger children (Nobes and Smith, 2002; Straus and Stewart, 1999). In the UK and North America, parental use of corporal punishment is most common among children of toddler and pre-school age (Clement et al, 2000; Ghate et al, 2003). Durrant (2005) attributes these age-based influences to children in this age group demonstrating high activity, exploration and independence, together with negativism, impulsivity and a limited understanding of harm and danger - a combination that can lead to a high frequency of disciplinary incidents.

Certain child behaviours and misdemeanours have been found to elicit higher levels of physical punishment as a discipline response and this may vary according to cultural norms and values. Studies in the UK and USA indicate that self-endangerment and aggression are among the most frequently cited behaviours for which physical punishment is considered to be acceptable (Durrant, 1996; Ghate et al, 2003; Holden et al, 1999). Smith et al (2005) also report that behaviours that are most often dealt with by way of physical punishment are those that break a moral code, directly challenge parental authority and control, or present a danger to the child or others. Children who have less easy temperaments are also more likely to be physically punished. Moreover, the context in which the disciplining incident occurs and the nature of interchange at the time of the misbehaviour are also important in terms of predicting physical punishment as a discipline response. For example, Socolar et al (1999) found that slapping typically occurred as a secondary response to a misdeed only when a primary response had failed and when parental anger was likely to be exacerbated.

Child effects are qualified by the interpretation parents give to their children's actions (Bugental and Happaney, 2002). Parental discipline responses may be mediated by attributions regarding a child's behaviour and perceptions of child characteristics, with parental tendencies to make hostile attributions about their children being associated with punitive parenting (MacKinnon-Lewis et al, 1992). For example, children who are viewed as defiant and responsible for their actions are judged as being more deserving of physical punishment. Related to this, aggressive behaviour by children in pre-school and early elementary school tends to evoke negative parent emotions and cognitions, which lead to more negative parenting behaviours (Miller, 1995). Ambiguous and unexpected events are also more likely to trigger parental attributional processes. Bugental and Happaney (2002) found that adults with a low-power attributional style (i.e. who believed that they had less power within care-giving relationships than did their children) showed defensive response patterns only when responding to a child whose behaviour was undesired but motivationally ambiguous. From this perspective, parental attributional processes are activated in response to relevant events in the care-giving environment and serve to moderate or mediate parental discipline responses.

Parenting styles are also associated with certain patterns in parental attributions. In situations depicting children's negative behaviours, authoritarian mothers were less focused on empathic goals and attributed child aggression and behaviours to less external sources than their more authoritative counterparts (Coplan et al, 2002). Authoritarian mothers were also more likely to respond with greater anger and embarrassment across all child-rearing scenarios. These findings 
suggest that authoritarian and authoritative mothers differ in their affective response patterns consistently across all child-rearing contexts, but that more challenging child-rearing situations accentuate differences in the cognitive reactions of authoritative versus authoritarian mothers.

In summary, the use of physical punishment is associated with several factors related to child characteristics. A notable development is a shift from an exclusive reliance on parent effects to considering the influences of child characteristics and behaviour on parental discipline responses. Factors such as child gender and age have proved inconsistent in terms of their potential to explain variance in discipline responses involving physical punishment, with some studies suggesting that boys tend to be physically punished more often and more severely than girls and other studies showing no effects of child gender. Similarly, while many studies report higher incidence of physical punishment among younger children in early childhood, other studies indicate that older children tend to be more severely punished. A significant consideration in research on child effects is that such effects are qualified by the interpretation parents give to their children's actions, with parental attributional behaviours initiated most often in response to ambiguous disciplinary incidents. Parental tendencies to make hostile attributions about their children have also been associated with punitive parenting.

\section{Parent characteristics}

A wide range of parental characteristics may influence a parent's use or approval of physical punishment. With regard to gender of parents, findings are inconclusive, with some studies finding no gender differences (Hemenway et al, 1994; Murphy-Cowan and Stringer, 1999; Nobes et al, 1999), while other studies indicate that mothers tend to use physical punishment more than fathers (Anderson et al, 2002; Straus and Stewart, 1999). Younger parents have also been found to use higher levels of physical punishment (Giles-Sims et al, 1995; Dietz, 2000; Durrant et al, 1999). Parenting values and beliefs have been shown to influence the discipline responses of parents to their children (Pinderhughes et al, 2000). Parents who believe that parenting positively affects child outcomes are less likely to adopt coercive strategies as a discipline response. Generally, it is less-educated parents who use physical punishment more (Durrant et al, 1999). However, exceptions to these findings have been highlighted, with certain studies linking physical punishment to higher levels of education (Wolfner and Gelles, 1993) and other studies suggesting no effect of education level (Dietz, 2000).

Parents who are depressed (Bluestone and Tamis-LeMonda, 1999), have drug/alcohol problems (Woodward and Fergusson, 2002) or anti-social/hostile personality characteristics (Fisher and Fagot, 1993) are also more likely to use physical punishment with their children. The more frustration, irritation or anger a parent feels in response to conflict with a child, the more likely they are to use coercive discipline strategies, including physical punishment (Ateah and Durrant, 2005; Holden et al, 1995). Parental anger and frustration also increase the likelihood that parents will use a more intense level of force than they anticipate (Vasta, 1982).

The intergenerational transmission of parenting practices and attitudes is also likely to be a significant factor in influencing parents' responses to the discipline of their children. Findings are consistent that parents who were themselves physically punished as children or adolescents have an increased likelihood of physically punishing their own children (Bower-Russa et al, 2001; Ghate et al, 2003; Graziano and Namaste, 1990). In a longitudinal study on the development of attitudes about physical punishment, a temporal link was suggested between children's experiences of being slapped and their later endorsement of slapping as a discipline strategy (Deater-Deckard et al, 2003). However, there was no correlation among adolescents for whom physical maltreatment in early or middle childhood had been suspected. Kendler's (1996) longitudinal twin study carried out across several generations found evidence that parental attitudes, derived from the family of origin, influenced parental behaviour in addition to genetically influenced parental temperamental characteristics. 
Interestingly, two exceptions to the above findings come from studies carried out in Northern Ireland and Korea. With regard to the Northern Ireland study, socio-economic background was found to influence the extent to which physical punishment was transmitted across generations. Murphy-Cowan and Stringer (1999) found that experience of physical punishment in childhood in working-class families predicted the frequency of its use with children across generations. However, this was not found in middle-class families, where parents who had experienced high frequencies of physical punishment reported using lower levels with their own children. Similarly, among Korean immigrants in the USA, mothers who had experienced physical punishment as children were less likely to respond with physical aggression to conflicts with their children (Park, 2001).

Experience of physical punishment in childhood also predicts approval of this practice and approval has been found to be one of the strongest predictors of the use of physical punishment by parents (Durrant, 2005). In a study examining potential predictors of mothers' use of physical punishment with their children - i.e. childhood experience of corporal punishment, knowledge of child development, knowledge of alternative responses to parent-child conflict, disciplinary goals, perceived seriousness and intent of child's behaviours, maternal anger, and approval of physical punishment - parental approval of physical punishment was the strongest predictor of its practice (Ateah and Durrant, 2005). A recent study of the acceptability of physical punishment of children in 14 countries in the European Union found that higher levels of acceptability were reported among men, older parents and less educated parents (Gracia and Herrero, 2008). Similarly in the UK, Ghate et al (2003) found that parents who believed that corporal punishment was acceptable were five times more likely to use it than those who did not. Parents' own experiences of discipline in childhood can also shape the particular attributional style they adopt when parenting their children (Bugental and Happaney, 2002).

To summarise, key factors related to parental characteristics and the use of physical punishment include the parents' age, with younger parents associated with more frequent use of physical punishment. No clear effects of parents' gender have been identified, although some studies suggest that mothers tend to use physical punishment more frequently than fathers. Parents' values have also been found to influence discipline responses, with belief in the positive effect of parenting associated with less coercive parental discipline responses. Finally, parents' mental health and experiences of discipline in their own childhoods are also significant in shaping the use of parental discipline strategies.

\section{Contextual factors}

Contextual factors, such as family structure, have been found to be associated with parental use of physical punishment (Smith and Brooks-Gunn, 1997). Parents of larger families are more likely to approve of and use corporal punishment than parents of smaller families (Eamon and Zuehl, 2001). Increased use of corporal punishment is also associated with marital conflict or violence, relationship stress and parenting stress (Coyl et al, 2002; Wilson et al, 2002; Wissow, 2001). A recent study of family structure and physical punishment indicated that psychosocial and economic stresses were more important than family structure in predicting physical punishment (Nobes and Smith, 2002). Child maltreatment was associated with problems such as poverty, poor mental health and discordant marital relations, but not the number of parents in the family. The desire to prevent a child from doing something dangerous is also instrumental in eliciting physical punishment on the part of a parent (Anderson et al, 2002; Bower-Russa et al, 2001). In an analysis of why Irish parents use physical punishment, Greene (1994) has indicated that its use is likely to be influenced by a range of factors including sanctioning of physical punishment by society, parental beliefs that physical punishment is effective and does not harm children, and parental stress associated with child-rearing.

Research on cultural/ethnic differences in attitudes towards or use of physical punishment is inconclusive and largely contradictory (Smith et al, 2005). Overall, there is not a great deal of evidence to suggest significant differences in prevalence, chronicity or severity rates for the use 
of physical punishment across different ethnic groups. Where differences are reported, the effects are very small. The existence of laws prohibiting physical punishment of children, as well as a lower number of child maltreatment deaths, were significantly associated with lower levels of acceptability of physical punishment of children. Findings of studies on variations in attitudes to physical punishment across different nations suggest a strong association between approval and practice of coercive discipline strategies in these countries. In Barbados and Korea, for example, where support for corporal punishment is very strong, rates of severe punishment are very high. In Canada and China, where support is lower, its administration appears to be less severe. In Sweden, where support for physical punishment is very low and laws are explicit about its unacceptability, its use is rare. Smith et al (2005) point out that the issues related to ethnicity are confounded with a range of other factors and variables that make it difficult to establish the effect or relative influence of culture or ethnic group status. Several studies have investigated the role of religious beliefs as a determinant of parenting attitudes and have also linked them to behavioural intentions (Ellison et al, 1996; Gershoff et al, 1999). Conservative Protestants reported a greater frequency of slapping their 3-year-old children, as well as holding more positive attitudes about corporal punishment, than other groups.

In summary, contextual factors, such as family composition and structure, demonstrate no clear effects on the extent to which parents adopt physical punishment as a discipline strategy. More significant in influencing discipline responses are the levels of stress that parents report, such as marital conflict, relationship and parenting stress. The influence of cultural/ethnic differences on the use of physical punishment is a complex issue. Research findings have been largely inconclusive and contradictory in explaining patterns of use related to physical punishment.

\section{Effects of physical punishment on children}

Studies with documented effects of physical punishment on children have been plentiful, yet a thorough understanding of its merits and potential effects as a form of punishment has not been reached. The research on physical punishment has benefited greatly in recent years by the publication of a number of authoritative reviews (Smith et al, 2005; Kalb and Loeber, 2003; Larzelere, 2000; Deater-Deckard and Dodge, 1997) and a meta-analysis of 92 studies (Gershoff, 2002). Broadly speaking, the research has been concerned with the effects of physical punishment on compliance, internalisation of rules, aggressive and anti-social behaviour, school achievement and motivation for learning, peer and parent-child relationships, mental health/ psychological well-being, and risk of physical abuse. Gershoff (2002) highlights that much of the research is underpinned by a bias towards uncovering negative child outcomes linked with physical punishment. The associations that have been uncovered between parental use of physical punishment and key outcomes and indicators of children's development will now be briefly presented.

One key goal that parents have in administering physical punishment is that children will immediately cease misbehaving and be compliant with parental demands. There is general consensus that physical punishment is effective in attaining immediate compliance (Newsom et al, 1983; Larzelere, 2000). However, this claim should be interpreted with caution. In Gershoff's (2002) meta-analysis, 5 studies linked physical punishment with immediate compliance, but the associations were inconsistent across the studies: 2 of the 5 studies found that physical punishment was linked with decreased compliance, while 3 of the 5 studies revealed that physical punishment was associated with increased compliance. However, these latter studies consisted of clinical samples of children referred for conduct disorder, so the extent to which these findings can be generalised to other populations of children needs to be questioned. Thus, the findings relating physical punishment and immediate compliance are far from clear. Furthermore, as highlighted by Smith et al (2005), the goal of immediate compliance can be achieved equally well by other methods of punishment. 
While immediate compliance is an important socialisation goal for parents, especially when their children are in danger, long-term socialisation goals involve the internalisation of parental standards and rules to enable children to regulate their own behaviour. Gershoff (2002) concluded that in 13 of 15 studies physical punishment was associated with lower levels of moral internalisation, including such things as feelings of guilt following misbehaviour, tendencies to make up to someone upon doing wrong and long-term compliance. This finding resonates with a larger body of literature, which emphasizes that power-assertive discipline strategies in the absence of induction or explanation do little to facilitate the internalisation of appropriate values and attitudes (Eisenberg and Valiente, 2002; Kochanska et al, 2001).

By far the most commonly studied association is that between physical punishment and children's aggressive behaviour. Theoretically, it is hypothesised that through the use of physical punishment, parents model aggressive behaviour for their children and promote biases towards aggression in children's social relationships. A plethora of research has demonstrated a clear association between physical punishment and child aggressive behaviour. Gershoff's (2002) meta-analysis concluded that there was a small to moderate effect of parental use of physical punishment on children's aggression and a moderate effect on adult aggression. Clear associations between physical punishment and anti-social behaviour have also been demonstrated. For example, Fergusson and Lynskey's (1997) longitudinal study, based in New Zealand, found that young people who had been regularly or severely physically punished were twice as likely to be involved in recurrent violent offending as other young people. This association persisted even when confounding variables such as socio-economic status and family history had been controlled for statistically. A further illustrative example of such research was conducted by Cohen and Brook (1995), who assessed levels of power-assertive punishment and conducted psychiatric assessments on children and mothers in a representative sample of 976 families. A follow-up of the families revealed that if children belonged to the highly punished group, their chances of showing conduct disorder 8 years later were doubled. The authors concluded that physical punishment had a causal effect on increasing conduct disorders. However, the possibility of reciprocal influence from initial child problem behaviour to punishment is an important caveat in interpreting this proposed causal relationship. Finally, Mulvaney and Mebert (2007) examined the impact of physical punishment on young children's behaviour problems. Using data from a large US longitudinal dataset, they found that parental physical punishment uniquely contributed to negative behavioural adjustment in children aged 3-6 years. In addition to problem acting-out behaviours, links have been drawn between physical punishment and mental health difficulties, such as depression, anxiety and other mental health problems. Gershoff (2002) considered 20 studies of physical punishment and mental health in childhood (12 studies) and adulthood (8 studies); there was a clear consistency in the findings across all studies that mental health problems in childhood and adulthood were associated with parents' use of physical punishment.

In terms of children's cognitive development, school achievement and motivation for learning, Smith et al (2005) reviewed 6 studies that demonstrated an association between harsh physical punishment and poor academic achievement across a range of ages and ethnic groups. For example, one longitudinal study conducted in the USA (Shumow et al, 1998) used a variety of teacher- and parental-report measures and school achievement results. Parental harshness was negatively associated with both parent and teacher reports of children's adjustment problems and poorer academic achievement, even after controlling for race, family structure, parental education and family income. These authors concluded that parental harshness was associated with poorer cognitive achievement and social adjustment at school. However, this relationship between parental harshness and behaviour problems is not ubiquitous. Rather it appears to be moderated by ethnic and cultural differences. Deater-Deckard and Dodge (1997) suggest that the effects of physical discipline on child behaviour, such as aggression, may vary depending on how prevalent and acceptable the behaviour is within that group. 
Potential effects of physical punishment on peer and parent-child relationships have also been investigated. Hart et al (1992) explored relations among parents' disciplinary styles, pre-schoolers' peer status and playground behavioural orientations. Power-assertive disciplinary strategies were linked with higher levels of rough-and-tumble play, lower levels of disruptive behaviour among girls and lower levels of being preferred by peers. The authors suggest that parental disciplinary methods indirectly affect children's peer status through their effect on children's pro-social and aggressive behaviours. Much more research has considered the effects of parental physical punishment on the quality of parent-child relationships. In her review of 13 relevant studies, Gershoff (2002) consistently found an association between physical punishment and poorer quality parent-child relationships. She suggests that physical punishment by parents may lead to an avoidance response by children, which may undermine children's security of attachment and trust in their parents (Bugental and Goodnow, 1998). Corroborating this, Coyl et al (2002) found that infants who were spanked frequently by their mothers exhibited lower levels of attachment security. Smith et al (2005, p. 14) suggest that the 'establishment of positive reciprocal relationships between parents and children are antithetical to parental treatment which included physical punishment'.

Finally, one commonly used argument against parental use of physical punishment is that it places children at risk of physical abuse if it is administered too frequently or too severely. Indeed, as previously discussed (see $p .8$ ), the distinction between physical punishment and physical abuse is not clearly defined and may even vary from one cultural context to another. According to Smith et al (2005), two-thirds of physically abusive incidents arise out of parental disciplinary actions. These authors found a clear tendency for parents who had been physically punished to continue this practice once they became parents themselves. Gershoff's (2002) meta-analysis confirmed a strong association in 10 studies between parental physical punishment and parental physical abuse of the same children. Furthermore, the intergenerational transmission of physical punishment has been documented by Holden et al (1997). Corroborating this, Gershoff (2002) reported on 5 studies linking experience of using physical punishment and being a victim of physical abuse in childhood. These studies substantiate the fears of many - that physical punishment and physical abuse are intricately linked.

In reviewing the research findings presented, it is important to consider that this field of research is fraught with difficult methodological issues and biases. The majority of studies examining links between parental physical punishment and child behaviours are purely correlational in nature. In the real world, randomly assigning parents to physical punishment/no physical punishment experimental groups is untenable, so no causal relationships can be inferred. Thus, the research reviewed only allows an understanding of whether physical punishment and child variables are associated, but not causally linked. In addition, many studies rely on parental self-report via surveys. The depth of information yielded from these surveys can vary considerably, but many of them do not measure frequency or intensity of disciplinary episodes. Although parental selfreport measures, such as daily diaries, do demonstrate high validity (Smith and Brooks-Gunn, 1997), it is likely that less frequently used methods, such as in-depth interviews and home-based observations, would yield the most valid information. Holden (2002) has noted a number of issues with reliance on parental reports of harsher forms of physical punishment. Much of the research does not ask specifically about harsh physical punishment techniques, which may be construed as physical abuse. Furthermore, parents who are fearful of being reported to authorities are likely to under-report their use of extremely harsh techniques. Overall, lack of consensus about definitions has created difficulty in drawing clear conclusions across studies. Thus, while some studies conceptualise physical punishment as occurring along a continuum, with violence and abuse at one extreme and harshness as an intermediate variable, others treat physical punishment as a categorical variable which is either present or absent. Further, while harshness in punishment usually pertains only or primarily to physical punishment, the term may equally apply to other forms of discipline (Baumrind, 1997). 
A further concern is that measurement of parental use of physical punishment often becomes stripped away from the context and little information is gleaned about the antecedents and consequences of the punishment episode, or indeed the broader parent-child relationship context. Thus, Parke (2002) has advocated the analysis of parental use of physical punishment within the context of other socialisation practices in the family. Others (e.g. Locke and Prinz, 2002) question the cultural appropriateness of some of the measures of physical punishment and disciplinary practices.

In conclusion, notwithstanding the methodological issues and biases previously outlined, research has consistently demonstrated an association between parental use of physical punishment and a range of negative developmental outcomes for children. Assumed associations have been taken as causal in nature, with the direction of effect from parental behaviour to child outcome. Such research has been used to support proscriptions against the use of physical punishment. A number of authors have called for a more nuanced interpretation of the research findings, particularly in relation to the association between parental use of physical punishment and children's behaviour problems such as aggression (Deater-Deckard and Dodge, 1997; Baumrind, 1997). These authors suggest that there are important cultural variations in the effects on children of physical punishment and social contexts, both within and beyond the family unit, influence the meaning to the child of the disciplinary strategy, thus varying its effects. As Baumrind (1997, p. 179) states, 'Across cultures, the child effects of spanking are mediated by parental involvement and warmth and moderated by culturally differentiated normative experiences'. Furthermore, discipline plays an important, but by no means the most important role in optimal parenting (Baumrind, 1997). On the other hand, Smith et al (2005, p. 16) conclude that 'Corporal punishment does not guarantee a harmful effect, but the more children experience corporal punishment and the more frequent and severe it is, the more they are at risk for problems like aggression or depression'.

\section{Conclusion}

A number of key points are worth highlighting within this review of the literature on disciplining children. The theoretical and conceptual frameworks outlined at the beginning of the chapter inform and guide our understanding of key principles and processes underlying effective and constructive discipline strategies with children. Moreover, such theories serve to further highlight the importance of considering the complex interplay of factors that shape parental discipline responses, including individual child and parent characteristics and behaviours, and more broadly the contextual influences within which parenting occurs. Identifying clear links between parenting styles, discipline strategies and child outcomes is challenging due to lack of consensus in terms of how we define these strategies and the methodological issues related to measuring precisely the attitudes, behaviours and outcomes in question. Nevertheless, certain associations are emphasized in the literature, such as the links between parental warmth, inductive discipline strategies and higher levels of moral internalisation in children and, conversely, parental harshness and more negative behavioural outcomes for children - with the caveat that social and cultural considerations play an important role in determining the pattern of effects. 


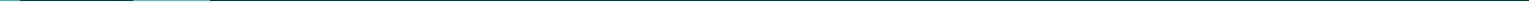




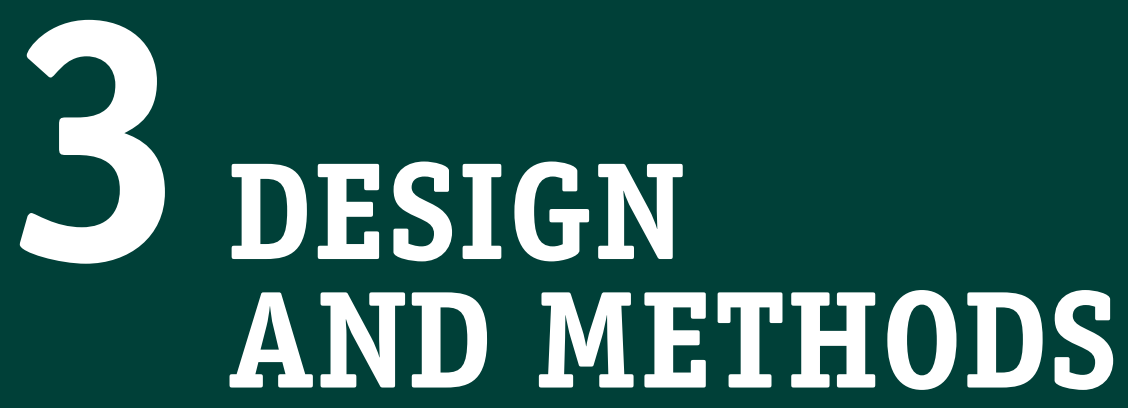


The Irish Survey of Parenting and Discipline Practices was designed to examine the parenting behaviour and discipline strategies used by parents in Ireland in bringing up their children. The survey was conducted by the Economic and Social Research Institute (ESRI) on behalf of a group of researchers at the Dublin Institute of Technology (DIT) and Trinity College, Dublin (TCD) and was funded by the Office of the Minister for Children and Youth Affairs at the Department of Health and Children. The survey was completed by 1,353 parents (aged 21-69 years) with children under 18 years of age and was conducted between December 2007 and April 2008.

This chapter provides a description of the questionnaire and standardised measures used in the study. It also explains how the survey was conducted and includes details on the pilot study, interviewer training, ethical issues, sampling and recruitment strategy, and study limitations. A detailed profile of the parents and children represented in the study is provided in Chapter 4.

\section{Research instruments}

The questionnaire was designed by the research team at DIT and TCD, with input from the ESRI Survey Division. The questionnaire was piloted in September 2007 to test its feasibility in the field. Sections of the questionnaire were adapted from questionnaires used in The National Study of Parents, Children and Discipline in Britain (Ghate et al, 2003) and Disciplining Children: Research with parents in Scotland (Anderson et al, 2002). The questionnaire also included extracts from a number of standardised measures. Table 1 provides an overview of the different sections included in the questionnaire, as well as indicating where items have been adapted from previous measures or questionnaires.

\section{Table 1: Overview of different sections of survey questionnaire}

\begin{tabular}{|c|c|c|}
\hline Section of questionnaire & Focus & Sources drawn upon \\
\hline $\begin{array}{l}\text { SECTION A: } \\
\text { General views on } \\
\text { parenting in Ireland }\end{array}$ & $\begin{array}{l}\text { Parents' views on parenting in } \\
\text { Ireland - perceived changes } \\
\text { in last } 20 \text { years; pressures } \\
\text { perceived to impact on } \\
\text { parenting and experiences of } \\
\text { support from spouse/partner in } \\
\text { parenting; parenting goals and } \\
\text { values. }\end{array}$ & $\begin{array}{l}\text { Section A5: Pressures perceived } \\
\text { to impact on parenting - } \\
\text { adapted from Anderson et al } \\
\text { (2002) }\end{array}$ \\
\hline $\begin{array}{l}\text { SECTION B: } \\
\text { Attitudes towards } \\
\text { smacking and contexts } \\
\text { in which it occurs }\end{array}$ & $\begin{array}{l}\text { Parental views on physical } \\
\text { punishment and rationales for } \\
\text { using physical punishment. }\end{array}$ & $\begin{array}{l}\text { Adapted from Anderson et al } \\
\text { (2002) }\end{array}$ \\
\hline $\begin{array}{l}\text { SECTION C: } \\
\text { Details of household and } \\
\text { randomly selected child }\end{array}$ & $\begin{array}{l}\text { Information on household } \\
\text { composition, ages of children in } \\
\text { the household and ethnic and } \\
\text { cultural background. } \\
\text { Additional information: } \\
\text { respondent's relationship to } \\
\text { the selected child; } \\
\text { details of care-giving for } \\
\text { selected child; } \\
\text { physical and psychological } \\
\text { well-being of the selected } \\
\text { child; } \\
\text { - temperament and behaviour } \\
\text { of child. }\end{array}$ & $\begin{array}{l}\text { Extract from Infant } \\
\text { Characteristics Questionnaire } \\
\text { (Bates et al, 1979) } \\
\text { Extract from Emotionality, } \\
\text { Activity and Sociability } \\
\text { Questionnaire } \\
\text { (Buss and Plomin, 1984) } \\
\text { Extract from Strengths and } \\
\text { Difficulties Questionnaire } \\
\text { (Goodman, 1997) }\end{array}$ \\
\hline
\end{tabular}


Table 1 continued

\begin{tabular}{|c|c|c|}
\hline Section of questionnaire & Focus & Sources drawn upon \\
\hline $\begin{array}{l}\text { SECTION D: } \\
\text { Parenting styles }\end{array}$ & $\begin{array}{l}\text { Discipline practices in the } \\
\text { broader context of parenting. }\end{array}$ & $\begin{array}{l}\text { Extract from Parenting Styles } \\
\text { and Dimensions Questionnaire } \\
\text { (Robinson et al, 2001) }\end{array}$ \\
\hline $\begin{array}{l}\text { SECTION E: } \\
\text { Discipline strategies } \\
\text { experienced by parents } \\
\text { in childhood }\end{array}$ & $\begin{array}{l}\text { Parental experiences of } \\
\text { discipline in childhood. }\end{array}$ & Adapted from Ghate et al (2003) \\
\hline $\begin{array}{l}\text { SECTION F: } \\
\text { Discipline strategies } \\
\text { adopted by parents with } \\
\text { child in the past year }\end{array}$ & $\begin{array}{l}\text { Parental use of discipline } \\
\text { strategies in the past year. }\end{array}$ & Adapted from Ghate et al (2003) \\
\hline $\begin{array}{l}\text { SECTION G: } \\
\text { Smacking }\end{array}$ & $\begin{array}{l}\text { Contexts in which physical } \\
\text { punishment is likely to be } \\
\text { used and parental feelings as } \\
\text { a consequence of the use of } \\
\text { physical punishment with a } \\
\text { child. }\end{array}$ & $\begin{array}{l}\text { Adapted from Ghate et al (2003) } \\
\text { and Anderson et al (2002) }\end{array}$ \\
\hline $\begin{array}{l}\text { SECTION H: } \\
\text { Attitudes towards } \\
\text { legislation on the use of } \\
\text { physical punishment }\end{array}$ & $\begin{array}{l}\text { Parental awareness of and } \\
\text { attitudes to current legislation } \\
\text { on physical punishment and } \\
\text { potential change in legislation. }\end{array}$ & Adapted from Ghate et al (2003) \\
\hline $\begin{array}{l}\text { SECTION I: } \\
\text { Demographics }\end{array}$ & General demographic details. & \\
\hline
\end{tabular}

\section{Standardised measures}

- Strengths and Difficulties Questionnaire: The Strengths and Difficulties Questionnaire (SDQ) is a widely used brief behavioural screening questionnaire appropriate for use with children aged 3-16 (Goodman, 1997). The SDQ is sensitive in detecting emotional and behavioural problems, and uses five sub-scales to tap into emotional symptoms, conduct problems, hyperactivity/inattention, pro-social behaviour and peer relationships. For the purpose of the present study, 15 items from the first three sub-scales (emotional symptoms, conduct problems and hyperactivity/inattention) were included.

- Infant Characteristics Questionnaire: The Infant Characteristics Questionnaire (ICQ) is a measure of infant temperament and is appropriate for use with children up to the age of 3 (Bates et al, 1979). The scale measures parent perceptions of the infant and focuses specifically on indices of difficult temperament. The parent or primary care-giver ranks each item on a 7-point scale, indicating what parents perceive their child to be like. A number of different versions have been developed depending on the age of the child. Following communication with the author of the scale, a modified version of the ICQ was used with 16 items, tapping into fussy/difficult, adaptability and resistance to control.

- Emotionality, Activity and Sociability Questionnaire: The Emotionality, Activity and Sociability (EAS) Questionnaire focuses on heritable individual differences in reactivity and behaviour, sometimes referred to as temperament (Buss and Plomin, 1984). The EAS is a 20-item questionnaire that taps into four dimensions of temperament: emotionality (the tendency to become aroused easily and intensely), activity (preferred levels of activity and 
action), sociability (the tendency to prefer the presence of others to being alone) and shyness (the tendency to be inhibited and awkward in new situations). It has previously been used with children as young as 4 years of age.

- Parenting Styles and Dimensions Questionnaire: The Parenting Styles and Dimensions Questionnaire (PSDQ) is a widely used and psychometrically robust questionnaire (Robinson et al, 2001), tapping into parental use of three distinct parenting styles: authoritarian, authoritative and permissive. Following Wu et al (2002), a modified PSDQ was used, which included 25 items pertaining to authoritative and authoritarian dimensions of parenting.

\section{Pilot study}

Following a comprehensive review of the national and international literature on parenting styles and discipline, a questionnaire was developed. Of particular significance to the development of the present questionnaire were two similar UK-based survey studies of parental discipline (Ghate et al, 2003; Anderson et al, 2002). The questionnaire, including standardised measures adapted for the present study, was piloted with 52 families, including both mothers and fathers. Feedback was sought and documented (from both respondents and interviewers) about parents' and interviewers' experiences of completing the questionnaires and the standardised measures. Following a review of this feedback, some amendments were made to the questionnaire, most notably re-wording of certain questions and the introduction of filter questions (for example, according to child's age or whether parents used physical punishment) to reduce the number of non-relevant questions that were administered.

\section{Interviewer training}

The Irish Survey of Parenting and Discipline Practices (hereafter called the Parenting Survey) was conducted by telephone by ESRI interviewers with the respondent in his or her home. All interviewers working on the survey had previous experience of survey work with the ESRI. Interviewers were briefed on the aims of the survey to ensure they had a thorough understanding of its intent.

Basic ESRI interviewer training included procedures for making contact with households, refusal avoidance, encouraging participation (particularly of hard-to-reach groups such as males and younger adults), answering frequently expressed concerns, re-contacting telephone numbers up to 5 times in the event of no reply and procedures for asking questions in a non-directive manner. Training for the survey covered the purpose of the survey, the content of the questionnaire and the handling of ethical issues around child protection. Interviewers were briefed on the procedures to follow if they had concerns that a child in the household was at risk (see Appendix).

\section{Sampling and recruitment}

A total of 1,353 parents participated in the survey (69\% mothers, 31\% fathers). The sample was selected from parents who had responded to the ESRI's Monthly Consumer Survey from May 2007 to November 2007. All parents of children aged under 18 years were asked at the end of the Monthly Consumer Survey if they would be willing to participate in an important survey on parenting later in the year (between December 2007 and April 2008). Over three-quarters of the parents were willing to be contacted again about the parenting survey.

The sample and response rates for the Monthly Consumer Survey are described below, followed by details of the response rate to the Parenting Survey and a comparison of the characteristics of those parents who were willing to be re-contacted to those who refused to be re-contacted. 


\section{Sample for Monthly Consumer Survey}

The Monthly Consumer Survey employs a three-stage clustered sampling design. The first stage is the selection of the primary sampling unit (PSU) from the GeoDirectory - a listing of all addresses in Ireland. Each month, 70 PSUs are selected. The sampling points are based on aggregates of townlands with a minimum population size of 500 addresses within each cluster. The PSUs are selected at random by systematic selection following a random start, having sorted by geographic area.

At the second stage, an address is randomly selected within the PSU. The address is used to look up a telephone number stem, from which 100 telephone numbers are generated. Not all of the numbers generated were actually live numbers to private households. The procedure means that unlisted as well as listed telephone numbers will be contacted. Some will not be valid numbers, some will be to businesses, some will be valid numbers to households that have no eligible persons, and so on. This means that there is quite a degree of 'wastage' in the telephone numbers generated in each PSU, but this does not adversely impact on the statistical nature of the resultant sample (it does, of course, mean that it is wasteful of resources in trying to contact respondents at numbers that do not exist, but this is not a statistical issue).

The third stage is the selection of the actual individual within the household who will fill out the questionnaire. We imposed a post-stratification selection rule in the selection of the individual within the household chosen for interview. This was based on gender, economic status (at work or not at work) and broad age group (under 45 years and age 45 years or over). This was done to ensure a representative mix of males and females, and different age groups. If one did not impose this post-stratification selection criterion, one would find that females over 45 years of age would be over-represented in the final sample for analysis (willingness to participate in surveys is highest among this group in almost all surveys undertaken).

\section{Sample size and response rates to Monthly Consumer Survey}

Table 2 outlines the response rates to the Monthly Consumer Survey. This shows that a total of 41,722 telephone numbers were called as part of the survey from May to November 2007. ${ }^{2}$ These calls resulted in a total of 7,605 fully completed and usable questionnaires and a total of 5,439 households where the household refused to participate in the survey. There were 1,108 households where potential respondents were excluded because of the post-stratification controls ${ }^{3}, 10,696$ where there was consistently no reply, 4,445 were business numbers and 12,429 numbers were not in service. From Table 2, one can see that when one excludes the ineligible households, contact was made with a total of 13,044 valid households. Fully completed and usable questionnaires were completed with 7,605 of these households, giving an effective response rate of $58 \%$ of the valid sample (or $43 \%$ if we assume that $42 \%$ of the non-contacts are eligible ${ }^{4}$ ).

2 Interviewers were instructed to attempt each telephone number 4 times before recording a 'non-contact', ensuring that at least 2 of the calls were on different weekday evenings and at least one was on the weekend.

3 These controls were adopted to avoid biasing the sample by interviewing too many older and female respondents (who tend to be most cooperative in survey research). These controls at the interview stage are preferable to relying on re-weighting to adjust for this bias. In practice, however, they prove difficult to rigidly enforce because of differences between areas in their demographic structure.

4 The estimate of $42 \%$ is derived from the fact that $42 \%$ of the calls where eligibility is known (including valid calls, 'out of quota', business and non-existent numbers) were to eligible households. 
Table 2: Monthly Consumer Survey response outcomes (May to November 2007)

\begin{tabular}{|l|c|c|c|}
\hline & $\begin{array}{c}\text { No. } \\
\text { of cases }\end{array}$ & $\begin{array}{c}\% \\
\text { of valid } \\
\text { numbers }\end{array}$ & $\begin{array}{c}\% \\
\text { including non-contacts with } \\
\text { adjustment for percentage eligible }\end{array}$ \\
\hline Completed & 7,605 & $58 \%$ & $43 \%$ \\
\hline Refused & 5,439 & $42 \%$ & $31 \%$ \\
\hline Total valid calls & 13,044 & $100 \%$ & $(13,044+10,696=23,740)$ \\
\hline No reply & 10,696 & - & \\
\hline Business & 4,445 & - & \\
\hline Non-exist & 12,429 & - & \\
\hline Out of quota & 1,108 & - & \\
\hline Total & 41,722 & & \\
\hline
\end{tabular}

\section{Willingness to be re-contacted for Parenting Survey}

Table 3 shows the percentage of Monthly Consumer Survey respondents who were parents of children aged under 18 years (33\%), the proportion of parents who were willing to be re-contacted regarding the Parenting Survey $(76 \%)$ and the proportion of those re-contacted who completed the Parenting Survey. Once contacted, $78 \%$ of these parents completed the interview.

Table 3: Parents' willingness to be re-contacted and response rate to Parenting Survey

\begin{tabular}{|l|c|c|}
\hline & No. of cases & $\%$ \\
\hline Parent of child(ren) under 18 years of age & 2,482 & $\begin{array}{c}33 \% \\
\text { (\% of respondents to } \\
\text { Consumer Survey) }\end{array}$ \\
\hline Willing to be contacted again & 1,888 & $\begin{array}{c}76 \% \\
\text { (\% of parents) }\end{array}$ \\
\hline Parents approached for Parenting Survey & 1,738 & \% of those re-contacted \\
\hline \multicolumn{2}{|c|}{} & $78 \%$ \\
\hline Completed Parenting Survey & 1,353 & $8.2 \%$ \\
\hline Refused & 142 & $7.2 \%$ \\
\hline Other non-response* & 126 & $6.8 \%$ \\
\hline Non-contact, despite repeated attempts & 118 & \\
\hline
\end{tabular}

* includes those not available (too busy or away), ill, partly completed questionnaire.

Table 4 compares parents who completed the Parenting Survey with all parents who were identified in the Monthly Consumer Survey. As can be seen, the parents who completed the Parenting Survey were very similar in terms of age, the age of the youngest child and level of education to all parents identified in the Monthly Consumer Survey. As with most surveys, women were more likely to participate than men, both in the Consumer Survey itself and in terms of willingness to participate in the Parenting Survey. Apart from women, there is little evidence of bias at this stage of selection. It is also worth noting the low response rate (across both surveys) among those younger than 30 years. Re-weighting was used to control for any such differences in response rates to ensure that the results are representative of all parents (see below).

While the willingness to participate in the Parenting Survey was high among parents who were contacted during the course of the Monthly Consumer Survey, the complexity of the design and the number of stages in the fieldwork will tend to depress the final response rate. This is because there is a certain attrition rate at each stage of selection. of the parents contacted in the course 
Table 4: Description of parents who completed Parenting Survey, compared to all parents identified in Monthly Consumer Survey (\%)

\begin{tabular}{|l|c|c|}
\hline & $\begin{array}{c}\text { Parents identified in } \\
\text { Monthly Consumer } \\
\text { Survey }\end{array}$ & $\begin{array}{c}\text { Parents who completed } \\
\text { Parenting } \\
\text { Survey }\end{array}$ \\
\hline Mothers & $64 \%$ & $69 \%$ \\
\hline Fathers & $36 \%$ & $31 \%$ \\
\hline Age under 30 & $5 \%$ & $3 \%$ \\
\hline Age 30-44 & $58 \%$ & $59 \%$ \\
\hline Age 45 and over & $37 \%$ & $38 \%$ \\
\hline Youngest child age 0-4 & $35 \%$ & $34 \%$ \\
\hline Youngest child age 5-9 & $27 \%$ & $28 \%$ \\
\hline Youngest child age $10-14$ & $23 \%$ & $25 \%$ \\
\hline Youngest child age $15-17$ & $15 \%$ & $13 \%$ \\
\hline Parent completed third-level education & $39 \%$ & $41 \%$ \\
\hline
\end{tabular}

of sample selection, $59 \%$ participated in the Parenting Survey ( $76 \%$ expressed willingness to be re-contacted and $78 \%$ of these actually completed the survey). If we take account of non-response to the Monthly Consumer Survey, the strictly defined response rate drops to $35 \%$ (58\% x $76 \% \times$ $78 \%$ ). However, the fact that parents who participated in the Parenting Survey are very similar to those who were unwilling to participate is reassuring.

A flow chart setting out sampling, recruitment, number of respondents and response rates at different points in the recruitment process is presented in Figure 1.

Figure 1: Flow chart of sampling, recruitment, number of respondents and response rates at different points in the recruitment process

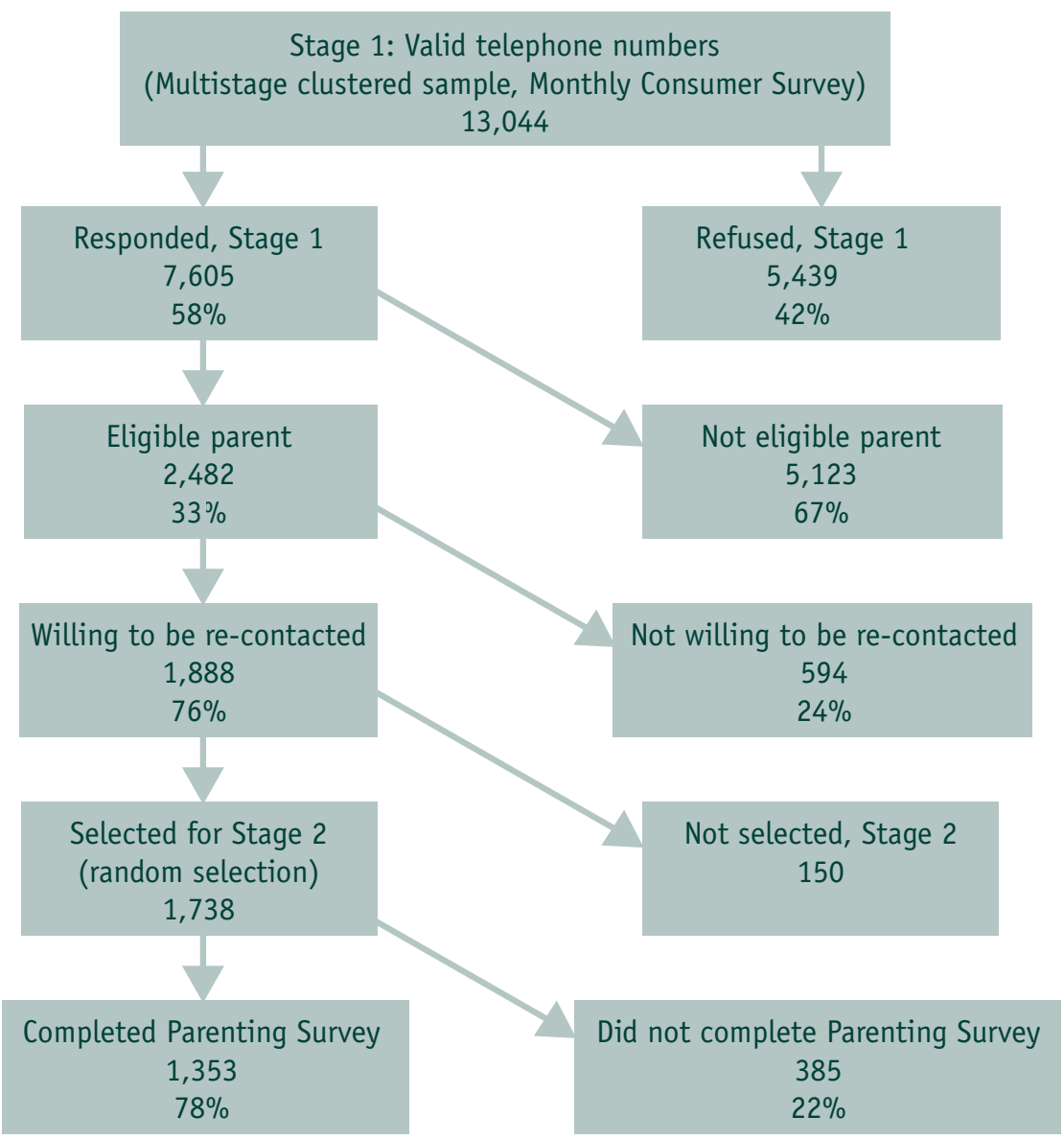




\section{Re-weighting the data}

The purpose of sample weighting is to compensate for any biases in the distribution of characteristics in the completed survey sample compared to the population of interest, whether such biases occur because of sampling error, from the nature of the sampling frame used or to differential response rates. Whatever the source of the discrepancy between the sample and population distributions, it is usual to adjust the distributional characteristics of the sample in terms of factors such as age, gender, economic status and so on to match that of the population. As with most surveys, the completed sample for the Parenting Survey under-represented 'hard to reach' groups such as young adults, males and those at work. Sample weights are needed to ensure that point estimates (such as means and proportions) calculated from the data represent the population as a whole.

In the current Parenting Survey, this was implemented using a standard statistical technique known as calibration, which involves adjusting sample distributions to external population figures, in this case derived from a special set of tables provided by the Central Statistics Office from the Quarterly National Household Survey (QNHS). The QNHS is based on interviews conducted in over 33,000 households in each quarter. The data used came from the 4th Quarter of 2007 and followed revisions arising from Census 2006.

The variables used in the weighting scheme were:

- age cohort (4 categories) of the parent by gender;

- level of educational attainment (4 categories) by gender;

- principal economic status ( 6 categories) by gender;

- marital status (4 categories) by gender and by age group (2 age groups for married adults);

- region (3 categories);

- number of persons aged 16 and over in the household (special figures provided by the CSO, 5 categories);

- age of youngest child (4 categories).

The weighting procedure involved constructing weights so that, when the weight is applied, the distribution of each of the characteristics for the responding individuals was equal to the distribution of these characteristics for the population of parents aged 16 and over. $^{5}$

Table 5 shows the population figures for certain key characteristics of parents, compared to the unweighted and weighted characteristics of the respondents to the Parenting Survey. It can be seen that, compared to population figures, fathers, younger parents, never-married parents, parents of children under 5 years and those in the Dublin region tend to be under-represented. The sample weights successfully adjust for the majority of these differences, as can be seen by comparing the column for the weighted data to the column showing the population percentages. However, the number of very young and single parents who completed the Parenting Survey was low (with no respondents under the age of 20). ${ }^{6}$ Thus, even with weighting applied, the sample will somewhat under-represent younger (under 30 ) and single parents. ${ }^{7}$ Generalisations to this group therefore need to be treated with caution.

5 Weighting was accomplished by using a minimum distance algorithm which adjusts the marginal distributions for a number of variables simultaneously using an iterative procedure.

6 In general, young adults are a difficult group to reach in survey research, so the fact that they are under-represented in this sample is not unusual.

While this could have been adjusted using weighting, the resulting weights would have extreme values which could compromise the quality of the analysis. 
Table 5: Sample data compared to population data

\begin{tabular}{|c|c|c|c|c|}
\hline & $\begin{array}{c}\text { Frequency } \\
\text { (Total } n=1,353 \text { ) }\end{array}$ & $\begin{array}{l}\text { Survey data } \\
\text { unweighted }\end{array}$ & $\begin{array}{c}\text { Survey data } \\
\text { weighted }\end{array}$ & $\begin{array}{c}\text { Population } \\
\text { data }\end{array}$ \\
\hline Mothers & 936 & $69 \%$ & $54 \%$ & $54 \%$ \\
\hline Fathers & 417 & $31 \%$ & $46 \%$ & $46 \%$ \\
\hline Age under 35 & 169 & $12 \%$ & $26 \%$ & $28 \%$ \\
\hline Age $35-44$ & 658 & $49 \%$ & $44 \%$ & $43 \%$ \\
\hline Age 45 and over & 526 & $39 \%$ & $29 \%$ & $28 \%$ \\
\hline Single & 47 & $3 \%$ & $12 \%$ & $15 \%$ \\
\hline Married & 1,227 & $91 \%$ & $83 \%$ & $80 \%$ \\
\hline $\begin{array}{l}\text { Divorced/Separated/ } \\
\text { Widowed }\end{array}$ & 71 & $5 \%$ & $5 \%$ & $5 \%$ \\
\hline $\begin{array}{l}\text { Education less than } \\
\text { Leaving Certificate }\end{array}$ & 258 & $19 \%$ & $28 \%$ & $28 \%$ \\
\hline Leaving Certificate & 382 & $28 \%$ & $26 \%$ & $28 \%$ \\
\hline $\begin{array}{l}\text { Education beyond } \\
\text { Leaving Certificate }\end{array}$ & 713 & $53 \%$ & $45 \%$ & $45 \%$ \\
\hline Dublin Region & 275 & $20 \%$ & $26 \%$ & $25 \%$ \\
\hline Working for pay & 969 & $72 \%$ & $74 \%$ & $74 \%$ \\
\hline Youngest child age $0-4$ & 438 & $32 \%$ & $43 \%$ & $44 \%$ \\
\hline Youngest child age 5-9 & 374 & $28 \%$ & $25 \%$ & $25 \%$ \\
\hline Youngest child age $10-14$ & 349 & $26 \%$ & $20 \%$ & $19 \%$ \\
\hline Youngest child age $15-17$ & 192 & $14 \%$ & $12 \%$ & $11 \%$ \\
\hline
\end{tabular}

In $98 \%$ of cases, the respondent to the Parenting Survey identified him or herself as the child's parent. In only a minority of cases, respondents identified themselves as foster parents, grandparents or stepparents/partner of child's parent. A detailed profile of the parents and their children is provided in Chapter 4.

\section{Ethical issues}

Procedures and guidelines of the DIT Research Ethics Committee for Good Research Practice underpin the present research. The questionnaire and procedure of the study were subject to review and approval by the Research Ethics Committee within the DIT. As the study involved a telephone survey questionnaire, consent from respondents was obtained verbally. Prior to obtaining consent, all respondents were provided with details of the study's aims and objectives, details of who funded the study and the organisations involved in carrying out the research. Respondents were also assured that all information exchanged during the interview would be held in strictest confidence. Participants were assured that the interviewers did not know the full identity of the people who are being interviewed since the telephone numbers were generated at random by a computer and interviewers had no way of looking up the name and address associated with the number. The ESRI, in collaboration with the research team, developed systematic procedures to be adopted in the case of a respondent reporting behaviours that were deemed damaging or injurious to a child's safety (see Appendix). 


\section{Data analysis}

Statistical analyses were conducted using the Statistical Package for the Social Sciences. In addition to frequency and descriptive analysis, bivariate analysis was used to compare parenting styles, behaviours and attitudes by gender and age of the parent, gender and age of the child, social class categorisation of the household and education level of the parent. All descriptive analyses based on percentages and proportions were carried out with weighted data. Where numbers of individuals are given, this is the unweighted number of cases. For the most part, tests of statistical significance were conducted with the unweighted figures, although the weighted percentages are reported unless otherwise stated.

For the purpose of analysis, the age of the selected child was recoded into four categories: 0-4 years, 5-9 years, 10-14 years and 15-17 years. Parental age was recoded into three categories: younger than 35 years, 35-44 years and 45 years and over. Finally, parental education level was recoded into three categories: those who left school before completing the Leaving Certificate, those who completed the Leaving Certificate and those who proceeded beyond the Leaving Certificate.

\section{Study limitations}

A critique of the strengths and weaknesses of methodological issues is essential in evaluating the confidence to be placed in the findings of the present study. A key strength of the study was the selection of a telephone interviewing methodology, which provides many of the advantages associated with face-to-face interviewing (such as the ability to establish rapport, allay participant concerns about confidentiality), but in a more cost-effective and anonymous manner. Telephone surveys are increasingly being used in Ireland and the methodology has been employed to research sensitive topics such as sexual knowledge, attitudes and behaviours of the Irish population (Layte et al, 2006), sexual violence (McGee et al, 2002) and domestic abuse (Watson and Parsons, 2005). However, telephone surveys are not without limitations, not least of which is that ESRI experience in using this method suggests a 30-minute time-limit on the length of the interview, which inevitably constrains the range of issues that can be explored.

In such a survey as this dealing with the sensitive topic of parental discipline strategies, we need to be aware of the possibility that a fear of social judgement may have motivated parents to under-report the extent to which they use physical punishment with their children. This methodological issue, referred to as social desirability bias, is not, however, unique to this study. Holden (2002) has noted that this problem characterises all research into physical punishment that relies on parental self-report: parents who are fearful of being reported to authorities are likely to under-report their use of extremely harsh techniques. Further, since we will be comparing the results with surveys that used face-to-face methods (Ghate et al, 2003; Anderson et al, 2002), we need to be conscious of the possibility that telephone and face-to-face surveys differ in terms of social desirability bias.

Social desirability bias refers to the tendency of respondents to answer in a way that makes them 'look good' to the interviewer or researcher. However, the literature is inconclusive regarding the impact of telephone or face-to-face survey mode on social desirability bias. On the one hand, Weisberg (2005) suggests that social desirability effects might be expected to be greater in face-toface surveys, where the respondents see the interviewer directly, than in telephone surveys. On the other hand, there is some evidence that telephone surveys may be more prone to social desirability bias effects than face-to-face surveys (Holbrook et al, 2003), but that these differences are small (De Leeuw and Van der Zouwen, 1988). Holbrook et al (2003) interpret this as arising because the face-to-face interviewer can build a stronger rapport with respondents, leading to greater confidence that the results will be confidential. Weisberg (2005) cautions that many of the differences in mode found between telephone and face-to-face surveys are based on very few studies and differences may arise because of how the survey is organised (characteristics of interviewers, similarity of interviewers to respondents in terms of region) rather than because of the mode. 
Overall, the literature is inconclusive about the significance and magnitude of differences between telephone and face-to-face interview methods in terms of the validity of sensitive information. Several features of the present study are likely to have facilitated an open response from the participants. First, participants' telephone numbers were generated in a random manner, so that the identity of the participant remained unknown to the interviewer and no identifying information was collected during the course of the interview. Given the anonymity inherent in the use of the telephone interview, the participants are likely to have felt more assured about confidentiality and thus more likely to report on their behaviour in an open manner. Secondly, the interviewers were all very experienced in conducting telephone interviews and in establishing rapport with respondents on the telephone. The ESRI has a high level of 'name recognition' among respondents in Ireland as a reputable and legitimate research institute. All of this is likely to enhance respondents' confidence in the legitimacy of the study and their trust in the guarantee of confidentiality.

Furthermore, the questionnaire was designed in such a way as to enhance participants' comfort with the situation and their honesty in responding to the questions - initial questions in the interview were non-threatening in nature, gradually leading to more sensitive questions, including their own experiences of discipline in childhood and eventually use of physical punishment with their own children.

The use of physical punishment is a sensitive subject and the privacy of respondents needs to be balanced with due consideration for the welfare of children. A major concern with the study was the possibility of discovering that a child in a household was at risk of physical abuse. A protocol was established, and training provided, for interviewers to follow in the event of a report of behaviours considered to be injurious or damaging to a child's safety (see Appendix).

The aim of the survey was to collect representative data from parents in Ireland on parenting styles and use of discipline strategies with their children. Response rates are critical to the extent to which the findings of the study can be generalised to the larger population of parents. Overall, a response rate of 58\% was achieved, which is similar to that reported by Anderson et al (2002) for a comparable survey on parenting in Scotland (their response rate was in the range 50\%-55\%). Furthermore, this response rate corresponds favourably with the response rate from other Irish surveys that have used telephone-interviewing methods. For example, McGee et al (2002) cited response rates of 62\%-64\% for their SAVI Report: Sexual Abuse and Violence in Ireland, while Layte et al (2006) reported a response rate of $61.3 \%$ for their Irish Study of Sexual Health and Relationships.

As mentioned earlier, the completed sample under-represented particular groups within the population, such as young adults, males and those who work (see Table 5). The data were weighted according to CSO data to ensure that they were representative of the population. However, even with the weights, certain sections of the population remain under-represented - in particular, single parents and parents under the age of 30 years. Generalisations to this group thus need to be treated with caution. Indeed, given the strong dominance of married parents in the sample $(83 \%)$, the possibility of exploring family structure effects was constrained in the study. Furthermore, the proportion of non-Irish parents in the sample was very low - only $2 \%$ of the parents were identified as African or Asian. The consequence of this is that important research questions pertaining to parenting among ethnic minorities in Ireland could not be addressed. 


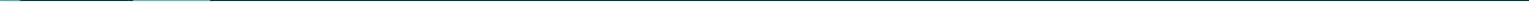




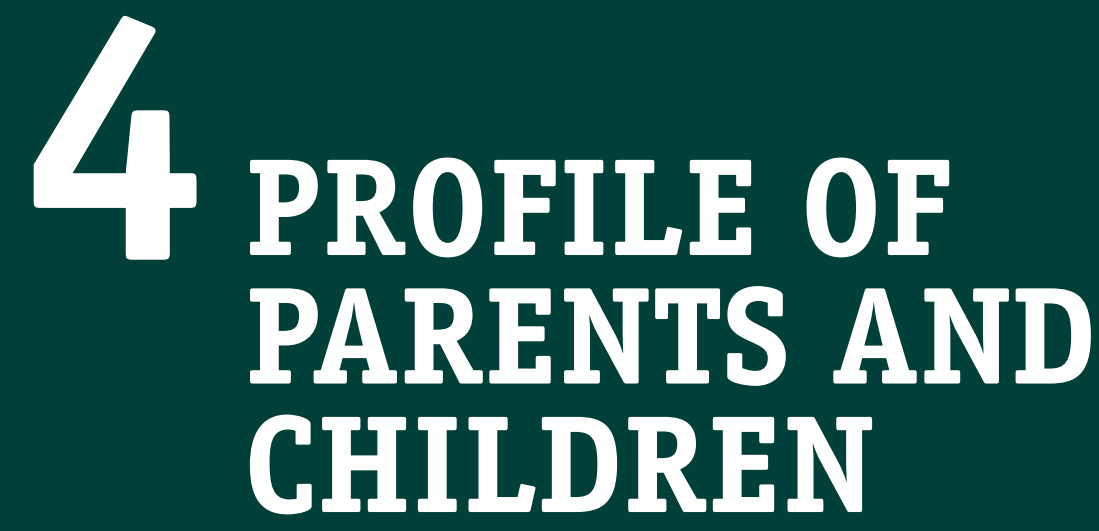


This chapter provides a profile of the parents and children represented in the study. Information on age, gender, ethnicity, marital status, education level and employment circumstances of the parents is outlined. Further details pertaining to the households are provided, including household composition, housing tenure, location (urban/rural), earning status of householders (dual/sole/ no earners), household income and socio-economic classification. Finally, details relating to the children of the parents are given, including age, gender, ethnicity, health status and birth order.

As explained in Chapter 3, it is standard practice in population surveys to re-weight or statistically adjust the information collected from the survey so that it is representative of the population. Such a process addresses any potential bias arising from sample design and differential response rates across different sections of the population. Table 5 in Chapter 3 illustrates some key sample characteristics prior to weighting and the corresponding weighted proportions that reflect the population of parents in Ireland. These weighted proportions have been used in the analysis for the report and are described in detail in this chapter.

\section{Profile of parents}

- Parents who participated in the study ranged in age from 21 to 69 years, with a mean age of 40.45 years $($ s.d. $=7.98)$.

- $54 \%$ of the parents were mothers and $46 \%$ were fathers.

- Mothers ranged in age from 21 to 69 years, with a mean age of 39.32 years (s.d. = 7.71).

- Fathers ranged in age from 24 to 68 years, with a mean age of 41.8 years (s.d. $=8.08$ ).

- The majority of parents were identified as Irish (93\%). A further $5 \%$ were identified as '0ther White' and $1 \%$ each were identified as African and Asian respectively.

- $79 \%$ of the parents were married and/or living with their spouses, making up the largest grouping of parents.

- Almost $12 \%$ of the parents were single and never married.

- Almost $5 \%$ of the parents were separated/divorced after marriage/cohabitation.

- Almost $4 \%$ of the parents were cohabiting or married for the second time.

The marital status of the parents in the study is illustrated in Figure 2: parents represented by the first two bars were living in two-parent households (almost 83\%), while the latter three bars represent lone-parent households (17\%).

Figure 2: Marital status of parents (\%)

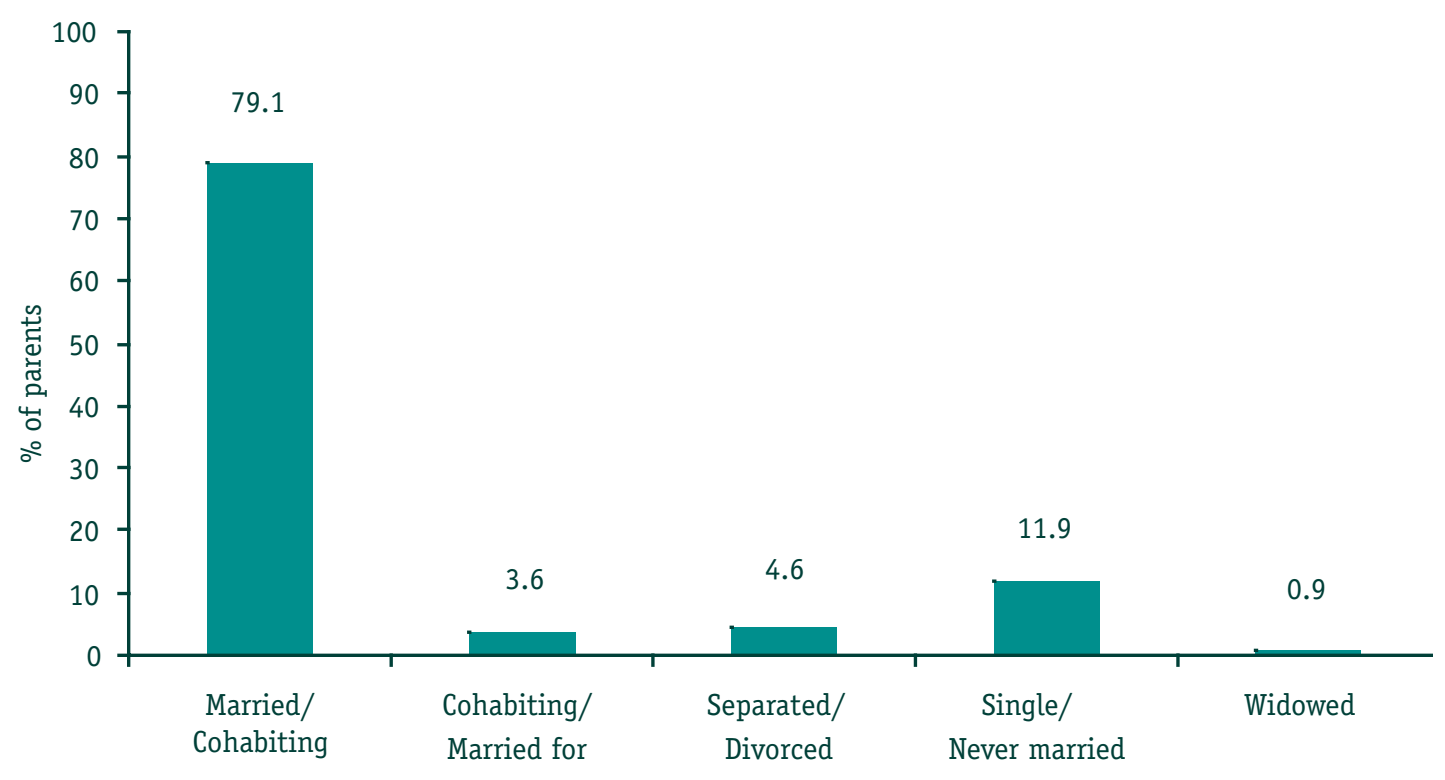


- In terms of education level, slightly less than half of the parents (45.5\%) had completed education beyond their Leaving Certificate (see Table 6), while $28 \%$ of parents had left school before completing their Leaving Certificate. No clear differences emerged between mothers and fathers in terms of highest education level achieved.

Table 6: Highest education level of parents (\%)

\begin{tabular}{|l|c|}
\hline Highest education level achieved & $\begin{array}{c}\% \\
\text { (weighted proportions) }\end{array}$ \\
\hline Primary school & 9.3 \\
\hline Intermediate/Junior Certificate & 18.8 \\
\hline Leaving Certificate & 26.4 \\
\hline Other second-level (certificates, diplomas completed after second-level) & 9.2 \\
\hline $\begin{array}{l}\text { Third-level (university, college of technology or art, teacher training, } \\
\text { professional qualifications) }\end{array}$ & 36.2 \\
\hline
\end{tabular}

- Almost three-quarters of the parents were in employment, while one-fifth were carrying out home duties. The average number of hours worked by employed parents was 36 hours per week $($ s.d. $=13.8)$. Among those involved in home duties, $94 \%$ were mothers and only $6 \%$ fathers. Two-thirds of the main wage-earners were fathers, while one-third were mothers.

Details pertaining to number of earners in the households, household income and social class categorisation of household are considered below.

\section{Profile of households}

- Households ranged in size from 2 to 13 persons, with the average size of a household being 4.27 members (s.d. $=1.23$ ).

- The number of children in the households ranged from 1 to 7 children, with an average of 2 children (s.d. $=0.97$ ).

- Just over one-third of the households consisted of one child (36\%) or 2 children (37\%). Less than $7 \%$ of the households contained 4 or more children.

- The majority of parents owned their home or had a mortgage on their house $(86 \%)$.

- Just over $11 \%$ of families were living in rented accommodation. Two-thirds of these were renting from local authorities or housing associations, and one-third from private landlords.

- Households were classified according to the number of earners therein:

$\rightarrow 11 \%$ of households were classified as 'no earner households' - this group is made up of lone-parent households (where the parent is not working) and two-parent households (where neither parent is working).

$\rightarrow$ Just over half of the households (54\%) were classified as 'sole earner households', where either the parent in a lone-parent household or one parent in a two-parent household is working.

$\rightarrow$ Finally, 30\% of households were classified as 'dual-earner households', where both parents in two-parent households are working.

- In terms of weekly household income, $11 \%$ of households had a weekly income of less than $€ 400$, while $36 \%$ had a weekly income of more than $€ 900$ per week (see Figure 3 ). Roughly similar proportions of households had weekly incomes of $€ 500-€ 749$ (23\% of households) and $€ 750-€ 899$ (19\% of households). 
Figure 3: Household income per week (\%)

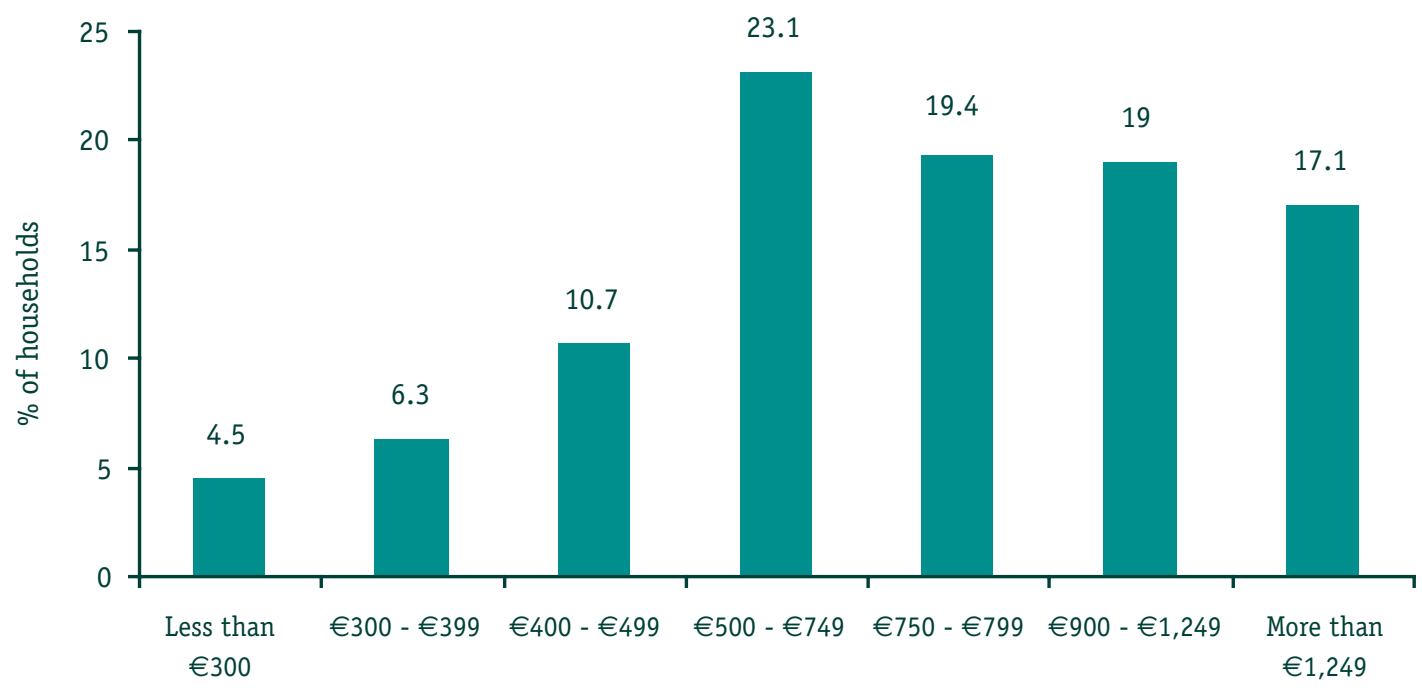

- In order to obtain a socio-economic categorisation of households, the occupation of the main wage-earner in each household was classified into one of 5 socio-economic groups (see Figure 4): self-employed or farmer (16\%); professional/managerial (31\%); other non-manual (17\%); skilled/ unskilled manual $(29 \%)$; and not classified $(7 \%)$.

Figure 4: Socio-economic classification of households (\%)

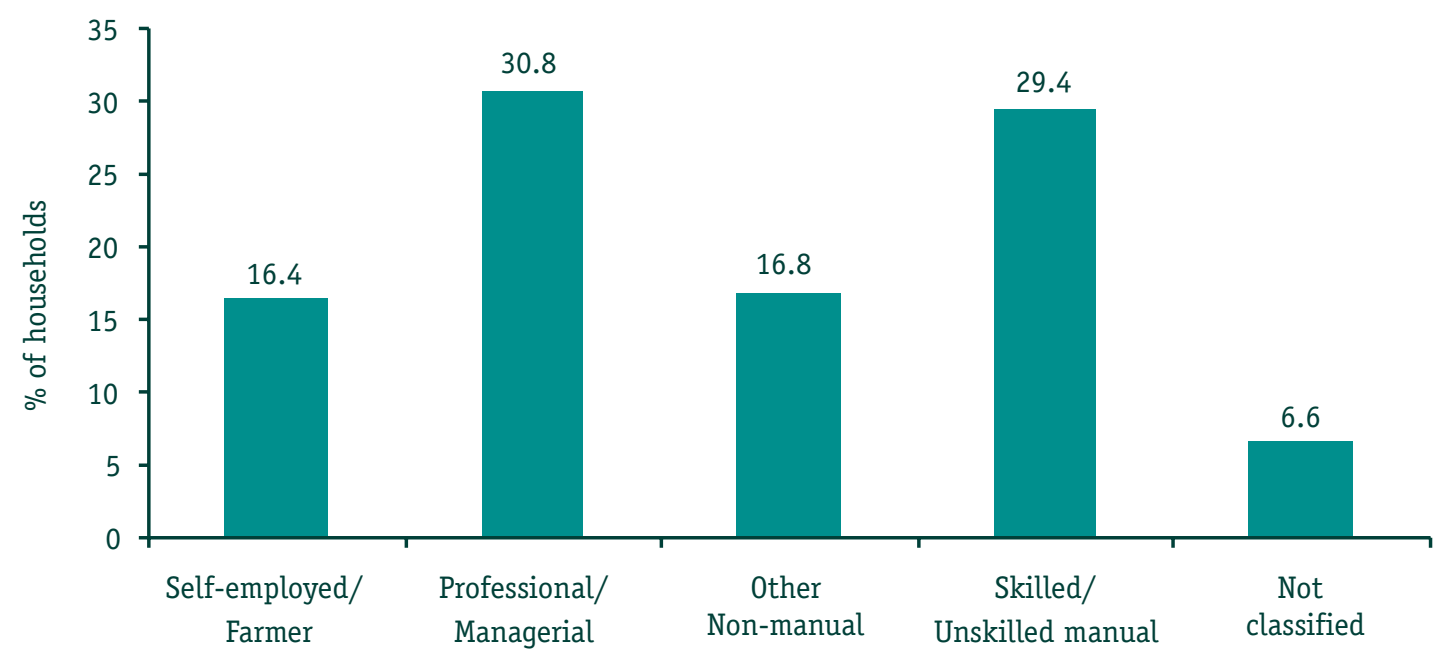

- Finally, in terms of the location of the households, there was an even rural/urban distribution, with half of the parents living in a village or isolated location and half living in a town or city. One-third of the parents lived in an isolated location, $16 \%$ in a village, $22 \%$ in a town and $29 \%$ in a city. Just over one-quarter lived in the Dublin region; $28.3 \%$ were from the Border, Midland and West regions; and $46.2 \%$ were from the Southern and Eastern regions.

\section{Profile of children}

Each parent nominated one child in their household whose birthday was next to occur, giving rise to a sample of selected or reference children on which segments of the survey are based. Based on re-weighted proportions:

- $47 \%$ of the children were girls, while $53 \%$ were boys.

- The children ranged in age from less than one year to 17 years, with a mean age of 8.32 years (s.d. $=5.247)$, with little difference in age between boys and girls. 
- $96 \%$ of the children were identified as Irish. A further $2 \%$ were identified as 'Other White' and $1 \%$ each were identified as African and Asian respectively..

- Over one-third of the children (35.9\%) were 'only children' (i.e. no siblings).

- Roughly similar proportions of children were 'oldest children' (27\%) and 'youngest children' (23\%). 'Middle children' accounted for $14 \%$ of the children.

- Similar proportions of boys and girls were 'only', 'youngest', 'middle' and 'oldest' children in their families.

- In $5 \%$ of cases, the selected child had a physical or mental health problem. In almost two-thirds of these cases, children's daily activities were restricted 'severely' $(21 \%)$ or 'to some extent' (43\%) by these difficulties. Of those children with a physical or mental health problem, $71 \%$ were boys and $29 \%$ were girls.

- In general, parents were the main carers of their children. In $61 \%$ of cases, the parent looked after the child 'all' or 'most of the time'. The other most significant carer of the child was the parent's partner, who in $44 \%$ of cases looked after the child 'all' or 'most of the time'. In $87 \%$ of cases, the partner was identified as the other parent of the child. In less than $10 \%$ of cases, children were looked after 'all' or 'most of the time' by older siblings, grandparents, other relatives and child-minders.

\section{Summary}

In summary, an analysis of the profile of parents and children reveals that the majority of families in the study are characterised by parents and children of Irish origin (over 95\%), in two-parent households (over $80 \%$ ), with at least one earner in the household (over $80 \%$ ). There is a broad mix of socio-economic groupings, with the largest proportions belonging within the professional and managerial classes $(31 \%)$ and skilled/unskilled manual classes (29\%). Education level of parents is also broadly mixed, with just less than one-third leaving school before the end of second level $(28 \%)$ and slightly less than half going beyond second-level education (45\%). As a representative sample of the population of parents in Ireland, there is a relatively even breakdown across types of location, with similar proportions living in cities and isolated locations, and slightly smaller proportions coming from towns and villages. 


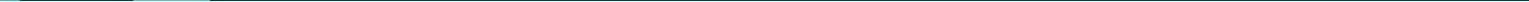




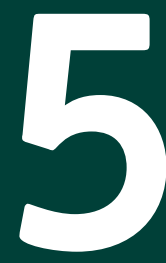

PRESSURES, PRIORITIES AND PLEASURES IN PARENTING 
Parenting beliefs and practices evolve within specific settings and situations. Here, we explore parents' general views on parenting in contemporary Irish society, thereby building a broader framework within which to situate more specific views on discipline strategies adopted with children. In particular, we examine parental perspectives on the changing nature of parenting, pressures that are perceived to impact on parenting practices and values, and, finally, priorities highlighted by parents in terms of child-rearing goals and aspirations. The chapter concludes with an exploration of what parents feel they enjoy most about parenting and its associated activities.

\section{Changing parenting contexts}

In order to gain insight into whether and how parents perceive parenting to have changed over time, parents participating in the survey were first asked if they believed that parenting today was different from parenting 20 years ago. A substantial majority of parents (70\%) expressed the view that parenting was 'very different' when compared with 20 years ago, with a further $27 \%$ indicating that parenting was 'somewhat different' than in the past. A very small minority $(4 \%)$ felt that parenting had 'not changed at all' compared to 20 years ago.

With a view to gaining further insight into some of the precise changes that may contribute to these perceptions of differences in parenting over time, specific issues of parental control, parental responsibility and pressure on parents were examined (see Figure 5). Parental control refers to parents' monitoring and knowledge of their child's activities and has been found to have an enduring influence on child outcomes, such as anti-social behaviour, across a diversity of cultures (Barber et al, 2005). The majority of parents in the present study (73\%) were of the opinion that parents had 'less control' than parents in the past. Approximately one-fifth of parents (19\%) considered that they had 'about the same' level of control as parents in the past, while a minority of $8 \%$ indicated that they had 'more control'. Parental perceptions of the extent to which they had more or less control were not related to the gender of the parent who responded.

With regard to perceptions of changes in parental responsibility over time, findings were somewhat mixed, with just under half of parents (45\%) stating that parental responsibility in contemporary contexts was 'about the same' as 20 years ago. A further $39 \%$ believed that parents today had 'more responsibility' than in the past, while a minority (16\%) believed that parents today had 'less responsibility' than in the past. There was some evidence that a greater proportion of parents in the age group 35-44 felt that parents had greater responsibility today than in the past.

Finally, parents were asked whether they felt that parenting had changed over time in terms of the pressure experienced in the parenting role. A striking proportion of parents $(84 \%)$ indicated that there was greater pressure on contemporary parents when compared with 20 years ago. Fathers were more likely to express the view that pressures on parents were 'about the same' as in the past. Only $3 \%$ of parents in the present study reported that pressures on parents were less now than 20 years ago. 
Figure 5: Parents' perceptions of parental control, responsibility and pressure today compared with 20 years ago (\%)

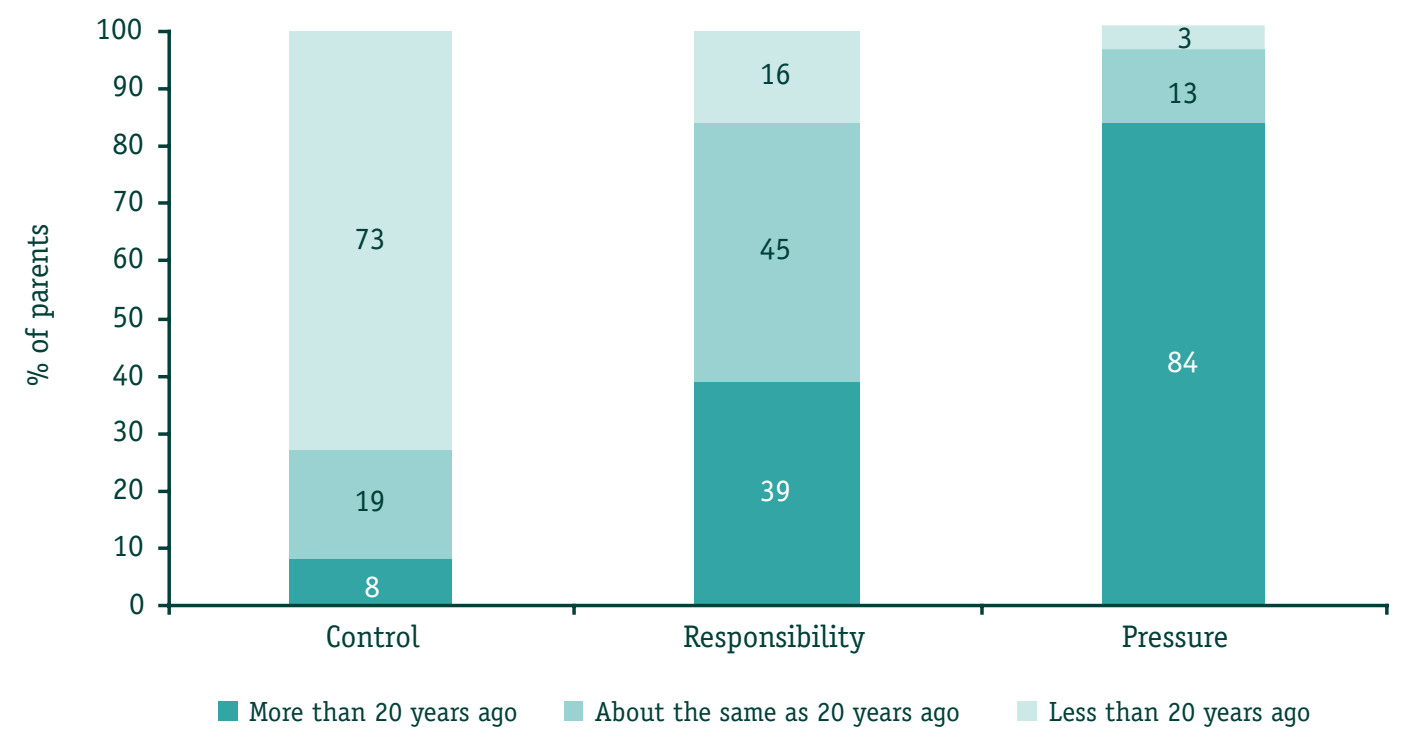

In summary, these findings indicate that parents perceive the task of parenting in contemporary society to be very different from parenting in previous generations. Most notably, a striking majority of parents asserted that pressures on parents today are greater than in past. Notable also is the view that parents have less control over their children than in the past in terms of monitoring and knowledge of children's activities and friendships, with just one-fifth of parents stating that levels of parental control were the same as in past times.

\section{Perceived pressures on parenting}

With the aim of capturing some detail on the precise nature of pressures that might impact on parents today, the following topics were explored with parents: work/life balance issues, concerns/ worries about financial matters, physical safety of children, emotional well-being of children and worries about children's educational outcomes. Parental views on these perceived pressures are outlined in Figure 6.

Figure 6: Parents' perceptions of the extent to which different pressures impact on parenting today $(\%)$

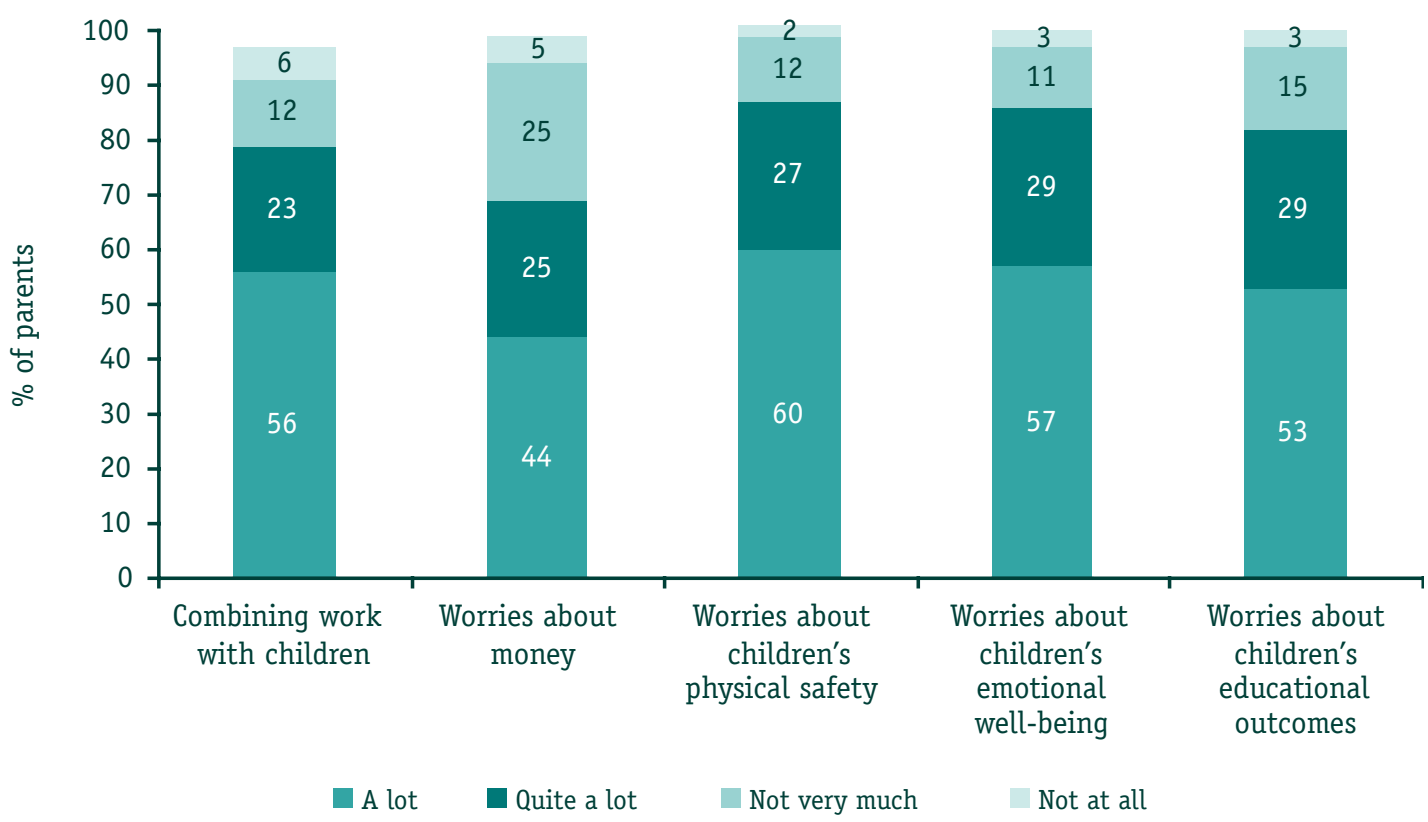


Approximately $30 \%$ of respondents in the present study were from 'dual-earner households', in which both parents in a two-parent household were working. Just over half of the parents interviewed $(56 \%)$ stated that combining bringing up children with work obligations and responsibilities impacted 'a lot' on their child-rearing, with a further $23 \%$ reporting that the impact was 'quite a lot'. Taken together, these findings suggest that over three-quarters of parents feel that working responsibilities impact substantially on bringing up their children. Only a small minority $(6 \%)$ indicated that combining work with bringing up children did not impact at all on child-rearing. No clear evidence emerged that the pressure of combining work with children varied according to whether it was a dual-earner household or whether it was the socio-economic classification of the household. This may be because deciding not to work is possibly a response to such pressure by (mainly) mothers in one-earner households.

Parents were also asked to rate the extent to which they felt that financial worries impacted on their parenting. Perceptions of pressures due to financial considerations were mixed, with $44 \%$ of parents stating that worries about money impacted 'a lot' on their parenting, while a further $25 \%$ indicated that such pressures impacted 'quite a lot'. One-quarter of parents expressed the view that worries about money did not impact very much on bringing up their children, with a minority of parents (5\%) indicating that financial considerations did not impact at all on their parenting. While many parents indicated that worries about money impacted on their parenting, there was no clear association between the extent to which parents worried about money and their level of household income or socio-economic status.

Parental worry about the physical safety of their children and the extent to which this impacted on parenting was also examined in the present study. A total of $60 \%$ of parents stated that anxiety about the physical safety of their children impacted 'a lot' on their children's upbringing. A further $27 \%$ indicated that such a preoccupation impacted 'quite a lot'. Strikingly, only $14 \%$ stated that such concerns did not worry them very much or at all.

With regard to worries about the emotional well-being of their child, just over half of parents (57\%) expressed the view that such concerns impacted 'a lot' on their parenting, with a further $29 \%$ indicating that these concerns impacted 'quite a lot'. A minority of parents reported that concerns about their child's emotional well-being did not worry them very much $(11 \%)$ or at all $(3 \%)$.

Finally, parents were asked to indicate to what extent they perceived concerns about their children's educational outcomes to impact on bringing up their children. Just over half of parents interviewed (53\%) stated that such concerns impacted 'a lot' on their parenting, with a further $29 \%$ indicating that these concerns impacted 'quite a lot'. Almost one-fifth of parents expressed the view that concerns about children's educational outcomes were not significant in terms of their impact on their parenting (15\% indicating 'not very much' and 3\% indicating 'not at all').

In summary, parents' self-reports on the impact of a variety of pressures on the parenting role suggest that most of these parents experience a great deal of pressure in their everyday parenting activities. This pressure does not appear to be clearly related to the age or number of children being parented, and is experienced more or less equally by mothers and fathers. Most notable were worries about children's physical and emotional safety and well-being, although well over half of parents who responded to these questions reported that all of these pressures impacted substantially on their parenting role.

\section{Support from spouse/partner}

We were interested in exploring the extent to which parents felt they were supported in their role as parent by their partner or spouse. A substantial majority (93\%) reported that they were 'very supported' by their spouse or partner, with a further $5 \%$ reporting that they were 'somewhat supported'. A very small minority (approximately $2 \%$ ) reported that they were 'not very supported' or 'not at all supported' by their spouse or partner. 
Parents were also asked about the extent to which their partner was involved in looking after the selected child. As seen in Table 7, just over $60 \%$ of parents stated that they looked after the child all or most of the time. In contrast, $44 \%$ of parents reported that their partner was involved in looking after the child all or most of the time. Only a minority of parents $(3.4 \%)$ and partners $(13.6 \%)$ spent little or no time looking after the selected child. These findings are in line with the high levels of support that parents reported receiving from partners (93\%).

Table 7: Comparison of percentage of time spent looking after the child, by respondent and partner (\%)

\begin{tabular}{|l|c|c|}
\hline Amount of time spent looking after the child & Respondent & Partner \\
\hline All of the time & 21.8 & 10.9 \\
\hline Most of the time & 38.8 & 33.5 \\
\hline Some of the time & 36.0 & 42.0 \\
\hline Little of the time & 3.2 & 6.6 \\
\hline None of the time & 0.2 & 7.0 \\
\hline
\end{tabular}

\section{Parental values and expectations}

Parents were asked to rate the importance of teaching children skills and values related to the following issues: getting on with others, academic/work skills, religious faith, self-control, standing up for yourself, practical skills, obedience to parents, independence and personal moral values. Overall, 6 of these 9 areas were highlighted as 'very important' for children's development according to over three-quarters of the parents interviewed (see Table 8). Most highly prioritised were pro-social qualities, such as personal moral values and getting on with others, with over $90 \%$ of parents prioritising these characteristics. Characteristics related to self-direction and autonomy were also rated highly, with at least $80 \%$ of parents asserting that self-control, standing up for yourself, practical skills and independence were 'very important' to teach children. Academic achievement and obedience to parents were rated as 'very important' by approximately $70 \%$ of parents. In contrast, religious faith was prioritised by only a minority of parents, with just under one-third $(31.7 \%)$ conveying the view that it was a 'very important' parental goal.

Table 8: Parents' perceptions of importance of different skills and values in raising children (\%)

\begin{tabular}{|l|c|c|c|}
\hline & Very important & Somewhat important & Not important \\
\hline Personal moral values & 94.1 & 5.9 & 0 \\
\hline Get on with others & 90.3 & 9.1 & 0.6 \\
\hline Academic/work skills & 70.2 & 29.2 & 0.6 \\
\hline Self-control & 88.4 & 11.5 & 0.1 \\
\hline Stand up for yourself & 86.0 & 13.9 & 0.1 \\
\hline Practical skills & 80.4 & 18.6 & 1.0 \\
\hline Independence & 79.3 & 20.5 & 0.2 \\
\hline Obedience to parents & 71.7 & 26.7 & 1.6 \\
\hline Religious faith & 31.7 & 51.5 & 16.8 \\
\hline
\end{tabular}

\section{Involving children in decisions}

Parents' views on the importance of involving children in decision-making within the context of their family lives were also examined. Just over one-third of parents (34\%) asserted the view that it was 'very important' for them to involve children in decisions, while a further $54 \%$ stated that it was 'somewhat important'; $13 \%$ of parents indicated that it was 'not important' to involve children in family decision-making. While many parents did not prioritise involving their child in family decisions, not surprisingly, there was increasing parental support for this value as a priority in 
child-rearing as the child grew older. Parents whose oldest children were in late childhood (10-14 years) and mid- to late adolescence (15-17 years) were more likely to highlight involving their child in family decisions. Conversely, parents of children in infancy and early childhood ( $0-4$ years) were significantly less likely to prioritise this value in their child-rearing goals.

\section{What parents enjoy most about parenting}

In this section, we outline findings on parents' perceptions of the most enjoyable aspects of their parenting role and associated activities (see Figure 7). Parental responses to this question were wide-ranging and are discussed under the following themes:

- parental fulfilment and sense of achievement;

- sharing time and activities with children;

- nurturance and guidance of children;

- affection and affirmation in child-parent relationships;

- friendship, companionship and family interaction;

- positive child outcomes - health and happiness.

A substantial majority of parents (28\%) stated that a sense of fulfilment and achievement in watching their child grow and develop constituted the most enjoyable, pleasurable aspect of their parenting activities. In some cases, it was not clear from responses whether this pleasure was derived from a personal sense of achievement in raising their children successfully or from the pleasure generated through their children's achievements and success.

Approximately $20 \%$ of parents reported that enjoying time with their children was the most pleasurable aspect of their parenting activities. For almost half of these parents ( $9 \%)$, this was described specifically as 'spending time and engaging in activities' with their children, while for a further $8 \%$ this pleasure was described more generally as the joy or pleasure of just 'being with the children'. Less notable, but highlighted by $3 \%$ of parents was the pleasure of interacting and communicating with their children.

For many parents (approximately 16\%), simply being a parent and the associated tasks of instrumental care, nurturing, responsibility and the parental role in guiding and shaping children's lives contributed most notably to the pleasure and satisfaction they derived from parenting activities. Some parents expressed this as simply 'being a parent', while others placed more emphasis on instrumental care and nurturing (2\%). A number of parents $(9 \%)$ indicated that having responsibility for a child or children contributed most significantly to their enjoyment of parenting. Finally, a smaller number of parents reported that the challenges of child-rearing and their role in guiding and shaping children's lives (1.5\% and $1.3 \%$ respectively) were most significant in terms of the pleasure they experienced in parenting.

Approximately $15 \%$ of parents emphasized the affection and affirmation generated in parenting activities as contributing most significantly to the pleasure of parenting. For almost half of these parents, enjoyment of parenting was associated with the love and affection they felt for their children and many of these parents highlighted the reciprocal and unconditional character of this relationship. A further $6 \%$ of parents derived most pleasure from the fun and laughter they experienced in the child-parent relationship. Finally, a smaller number of parents (3\%) indicated that the affirmation they received from their children, in terms of respect and appreciation for their parenting, contributed most significantly to their enjoyment of parenting.

The importance of friendship and companionship in child-parent relationships was highlighted by a number of parents $(8 \%)$, while a further $2 \%$ derived most enjoyment more generally from family interaction and the sense of belonging which being a parent generated. 
Child well-being, health and happiness were all emphasized as contributing substantially to respondents' enjoyment of parenting activities. Most notably, the experience of their children's happiness was reported by $6 \%$ of parents as the most important aspect of their enjoyment of being a parent. A number of parents $(1.6 \%)$ also derived great pleasure from seeing their children develop into different and individual personalities. Finally, a small number of parents prioritised specifically the enjoyment they derived from knowing that their child was healthy and well.

Figure 7: Parents' perceptions of enjoyable aspects of parenting (\%)

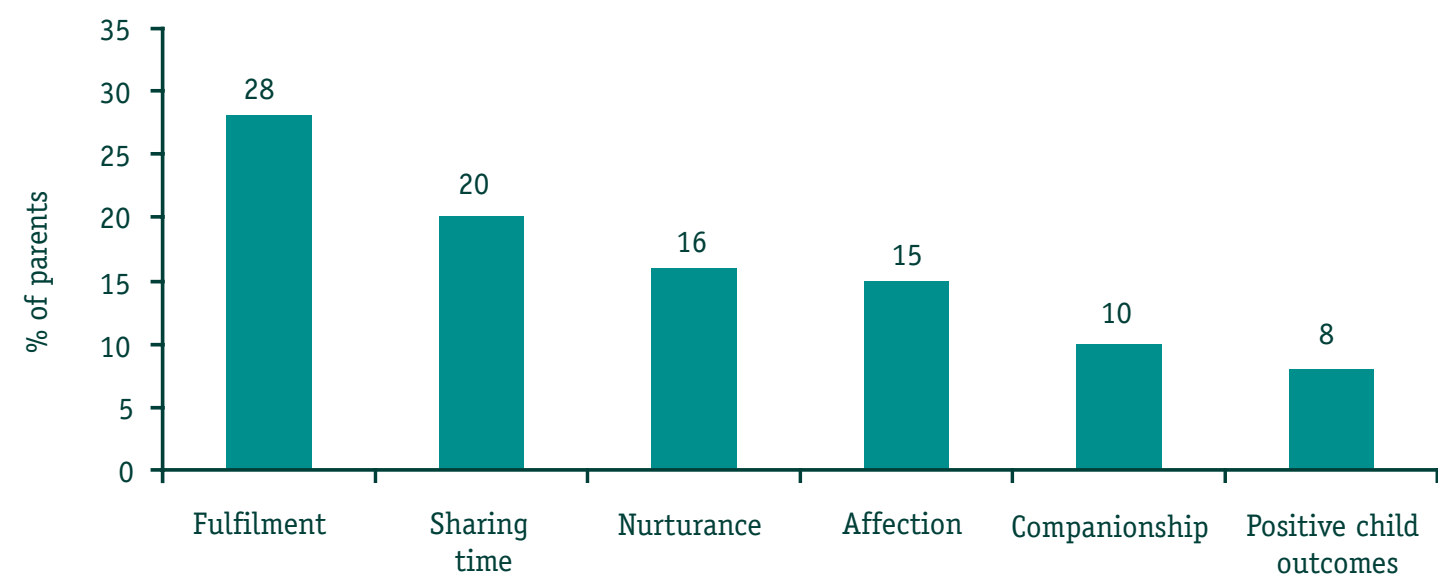

A number of other aspects of parenting were highlighted by small numbers of parents. Some simply stated that they enjoyed 'everything' about being a parent. For other parents, 'learning from their children' was put forward as the most enjoyable aspect of being a parent. Being able to relive their childhood and give their children things they did not have was highlighted by a small number of parents, while others suggested that being able to pass on aspects of themselves and their characteristics to their children contributed most significantly to enjoyment of the parenting role. Other enjoyable aspects of parenting mentioned by very small numbers of parents included staying at home, being pregnant, the openness, honesty and innocence of children, the future achievements of their children, and children taking on a caring role with them as they grow older.

The parent's gender was significant in terms of the emphasis placed on what contributed to the enjoyment of parenting. A significantly higher proportion of fathers ( $41 \%$ compared to $28 \%$ of mothers) indicated that the sense of fulfilment and achievement in watching their children develop constituted the most enjoyable aspect of parenting for them. In contrast, a significantly higher proportion of mothers (18\% compared to $11 \%$ of fathers) highlighted the affection and affirmation they received from their children as being the most enjoyable part of parenting. Finally, positive child outcomes were more likely to be highlighted by mothers as constituting the most enjoyable aspect of their parenting, with $12 \%$ of mothers highlighting this aspect compared to $4 \%$ of fathers.

\section{Key findings}

The findings presented in this chapter portray an overall impression of change and challenge for contemporary parents, as reflected in the views of the present study sample. Key findings include:

- Most parents believe that parenting has changed substantially when compared with parenting 20 years ago.

- Degrees of parental responsibility and pressure on parents were viewed as having increased, while, in contrast, a decrease in levels of parental control was highlighted.

- Key pressures for parents were concerns about the physical and psychological well-being of their children, concerns about their educational outcomes and, to a lesser extent, worries about financial issues.

- Over three-quarters of parents asserted that their working responsibilities impacted substantially on bringing up their children. 
- Perceived levels of spousal/partner support were high and this was consistent with reports of substantial input into the care-giving of children by a second parent or partner.

- In the child-rearing goals of parents, characteristics related to pro-social behaviours, selfdirection and autonomy were emphasized as being most important to teach children, while just one-third of respondents prioritised including children in decision-making with regard to family issues.

- A key issue contributing to the enjoyment of the parental role was the sense of fulfilment and achievement that parents experienced as a result of the healthy and successful development of their children. Also highlighted as significant were the pleasures of spending time in activities with children and family members, engaging with care-giving tasks on a daily basis, reciprocal affections, friendship and companionship in relationships, and positive child outcomes. Fathers were more likely than mothers to emphasize their fulfilment and sense of achievement in watching children develop and grow, while mothers were more likely than fathers to highlight affection and child outcomes.

\section{Discussion}

The view that parenting today is very different to parenting in the past reflects similar findings highlighted in a recent report on experiences of family life in Ireland. Daly (2004) highlights a major shift in contemporary parenting when compared with a generation ago, most notably a change in parental authority and a change in the extent to which the parental role is supported by society. Similarly, and more specifically, perceptions of reduced parental control in the present study reinforce the notion, outlined in prior research, that the lax or permissive parenting style adopted by some parents is one of the key challenges faced by parents today (Daly, 2004). Links between perceived levels of parental control, fewer negative behavioural outcomes for children and higher levels of child competence have also been identified in the literature (Hagekull et al, 2001).

Considerable pressure associated with the parenting role was emphasized in the present study. Similar, but less stark findings emerged in a recent study on parenting and discipline in Scotland, where $72 \%$ of parents also expressed the view that pressures on parenting had increased (Anderson et al, 2002). These authors emphasize that while this should not necessarily be taken as meaning that parenting itself is viewed or experienced as more difficult than in the past, the context in which it occurs is experienced as being more complex and challenging. Combining children's upbringing with the responsibilities of work was also highlighted in the present study as significant by almost three-quarters of all parents, consistent with prior research in an Irish context (Humphreys et al, 2000). In contrast, Anderson et al (2002) reported that only one-third of parents in Scotland experienced work pressures as impacting significantly on their parenting.

Despite the many challenges that emerged in interviews with parents, high levels of spousal and partner support were emphasized. The relationship of partner support with parental satisfaction has been implied by previous researchers. A key factor identified as enhancing the role of parents and contributing to positive experiences of parenting is the support received from a spouse or partner, according to Soriano et al (2001). Given the challenges faced by contemporary parents, as echoed in the views of parents in the present study, the high level of spousal support recorded in the present study is worth noting.

Characteristics related to pro-social behaviours, self-direction and autonomy were emphasized in the child-rearing goals and aspirations of parents as being most important to teach children. This is consistent to some extent with other European studies. For example, in a recent study of the child-rearing values of Estonian and Finnish mothers and fathers, all samples assigned the most importance to characteristics related to benevolence, self-direction and being trustworthy (Tulviste and Ahtonen, 2007). Notable also in the present Irish study was the low priority assigned to 'religious faith' when compared with other child-rearing goals and this is likely to represent a major shift in attitude in recent times. 
Increasingly, attention has been drawn to the importance of considering children as being active in the construction and determination of their own social lives (James and Prout, 1997). However, parents in the present study did not view involving their children in decision-making as a key priority in their parenting, with only one-third of respondents indicating that it was 'very important' for them.

Finally, a broad range of issues were reported by parents as contributing to the enjoyment they experienced as parents. Chief among these was the sense of fulfilment and achievement that parents experienced as a result of the healthy and successful development of their children. The pleasures of spending time with children and family members, engaging with care-giving tasks on a daily basis, reciprocal affections, friendship and companionship in relationships, and positive child outcomes were all highlighted as significant. Some gender differences were noted, with mothers more likely than fathers to highlight affection and positive child outcomes as facilitating enjoyment in parenting, while fathers were more likely to emphasize fulfilment in seeing their child develop. 


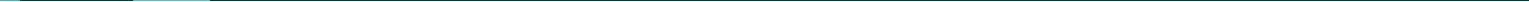


PARENTING STYLES

AND DISCIPLINE PRACTICES 
The focus in this chapter is on parental behaviours, specifically parenting styles and discipline strategies adopted with children. Findings are first presented on the range of discipline strategies adopted by parents with their children in the past year. These strategies are discussed under three broad headings: non-aggressive discipline strategies, psychologically aggressive discipline strategies and physical punishment. Potential effects of parental characteristics, child characteristics and broader contextual characteristics on these discipline responses are also examined. In addition, the discipline strategies experienced by parents themselves in childhood are explored, helping us to better understand the extent to which there has been a shift in terms of past and current trends in discipline responses, as well as the potential for intergenerational transmission of these discipline strategies. Finally, key patterns in parenting styles are identified, with particular reference to authoritative styles (typically involving more inductive responses to parenting and discipline and higher levels of parental warmth and involvement) and authoritarian styles (typically involving more verbal hostility and non-reasoning discipline strategies).

\section{Discipline strategies adopted by parents}

This section presents findings on the range and frequency of discipline strategies used by parents with their child during the course of the past year. In situations where respondents had more than one child, these parents were asked about the target child, selected at random during the early stages of the interview. Discipline strategies referred to included both physical and non-physical punishment, ranging from inductive strategies (such as 'discussed issue calmly with child') to psychologically and physically coercive strategies (such as 'called child stupid or lazy' and 'kicked or knocked child down'). In total, 22 strategies were included and are broadly classified under the headings of non-aggressive discipline strategies, psychologically aggressive discipline strategies and physical punishment (see Table 9).

Table 9: Discipline strategies classified as non-aggressive, psychologically aggressive and physical punishment

\begin{tabular}{|l|l|l|}
\hline $\begin{array}{l}\text { Non-aggressive discipline } \\
\text { strategies }\end{array}$ & $\begin{array}{l}\text { Psychologically aggressive } \\
\text { discipline strategies }\end{array}$ & Physical punishment \\
\hline Discussed issue calmly & Refused to talk to child & $\begin{array}{l}\text { Smacked or slapped child on } \\
\text { the bottom }\end{array}$ \\
\hline Made child take time-out & Said you would not love child & $\begin{array}{l}\text { Smacked or slapped child on } \\
\text { the hands, arms, legs }\end{array}$ \\
\hline Gave child chore & Called child stupid or lazy & $\begin{array}{l}\text { Smacked or slapped child on } \\
\text { the face, head or ear }\end{array}$ \\
\hline Threatened to ground child & $\begin{array}{l}\text { Shouted, yelled or swore at } \\
\text { child }\end{array}$ & $\begin{array}{l}\text { Shook, grabbed or pushed } \\
\text { child }\end{array}$ \\
\hline Actually grounded child & $\begin{array}{l}\text { Threatened to smack or hit } \\
\text { child, but did not }\end{array}$ & $\begin{array}{l}\text { Hit child with something like } \\
\text { a slipper, belt, instrument }\end{array}$ \\
\hline $\begin{array}{l}\text { Threatened to tell someone } \\
\text { else }\end{array}$ & $\begin{array}{l}\text { Walked out on child or left the } \\
\text { room or house }\end{array}$ & $\begin{array}{l}\text { Threw something at child that } \\
\text { could hurt }\end{array}$ \\
\hline $\begin{array}{l}\text { Told child he/she had made } \\
\text { you sad }\end{array}$ & \multicolumn{2}{|l}{ Kicked or knocked child down } \\
\hline Distracted child in some way & \multicolumn{2}{|l}{} \\
\hline
\end{tabular}




\section{Non-aggressive discipline strategies}

Parental discipline strategies most frequently adopted by parents typically fall into the classification of non-aggressive strategies. The frequency of their use is summarised in Table 10.

Table 10: Frequency of use of non-aggressive discipline strategies in the past year (\% of parents)

\begin{tabular}{|l|c|c|c|c|}
\hline Non-aggressive discipline strategies & Often & Occasionally & Rarely & Never \\
\hline Discussed issue calmly & 79.7 & 16.3 & 2.5 & 1.4 \\
\hline Made child take time-out & 26.4 & 30.3 & 14.7 & 28.5 \\
\hline Gave child chore & 12.1 & 17.9 & 14.5 & 55.5 \\
\hline Threatened to ground child & 28.4 & 39.5 & 12.2 & 19.9 \\
\hline Actually grounded child & 20.8 & 27.1 & 16.5 & 35.5 \\
\hline Threatened to tell someone else & 14.9 & 20.1 & 11.4 & 53.6 \\
\hline Told child he/she made you sad & 13.7 & 31.0 & 15.8 & 39.5 \\
\hline Distracted child in some way & 14.1 & 18.4 & 8.1 & 59.4 \\
\hline
\end{tabular}

Clearly, the most frequently adopted discipline response that parents reported using, and this was across all classifications of strategy, was discussed issue calmly, adopted 'often' by over three-quarters of parents interviewed $(79.7 \%)$ and 'occasionally' by a further $16 \%$. A very small minority $(1.4 \%)$ indicated that they 'never' used this strategy. A number of other non-aggressive discipline strategies were adopted by parents to a lesser extent - $28 \%$ of parents reported threatening to ground a child 'often', with a further 40\% adopting this strategy 'occasionally'; $26 \%$ of parents reported making a child take time-out 'often', with a further $30 \%$ adopting this strategy 'occasionally'. One-fifth of parents (21\%) indicated that they had actually grounded a child 'often' in the past year, while just over one-quarter (27\%) reported having grounded their child 'occasionally'.

Other non-aggressive strategies used less frequently by parents included threatening to tell someone else and telling the child that he/she made you sad, with approximately $15 \%$ of parents indicating that they used these strategies 'often'. The least common forms of behaviour among the non-aggressive discipline strategies was giving a child a chore, with just $12 \%$ of respondents reporting 'often' using this as a discipline strategy, and distracting a child in some way, with almost $60 \%$ of parents reporting that they 'never' used this strategy.

A selection of the non-aggressive discipline strategies adopted by parents in the past year were re-coded into two categories of 'ever in the past year' and 'never in the past year' (see Figure 8).

Figure 8: Non-aggressive discipline strategies adopted by parents in the past year (\% of parents)

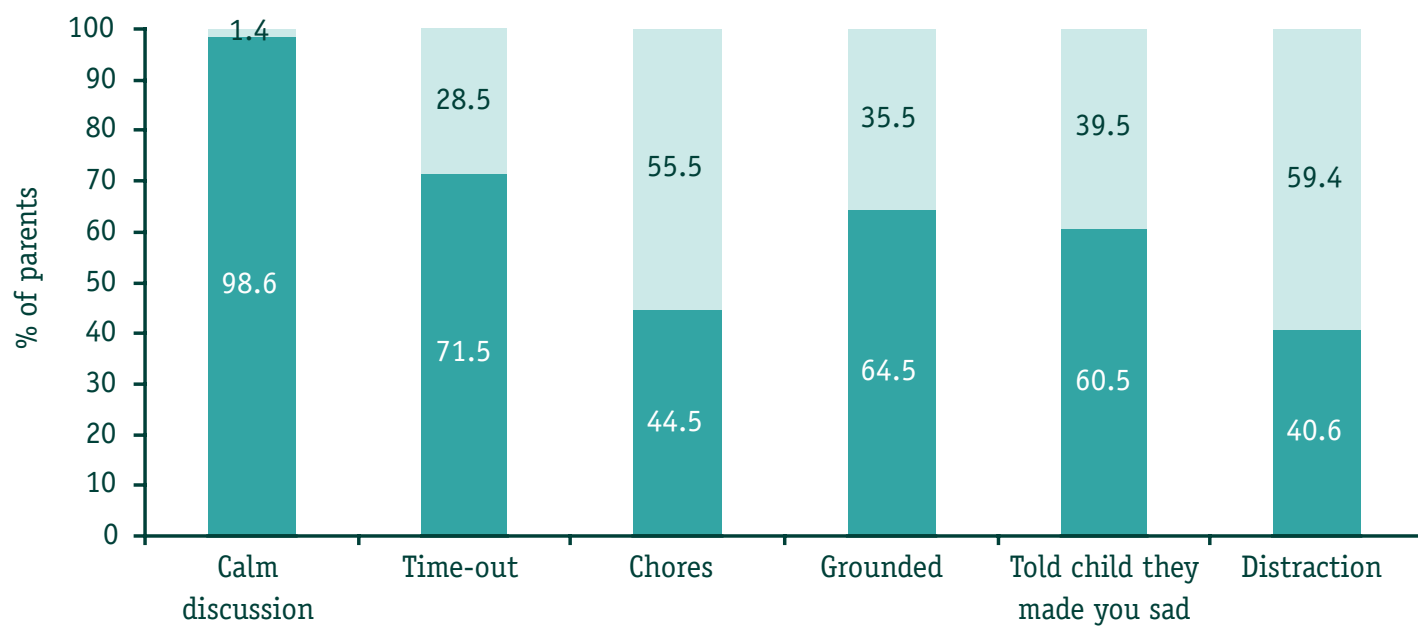


Differences according to the age of a child are worth noting with regard to the parental use of non-aggressive discipline strategies in the past year. Specifically, children in middle childhood (age group 5-9 years) were more likely to be made take time-out as a parental discipline response, while children in early adolescence (age group 10-14 years) were more likely to be given a chore. Both children in middle childhood and in early adolescence were also more likely to be threatened with being grounded and actually being grounded than children in other age groups. As would be expected, and consistent with the developmental skills and competencies of very young children, certain strategies like discussing the issue calmly were significantly less likely to be used with children in the 0-4 age group, while other strategies like distracting child in some way were significantly more likely to be used with these younger children.

Some differences by age of parent were also noted. Parents in the oldest age category (45 years and over) were less likely to make a child take time-out, while parents aged 35-44 were more likely to ground a child. One way of understanding these differences in parental age and choice of strategy is to consider that older parents are more likely to have children in older age categories and it may therefore be child age rather than parent age that influences the pattern of these effects.

Surprisingly, there were few differences between the discipline responses favoured by mothers and fathers. However, fathers were less likely than mothers to threaten to tell someone else. Some education and social class effects also emerged with reference to telling a child they had made you sad or upset you, with such a strategy significantly less likely to be used by parents whose education level was less than Leaving Certificate and significantly less likely never to be used by parents whose occupational status was recorded as in a professional/managerial role. However, no other clear education or social class dimensions to these parental responses were evident. Neither was there an effect of child gender evident in these findings.

In summary, the majority of parents reported using non-aggressive discipline strategies with their children during the past year. Most prevalent among these strategies was the use of verbal reasoning, through the calm discussion of an issue with a child. Making a child take time-out, threatening to ground a child and actually grounding a child were also used relatively frequently by parents. Least likely to be used among this category of responses was giving a child a chore to do or distracting a child in some way, used more frequently with children in early adolescence or early childhood respectively. Some differences by age of parent were noted, with older parents (aged 45+) less likely to make a child take time-out as a discipline response, while parents aged 35-44 were more likely to use time-out. Few differences by gender of parent or child were evident, although fathers were less likely than mothers to threaten to tell someone else.

\section{Psychologically aggressive discipline strategies}

Very few parents reported using psychologically aggressive discipline strategies in response to parent-child conflict. The frequency of use of such strategies is summarised in Table 11.

Table 11: Frequency of use of psychologically aggressive discipline strategies in the past year (\% of parents)

\begin{tabular}{|l|c|c|c|c|}
\hline $\begin{array}{l}\text { Psychologically aggressive discipline } \\
\text { strategies }\end{array}$ & Often & Occasionally & Rarely & Never \\
\hline Refused to talk to child & 2.3 & 4.8 & 8.6 & 84.3 \\
\hline Said you would not love child & 0.2 & 1.4 & 2.0 & 96.5 \\
\hline Called child stupid or lazy & 2.4 & 7.3 & 10.2 & 80.2 \\
\hline Shouted, yelled or swore at child & 4.7 & 19.9 & 23.0 & 52.4 \\
\hline Threatened to smack or hit child, but did not & 3.8 & 14.5 & 8.2 & 73.5 \\
\hline $\begin{array}{l}\text { Walked out on child or left the room } \\
\text { or house }\end{array}$ & 0.9 & 7.2 & 5.4 & 86.5 \\
\hline
\end{tabular}


In all cases, a majority of parents reported 'never' using any of these strategies. Most frequently used was shouting, yelling or swearing at a child, with just $4.7 \%$ of parents indicating that they used this strategy 'often'. However, almost one-fifth of parents (20\%) reported that they had used this strategy 'occasionally' with a child in the past year. Just over half of parents interviewed $(52 \%)$ indicated that they had 'never' used this strategy. $18 \%$ of parents reported threatening to smack or hit their child either 'often' (3.8\%) or occasionally $(14.5 \%)$, while almost $10 \%$ of parents reported having called a child stupid or lazy either 'often' (2.4\%) or 'occasionally' (7.3\%). Lovewithdrawal strategies, such as refusing to talk to a child, were also used 'often' by a small minority of parents $(2.3 \%)$ and 'occasionally' by a further $4.8 \%$.

Psychologically aggressive strategies least frequently adopted according to parents' self-reports were walking out on a child/leaving the room or house and telling a child that you would not love them.

Figure 9 illustrates the psychologically aggressive discipline strategies 'ever' or 'never' used by parents in the past year.

\section{Figure 9: Psychologically aggressive discipline strategies adopted by parents in the past year (\% of parents)}

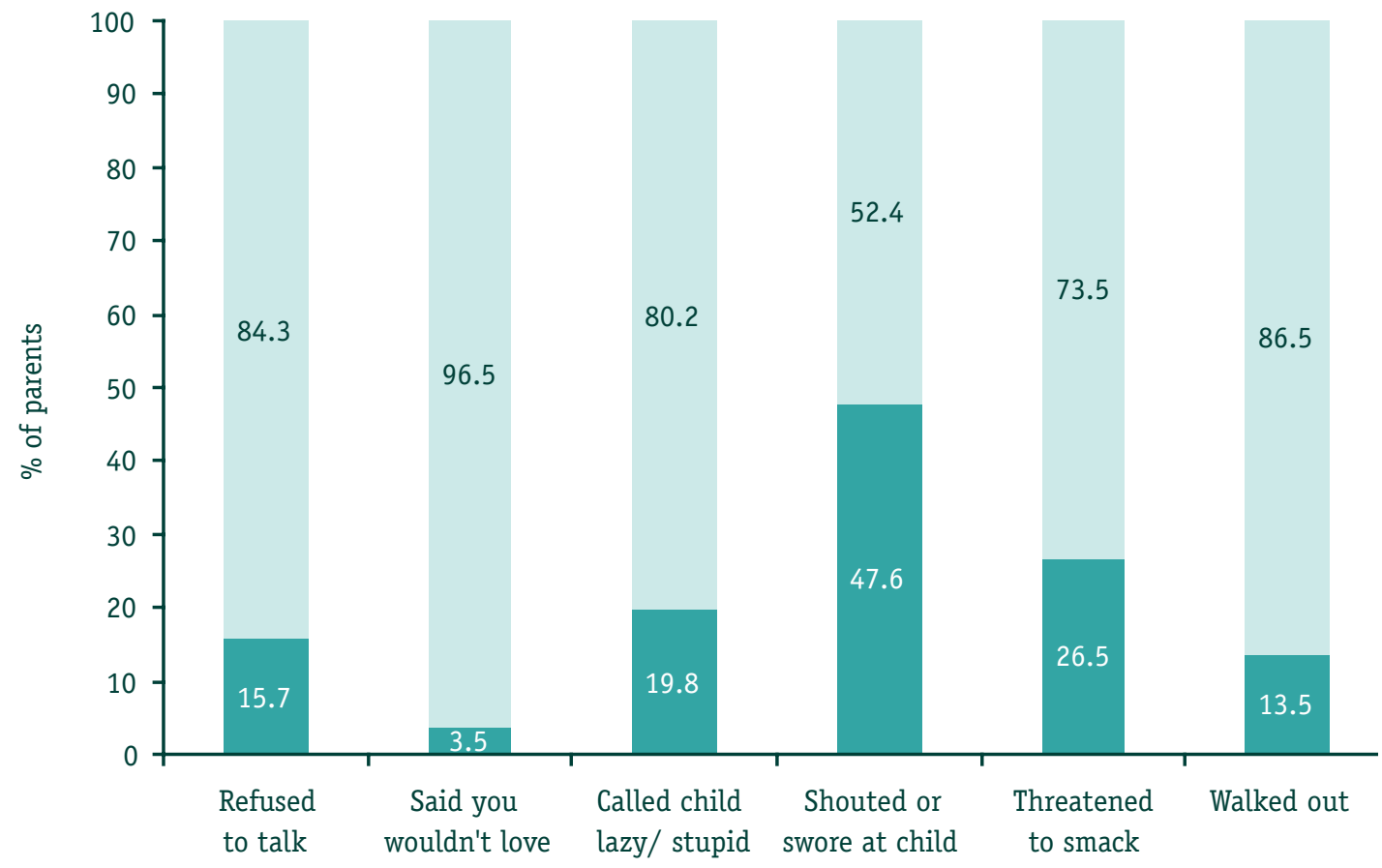

Ever in past year

Never in past year

Age of child effects emerged in relation to the parental use of psychologically aggressive discipline strategies. Threatening to smack a child was significantly more likely to be used as a discipline response with children aged 5-9. In contrast to this, calling a child stupid or lazy was significantly more likely to be used with the older adolescent age group (15-17 years), although this strategy was employed only 'occasionally'. As with non-aggressive strategies (see Figure 8), developmental competencies of children clearly determined the pattern of use of certain strategies, with parents significantly less likely to shout, yell or swear at children under 4 years of age.

The use of psychologically aggressive discipline strategies appears to be equally distributed across child gender, with no significant differences evident for using these strategies with boys or girls. There was also little substantial effect of age of parent in the use of these strategies, although parents in the older age bracket were less likely to threaten to smack a child. Gender of parent also appeared to play some role in shaping the use of psychologically aggressive strategies, with fathers less likely to walk out of the house or room in response to parent-child conflict. No significant effect of social class or educational level was evident. 
To summarise, the majority of parents indicated that they never used any of the discipline strategies categorised as psychologically aggressive. However, just under half of parents indicated that they had shouted or yelled at a child in the past year. Threatening to smack a child was more likely to be used with children between the ages of 5 and 9, while calling a child stupid or lazy was more likely to be used with children in the oldest age group (15-17 years). Older parents were less likely to threaten to smack a child, while fathers were less likely than mothers to walk out on a child as a response to a disciplinary incident.

\section{Physical punishment discipline strategies}

The use of physical punishment as a discipline strategy was low according to the self-report data collected from parents. The vast majority of these parents indicated that they had 'never' used any physical punishment as a discipline strategy in the past year. Less severe forms of physical punishment, such as smacking a child on the bottom, hand or leg, were highlighted slightly more frequently by parents. Specifically, almost $8 \%$ of parents reported that they had smacked a child on the bottom either 'often' (1.2\%) or 'occasionally' $(6.6 \%)$, while $5 \%$ reported smacking a child on the hand, arm or leg either 'often' $(0.7 \%)$ or 'occasionally' $(4.3 \%)$. More severe physical punishment strategies were reported by a very small minority of parents, with almost $3 \%$ indicating that they shook, grabbed or pushed a child in the past year either 'often' (1.4\%) or 'occasionally' (1.3\%).

Table 12 lists the different categories of physical punishment adopted by parents as discipline strategies and their frequency of use in the past year. As seen, the strategies most frequently used were smacking or slapping a child on the bottom or on the hands, arms or legs. It should, however, be highlighted that these strategies were used relatively infrequently over the past year, according to parents' self-reports, as seen in Figure 10.

Table 12: Frequency of use of physical punishment in the past year (\% of parents)

\begin{tabular}{|l|c|c|c|c|}
\hline Physical punishment discipline strategies & 0ften & Occasionally & Rarely & Never \\
\hline Slapped child on bottom & 1.2 & 6.6 & 8.0 & 84.1 \\
\hline Slapped child on hand, arm or leg & 0.7 & 4.3 & 6.3 & 88.7 \\
\hline Slapped child on head, face or ear & - & 0.1 & 0.1 & 99.8 \\
\hline Shook, grabbed or pushed child & 1.4 & 1.3 & 4.6 & 92.7 \\
\hline Hit child with slipper, belt or other instrument & - & - & 0.6 & 99.4 \\
\hline Threw something at child that could hurt & - & - & 0.1 & 99.9 \\
\hline Kicked or knocked down child & 0.2 & 0.3 & 0.1 & 99.4 \\
\hline Washed child's mouth out & - & - & 0.1 & 99.9 \\
\hline
\end{tabular}

Figure 10: Frequency of use of smacking among parents who smacked child on bottom or on hands, arms or legs in the past year (\% of parents)

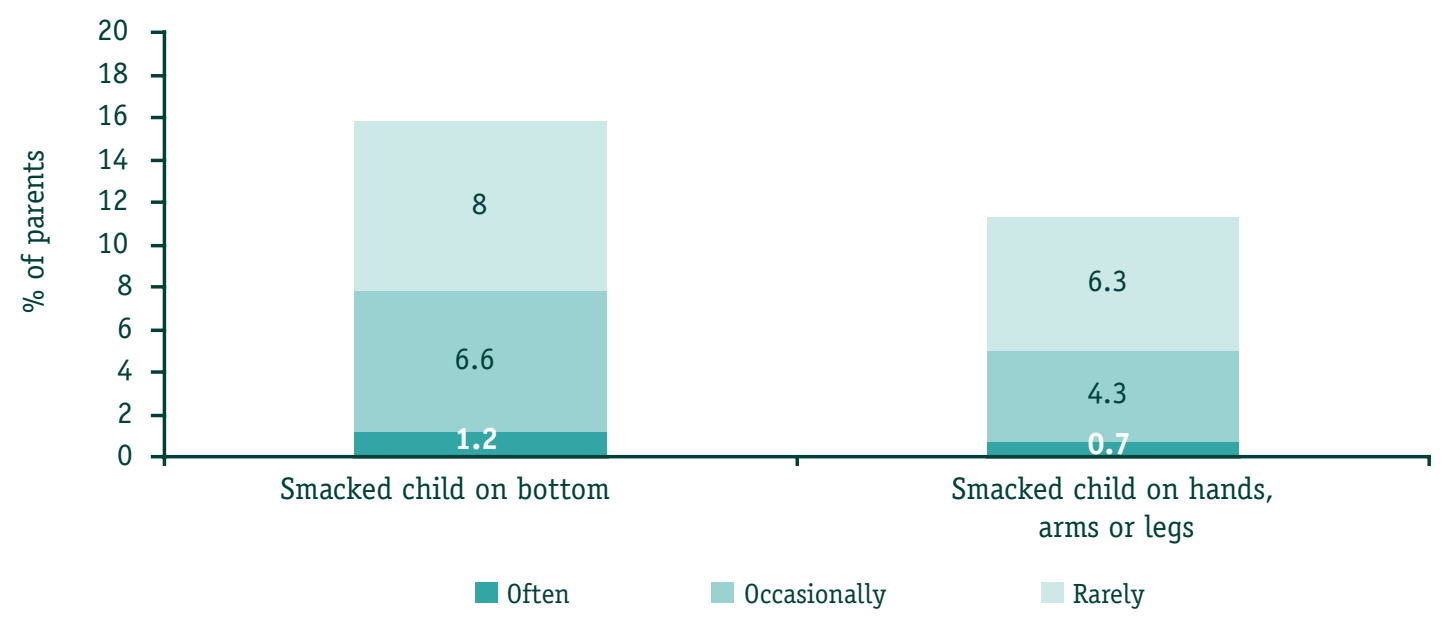


A more accessible way of exploring patterns in the use of physical chastisement is to create a summary variable that combines the main types of such behaviour. Summing across the different types of physical punishment outlined above, one-quarter of parents (25.1\%) reported using any physical punishment with their children in the past year, while $74.9 \%$ reported using no physical punishment with their children in the past year.

A clear effect of age of child emerged in findings on the parental use of any physical punishment, with younger children - specifically those within the early childhood and middle childhood age categories - experiencing significantly higher levels of physical punishment than children in the older age groups (see Figure 11).

Figure 11: Parental use of any physical punishment in the past year, by age of child (\% of parents)

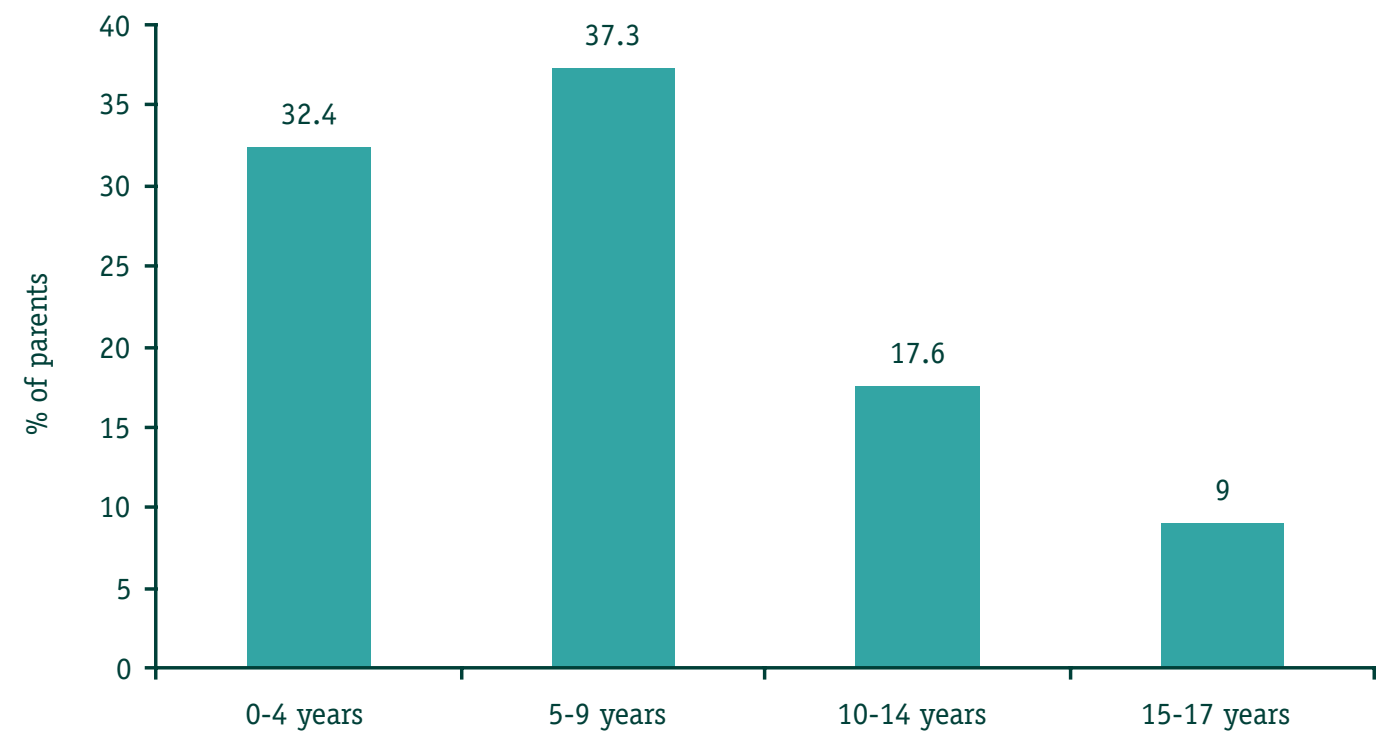

Children in the $0-4$ age group were further classified into two sub-groups, broadly representing infancy (0-1 year of age) and early childhood (2-4 years of age). Not surprisingly, age differences in the use of physical punishment were evident, with children in infancy (0-1 year) being less likely to experience physical punishment than children in early childhood. Taken together, these findings suggest that children between the ages of 2 and 9 years are significantly more likely to be physically punished than children in other age groups. Incidence of physical punishment across children in infancy, early and middle childhood is further broken down in Figure 12.

Figure 12: Incidence of physical punishment across children in infancy, early and middle childhood (\% of parents)

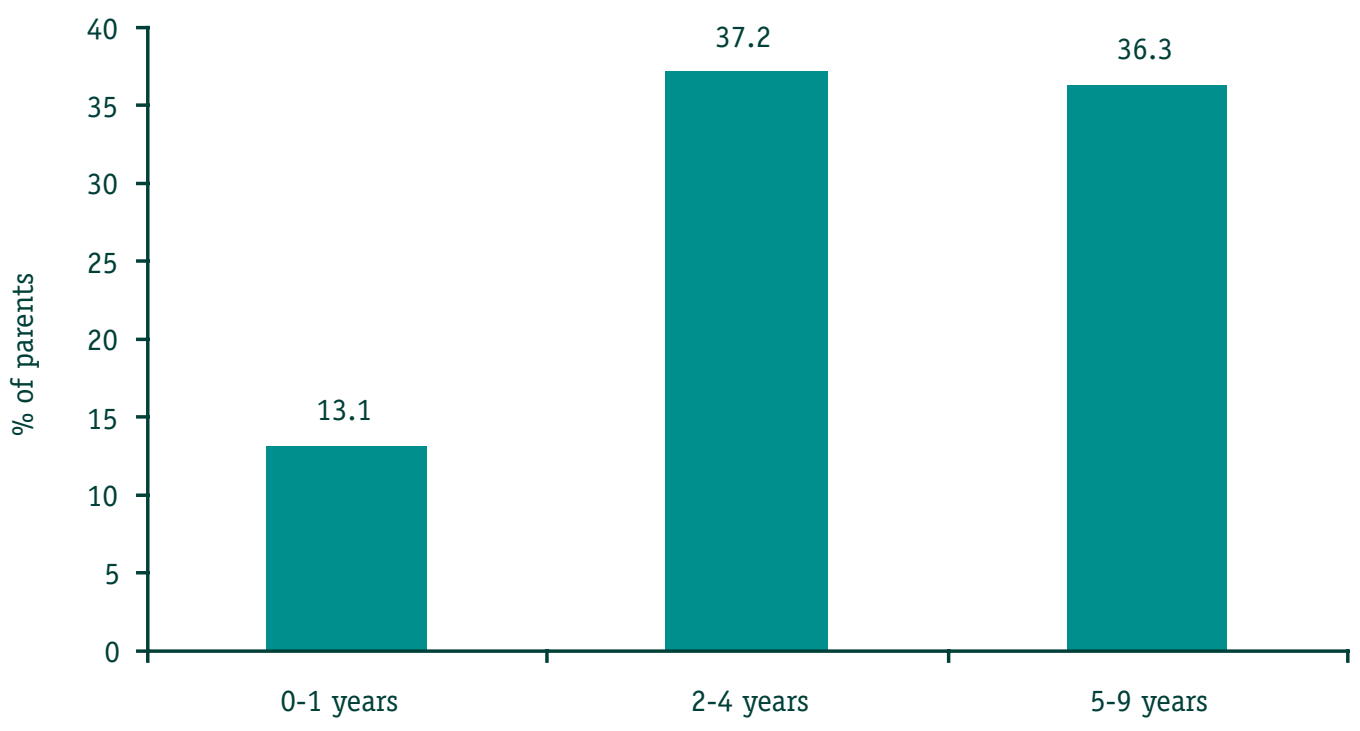


Some effects by age of child were also evident within the particular categories of physical punishment used. While parents were more likely to use physical punishment with young children in general, children in the 0-4 and 5-9 age groups were most likely to experience certain types of physical punishment. Specifically, parents were more likely to use strategies such as smacking on the bottom, hands, arms or legs with children between 0-9 years of age. With reference to parents of children in the younger age groups, surprisingly, almost $10 \%$ reported 'ever' in the past year slapping their infants on the bottom (9.8\%), while a very small minority of these parents $(2.4 \%)$ reported slapping their infants on the hand, arm or leg, and shaking, grabbing or pushing these very young children. However, such kinds of physical punishment were reported to a greater extent by parents of children in early and middle childhood. Incidence of different forms of physical punishment across children in infancy, early and middle childhood is illustrated in Figure 13.

\section{Figure 13: Type of physical punishment used by parents of children in infancy, early and middle childhood (\% of parents)}

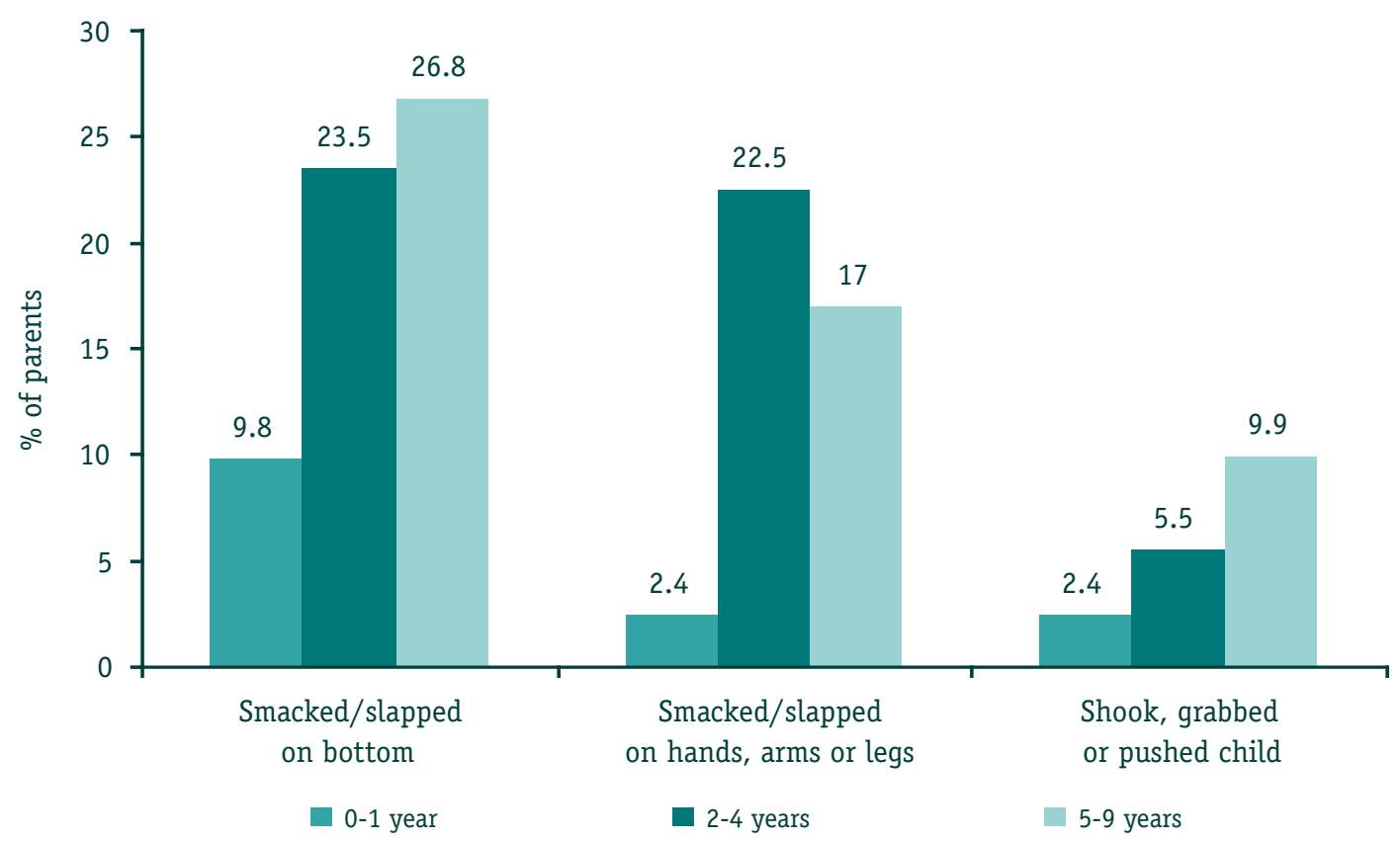

Differences in age of parent and physical punishment were also evident, with parents in the youngest age category (under 35 years) being significantly more likely to slap a child on the bottom, hands, arms or legs than parents in other age groups. No effect of social class or educational level was evident in the parental use of physical punishment. Neither were effects by gender of parent or child recorded.

In summary, a number of patterns can be noted in these findings on parental use of physical punishment. Overall, the use of physical punishment with children was low, with $25 \%$ of parents reporting having used it with their child in the past year. The strategy most frequently used was slapping a child on the bottom or on the hands, arms or legs, while the use of more severe forms of physical punishment were reported by a very small minority of parents. However, approximately $6 \%$ of parents reported shaking or grabbing their child in the past year. A clear effect of age of child emerged, with younger children experiencing significantly higher levels of physical punishment than children in the older age groups. In particular, children between the ages of 2 and 9 were more likely to be physically punished than children in the other age groups. Younger parents, under 35 years, were also more likely to use physical punishment with their children. 


\section{Physical punishment as an adjunct to other discipline strategies}

One interesting question to examine is the extent to which parents who report using physical punishment as a discipline strategy with their children use it in conjunction with other nonphysical discipline strategies or use it more exclusively as a discipline response. Findings in the present study would indicate that more coercive and physical punishment strategies tend to be used as an adjunct to, or alongside a range of, other discipline strategies. For example, the use of physical punishment tends to be associated with a greater likelihood of also using certain non-aggressive strategies. In particular, physical punishment is significantly associated with the parental use of time-out as a discipline strategy and this is consistent with both these forms of punishment being used more frequently with younger children. Similarly, parents who use physical punishment are more likely to have used psychologically aggressive strategies, such as threatening to hit or smack a child, threatening to tell someone else and shouting or yelling at a child. Nonaggressive inductive strategies, such as discussing the issue calmly with a child, were also likely to be used by these parents. These findings go some way to suggesting that parents who punish their children physically may do so following verbal threats and in conjunction with other discipline strategies, rather than as an alternative to these strategies.

\section{Parental experience of discipline strategies in childhood}

An additional focus of this chapter is on parents' own experiences of parental discipline and punishment during their childhood. Respondents were asked to report on the different discipline strategies they themselves experienced as they grew up. It is important to highlight that caution is needed when drawing comparisons between discipline strategies experienced by parents in their own childhood and those currently being reported by parents as used with their own children; this is because parental reports of the strategies they experienced refer to the prevalence of these experiences across childhood, while current parental reports on discipline strategies, in contrast, refer to the incidence of these strategies within the past year.

The discipline strategies investigated in the present Irish study were adapted from questionnaires used in similar UK studies (Ghate et al, 2003; Anderson et al, 2002). These strategies included 2 non-aggressive strategies (discussed the issue calmly with child; made child take time-out); 4 psychologically aggressive strategies (refused to talk to child; shouted, yelled or swore at child; said would not love child or would send away; threatened to smack or hit, but did not do so); and 4 items representing physical punishment (smacked child on bottom, hands, arms or legs; smacked or slapped child on face or head; hit with slipper, belt, or other instrument; beat child up). In the following sections, we outline and discuss findings related to parents' own experiences of such discipline responses during their own childhood.

\section{Non-aggressive discipline strategies experienced by parents in childhood}

Some notable differences in current and past trends of non-aggressive parental discipline strategies emerge when we compare parents' own experiences of discipline responses in childhood with the strategies that they currently adopt with their own children (see Figure 14). These differences are most apparent when reflecting on more inductive reasoning strategies, such as discussing an issue calmly - almost all parents $(98.6 \%)$ reported currently using this strategy with their children, while just over three-quarters of parents $(75.9 \%)$ indicated that they had experienced this strategy during their own childhood. Surprisingly, there was relatively little difference in the extent to which parents experienced time-out as a discipline strategy in childhood (64.4\%) and adopted it currently with their own children $(71.5 \%)$. 
Figure 14: Non-aggressive discipline strategies experienced by parents in childhood and currently adopted with their own children (\% of parents)

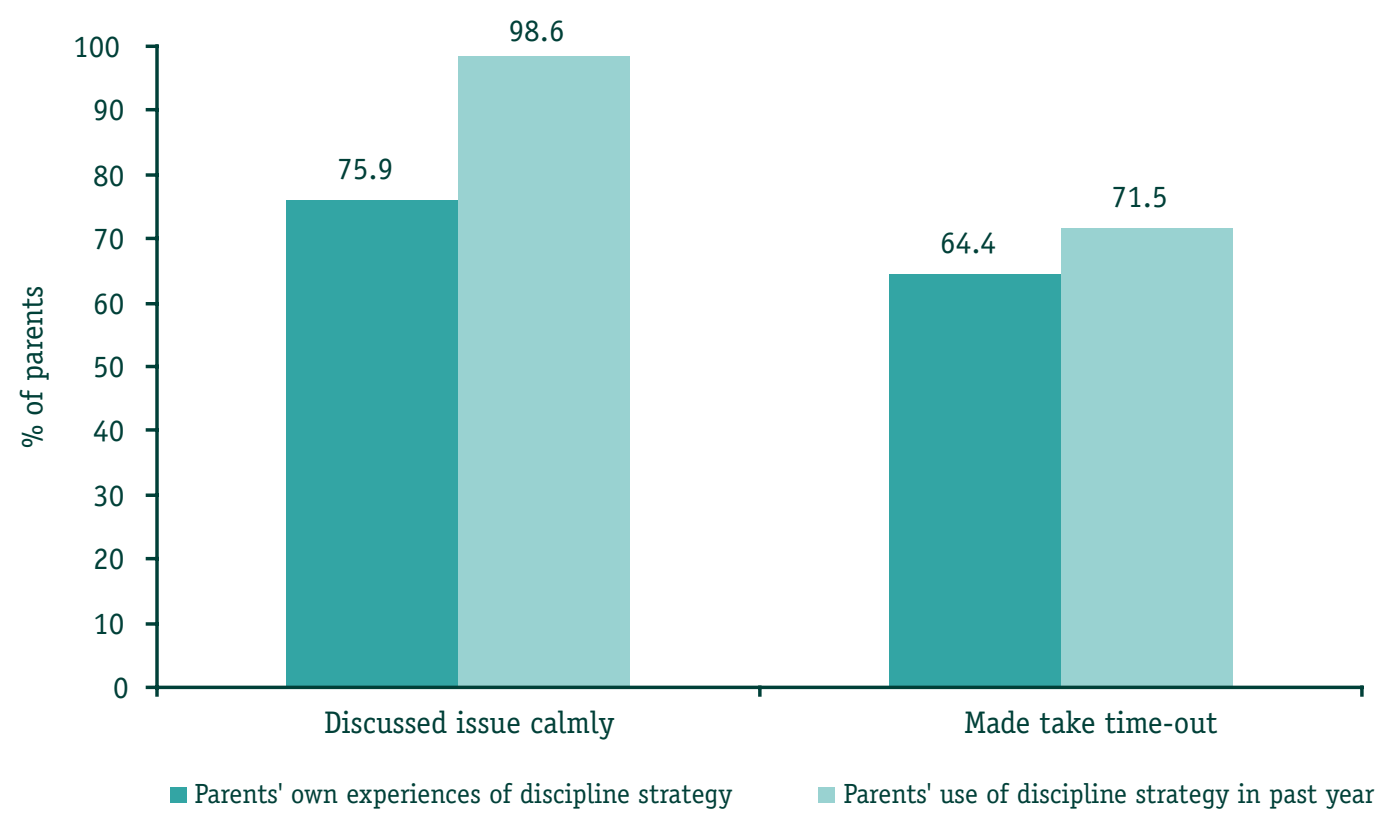

\section{Psychologically aggressive discipline strategies experienced by parents in childhood}

More striking differences emerge when we compare the extent to which parents experienced psychologically aggressive discipline strategies in their own childhood with their adoption of these strategies with their own children (see Figure 15). Love-withdrawal strategies, such as refusing to speak to a child or telling a child that you would not love them, have decreased quite substantially over time, according to parents' reports. More specifically, parents reported experiencing 'the silent treatment' from their own parents almost three times as often as they adopted it with their own children (45\% compared to $15.7 \%$ ). A similar trend emerges with regard to the strategy of telling a child you would not love them, with parents five times more likely to have experienced this strategy in their own childhood than they currently adopt it with their own children (17.6\% compared to $3.5 \%$ ). There was also a reported decrease in the use of the psychologically aggressive strategy of shouting or yelling at a child: almost three-quarters of parents reported having experienced this strategy during their own childhood, while just under half of parents reported ever having used it currently with their own child $(74.3 \%$ compared to $47.6 \%$ ). Once again, a marked decrease was noted in the use of the strategy of threatening to smack or slap a child, with over three-quarters of parents having experienced this during their own childhood compared to just over one-quarter of parents currently reporting the use of this strategy with their own children (76.9\% compared to $26.5 \%)$. 
Figure 15: Psychologically aggressive discipline strategies experienced by parents in childhood and currently adopted with their own children (\% of parents)

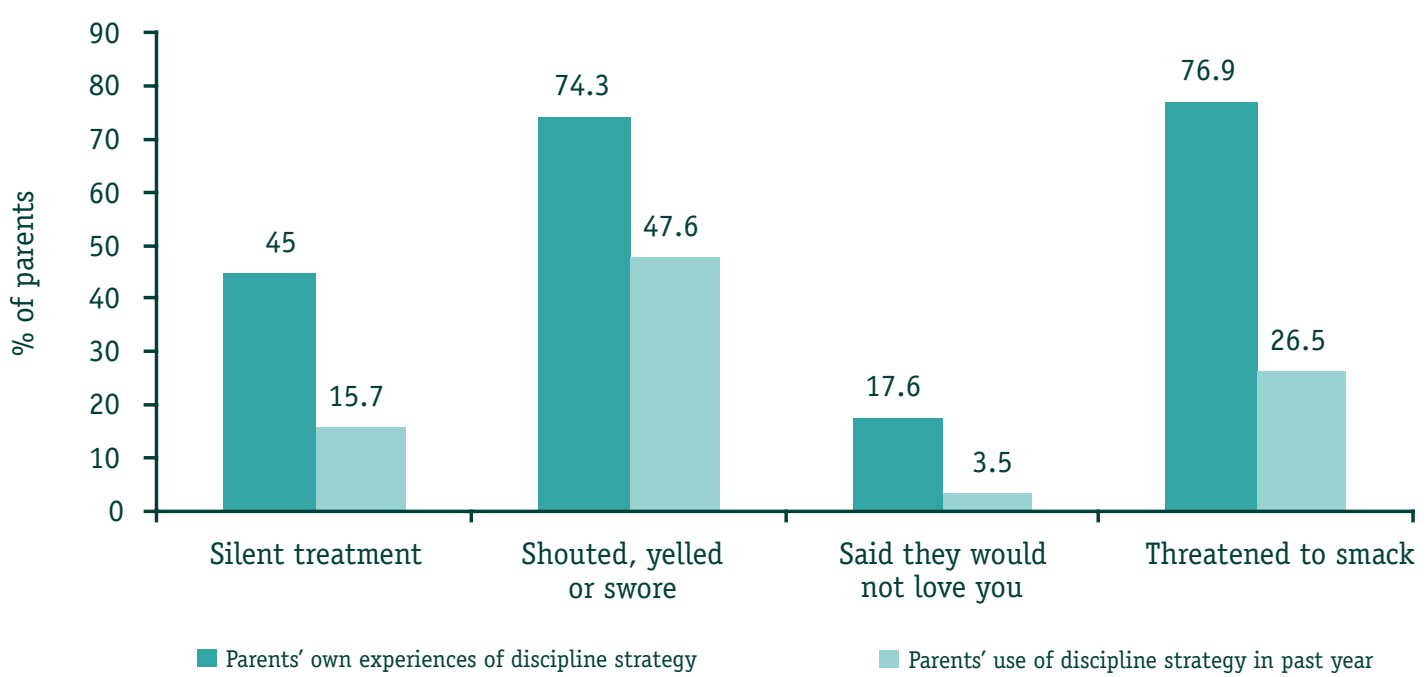

\section{Physical punishment experienced by parents in childhood}

Findings related to physical punishment once again highlight a decrease in the use of all of the four types of physical punishment strategies examined (see Figure 16). Specifically, a large majority of parents $(81.2 \%)$ reported having experienced being slapped on the bottom, hands, arms or legs in their own childhood, compared to $15.9 \%$ of current parents who reported slapping a child on the bottom in the past year (11.3\% reported currently ever slapping on hands, arms or legs). Drawing on the self-report data of these parents, therefore, it is possible to estimate that slapping or smacking a child occurs much less frequently in current parenting practices when compared to parenting practices in the past.

In terms of more severe forms of punishment, according to parental reports, it appears that practices such as being hit with a slipper or being smacked or slapped on the face, head or ears have decreased in present times, with less than $1 \%$ of parents interviewed $(0.6 \%$ and $0.2 \%$ respectively) reporting having used such physical punishment with their child in the past year. In contrast, reflecting upon their own childhoods, almost one-third of parents $(29.2 \%)$ reported being hit with a slipper or similar instrument, while almost one-quarter $(23.5 \%)$ had experienced being smacked or slapped on the face, head or ears. Finally, almost $5 \%$ of parents reported having been beaten up by their parents in childhood.

Figure 16: Physical punishment experienced by parents in childhood and currently adopted with their own children (\% of parents)

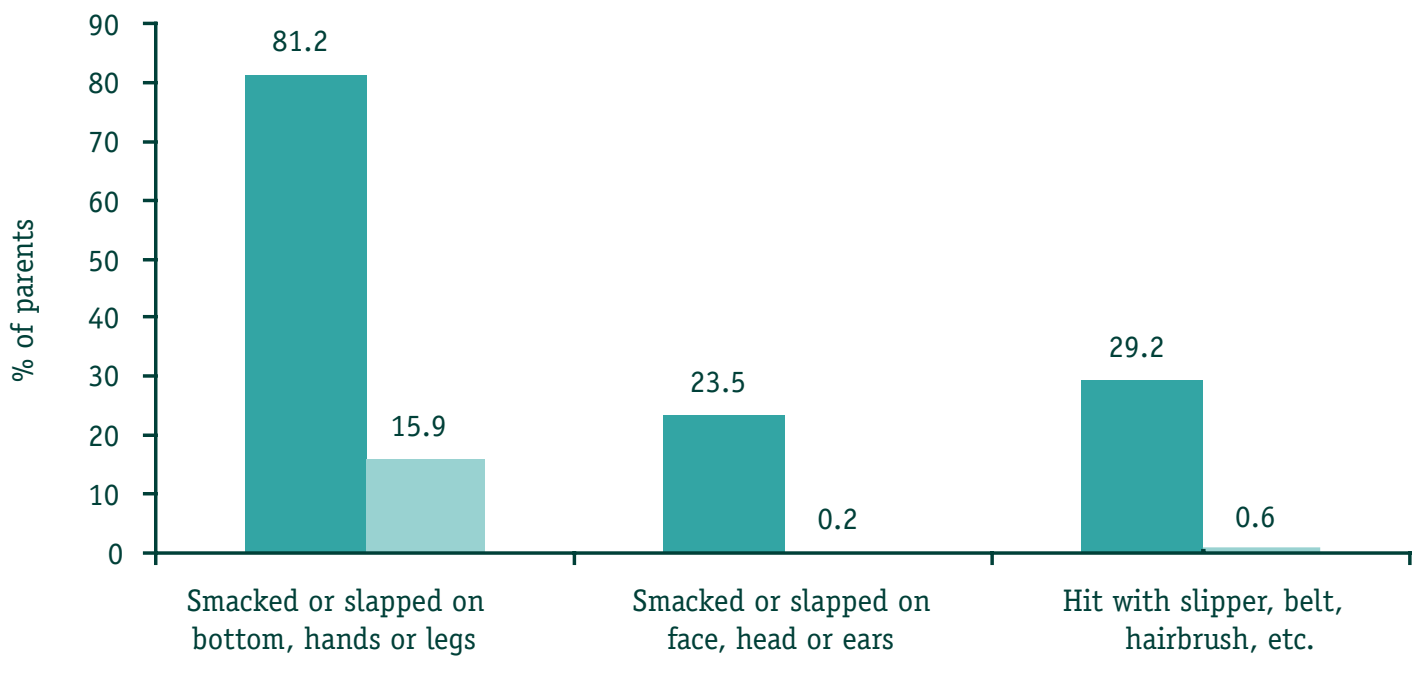

- Parents' own experiences of discipline strategy

Parents' use of discipline strategy in past year 
No differences in childhood experiences of physical punishment emerged according to the gender of the parent. One exception was that fathers in the study were more likely than mothers to have been slapped on the face, head or ears during their own childhood.

In summary, parental behaviours related to discipline and punishment appear to have changed over time as reflected in the parents' self-reports. Based on evidence in the present study, changes are highlighted in the extent to which parents use different types of discipline strategies and most notably there has been a decrease in the use of physical punishment in the course of the last generation or so. Childhood experiences as recalled by parents themselves indicate that many children in the past experienced some kind of physically punitive behaviour from their parents. More common forms of physical punishment, such as smacking or slapping a child, are still currently adopted by a minority of parents. However, there was substantial evidence to suggest that more severe physical punishment has decreased across these time phases. Notable also was a decrease in psychologically aggressive discipline strategies over time and higher levels of inductive strategies currently being reported by parents.

\section{Intergenerational transmission of physical punishment}

In contrast to patterns of discontinuity and change in parental behaviours across time and across generations, there was also some evidence of continuity and potential influence of experiences in childhood and current practices with regard to the current use of physical punishment. However, given the relatively high prevalence of physically punitive behaviours experienced by parents in childhood, identifying a meaningful association between such experiences and current parental behaviours is a complex task. Links between current use of any physical punishment and experiences in childhood were explored and a number of associations may be noted.

Key links which emerged were that parents who had been smacked on the bottom, hands, arms or legs, and parents who had been hit with an instrument, such as a slipper or hairbrush, were significantly more likely to have used physical punishment with their own children in the past year. Conversely, those parents who had not been slapped in this way during their childhood were significantly less likely to use physical punishment with their own children. Parents who had never been shouted or yelled at in childhood or whose parents had never threatened to smack them were less likely to have used any physical punishment with their own children in the past year. It should be highlighted, however, that the majority of parents who reported having experienced physical punishment in childhood did not use physical punishment with their own children and this lends support to the notion that cycles of intergenerational transmission of parenting behaviours and discipline strategies can be altered and patterns of behaviours are not solely determined by past experience.

\section{Parenting styles}

As highlighted in Chapter 3, parenting styles were measured using an adapted version of a standardised questionnaire, which tapped into authoritative and authoritarian dimensions of parenting.

- The authoritarian domain comprised 3 sub-scales - verbal hostility (e.g. I shout or yell when the child misbehaves), corporal punishment (e.g. I smack when the child is disobedient) and non-reasoning punitive (e.g. I use threats as a punishment with little or no justification).

- The authoritative domain was also made up of 3 sub-scales - warmth and involvement (e.g. I show sympathy when the child is hurt or frustrated), reasoning/induction (e.g. I explain the consequences of the child's behaviour) and democratic participation (e.g. I allow the child input into family decisions).

For each parent, the responses on the sub-scales were totalled to give a score for each sub-scale, as well as a total authoritarian and authoritative score. Thus, parents are not classified as being authoritative or authoritarian, rather each parent displays features of both parenting styles. The 
average scores obtained across each sub-scale are illustrated in Figure 17 for the Authoritative Parenting scale and related sub-scales, and in Figure 18 for the Authoritarian Parenting scale and related sub-scales. For each sub-scale, the minimum score that could be obtained is 1 and the maximum score is 5 . The bars represent the average score obtained by the sample of parents in the study.

Comparison of Figures 17 and 18 illustrates that parents in the study scored higher on all aspects of authoritative parenting than authoritarian parenting. Within the authoritative domain, scores on warmth and involvement and reasoning/induction were highest, while scores on democratic participation were slightly lower. Within the authoritarian domain, scores on the verbal hostility and non-reasoning punitive sub-scales were highest, while scores on the corporal punishment sub-scale were lowest.

The key finding to emerge from this analysis is that, overall, parents engage more frequently in parenting behaviours consistent with an authoritative style of parenting and engage less frequently in parenting behaviours consistent with an authoritarian style of parenting.

\section{Figure 17: Average scores on the Authoritative Parenting scale and related sub-scales} ( minimum $=1$; maximum $=5$ )

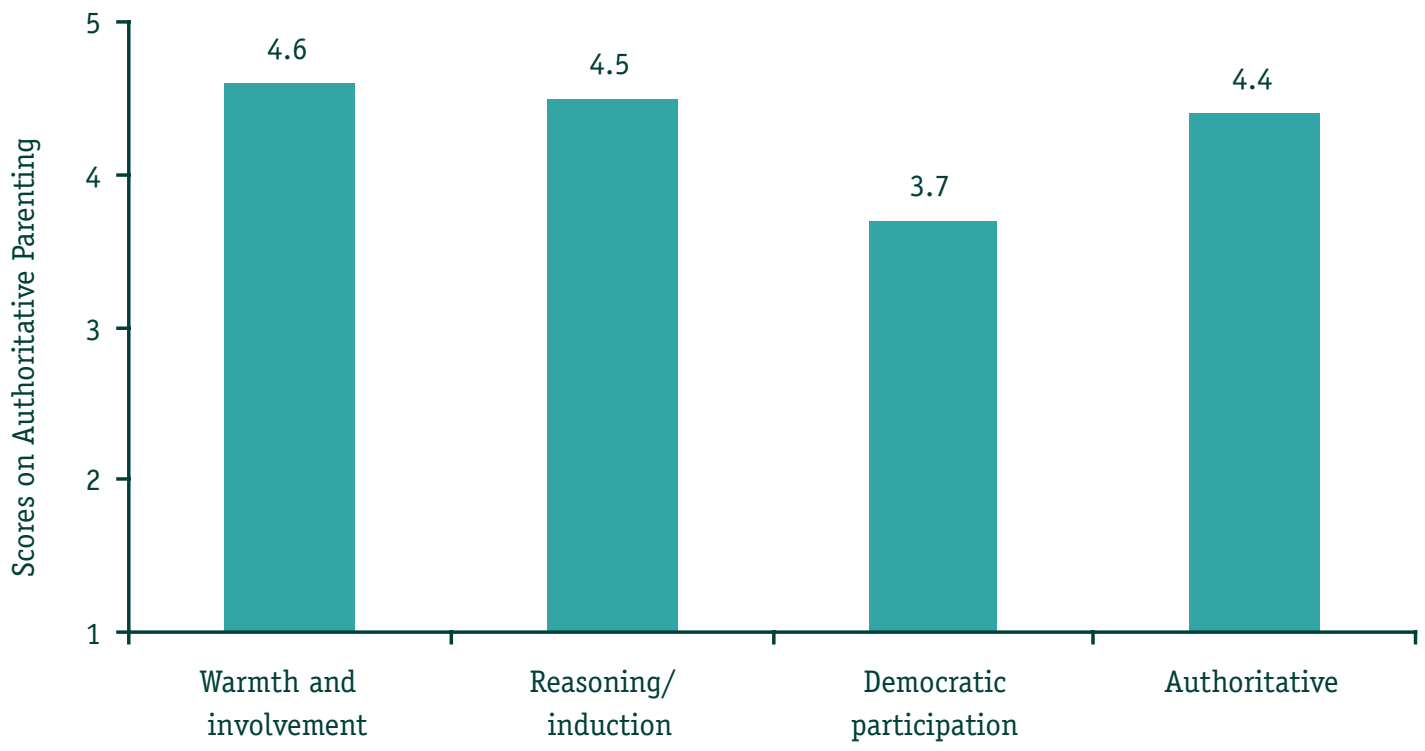

Figure 18: Average scores on Authoritarian Parenting scale and related sub-scales $($ minimum $=1 ;$ maximum $=5)$

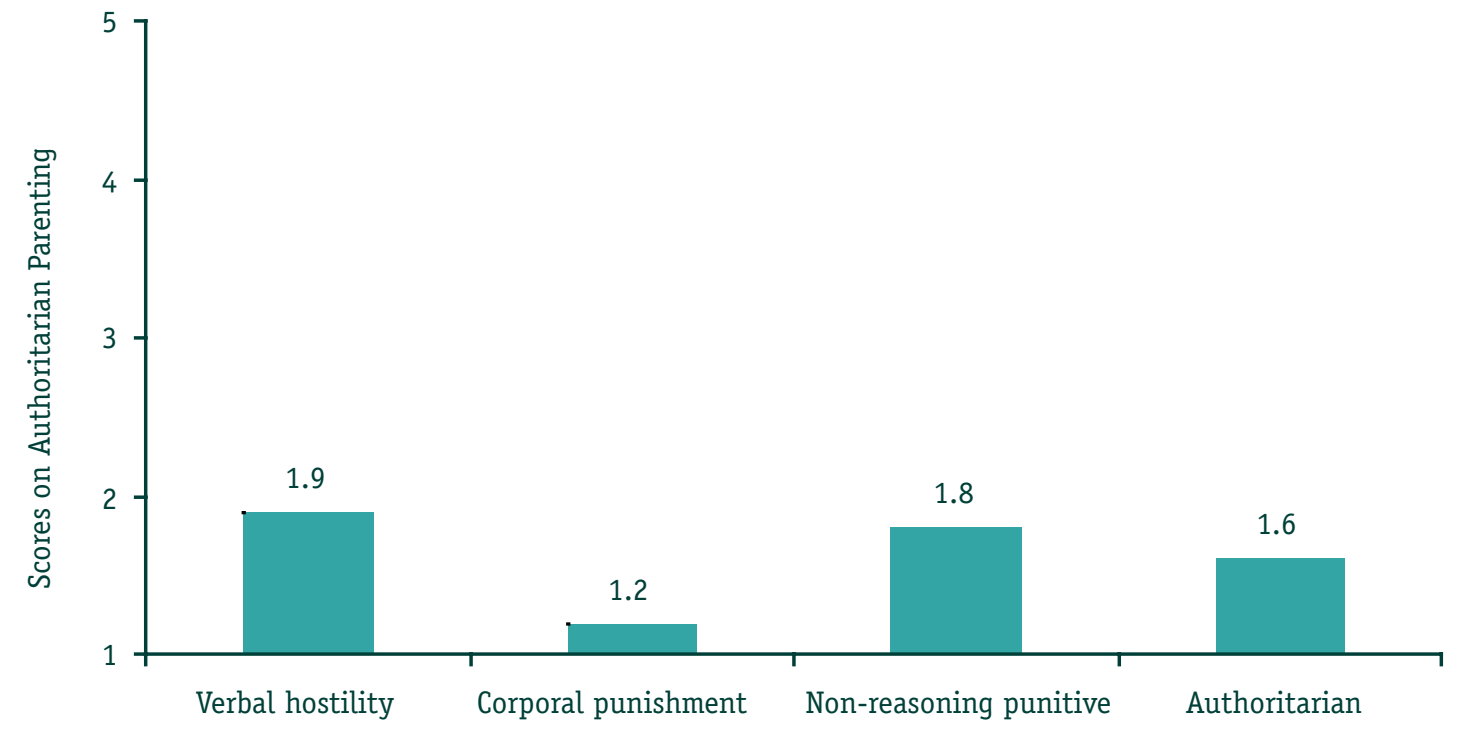


Further analysis considered whether there were any systematic variations in parenting styles according to social class categorisation, parental education, parent age and gender, feelings of support from partner, number of children in the household, children's age, and parental use of physical punishment in the past year. The significant differences found are summarised in Table 13.

No clear trends in parenting style emerged according to social class categorisation or parental education, the number of children in the household or feelings of support from partner. A clear distinction in parenting styles did, however, emerge between parents who had used physical punishment with their children in the past year and those who had not. Those who had used physical punishment in the past year scored significantly lower on democratic participation than those who had not used physical punishment. No differences emerged between the two groups on any of the other sub-scales of the Authoritative Parenting scale. In terms of the authoritariantype behaviours, parents who used physical punishment scored significantly higher than those who had not on all aspects of authoritarian parenting: the sub-scales of verbal hostility, corporal punishment, non-reasoning punitive and the overall authoritarian scale.

Two aspects of parenting behaviour were related to parental age: older parents ( 45 years and over) scored higher on democratic participation than younger parents, while younger parents (under 35 years) scored higher on corporal punishment. These patterns reflect the different strategies adopted depending on the age of the child, as the children of older parents will tend to be older. Parental age was not related to overall authoritarian or authoritative scores. Parental gender was related to three dimensions of parenting behaviour: mothers scored significantly higher than fathers on warmth and involvement, induction and reasoning, and the overall authoritative scale. No differences emerged between mothers and fathers on any aspects of authoritarian parenting.

Finally, parenting behaviours also emerged as significantly related to the age of the selected child. A number of significant patterns emerged: parents of younger children scored lower on democratic participation, induction and reasoning, and verbal hostility. Scores on corporal punishment were highest for parents of younger children (0-4 and 5-9 years) and lowest for parents of older children. In terms of overall authoritative scores, parents of young children ( $0-4$ years) scored significantly lower than parents of older children (10-14 and 15-17 years).

\section{Table 13: Summary of significant differences in parenting behaviours}

\begin{tabular}{|l|l|}
\hline Dimension of parenting behaviour & Key significant differences \\
\hline Democratic participation & $\begin{array}{l}\text { Lower for parents who used physical punishment } \\
\text { Lower for parents of young children } \\
\text { Higher for older parents (45+ years) }\end{array}$ \\
\hline Warmth and involvement & Higher for mothers \\
\hline Induction and reasoning & $\begin{array}{l}\text { Higher for mothers } \\
\text { Lower for parents of younger children }\end{array}$ \\
\hline Verbal hostility & $\begin{array}{l}\text { Lower for parents of younger children } \\
\text { Higher for parents who used physical punishment }\end{array}$ \\
\hline Corporal punishment & $\begin{array}{l}\text { Higher for parents who used physical punishment } \\
\text { Higher for younger parents (under 35 years) } \\
\text { Higher for parents of younger children }\end{array}$ \\
\hline Non-reasoning punitive & Higher for parents who used physical punishment \\
\hline Authoritative & $\begin{array}{l}\text { Higher for mothers } \\
\text { Lower for parents of younger children }\end{array}$ \\
\hline Authoritarian & Higher for parents who used physical punishment \\
\hline
\end{tabular}




\section{Discipline strategies and child behaviour}

Parental discipline strategies were investigated in relation to child behaviour and temperament. Behaviour problems were measured using the emotion, conduct and hyperactivity sub-scales of the Strengths and Difficulties Questionnaire (SDQ). Higher scores on each sub-scale indicated higher levels of difficulty. Children were classified into normal, borderline and problematic depending on their level of behaviour problems. Analysis focused on whether there were any systematic variations in the use of physical punishment or parenting styles for children with and without behaviour difficulties. An important caveat to these findings is that only a small proportion of children (approximately $10 \%$ ) were classified as borderline or problematic across each of the domains (hyperactivity, conduct and emotion).

The findings indicate that there were no differences in parental use of physical punishment for children with and without emotional problems. However, there was a difference in parental use of physical punishment between children with and without both hyperactivity and conduct difficulties. As illustrated in Figure 19, parents of children classified as problematic on both the hyperactivity and conduct sub-scales of the SDQ were more likely to have used physical punishment in the past year. This pattern, however, did not emerge for children classified as problematic on the emotion sub-scale.

Figure 19: Use of physical punishment according to presence of hyperactivity and conduct problems (unweighted proportions) (\% of parents)

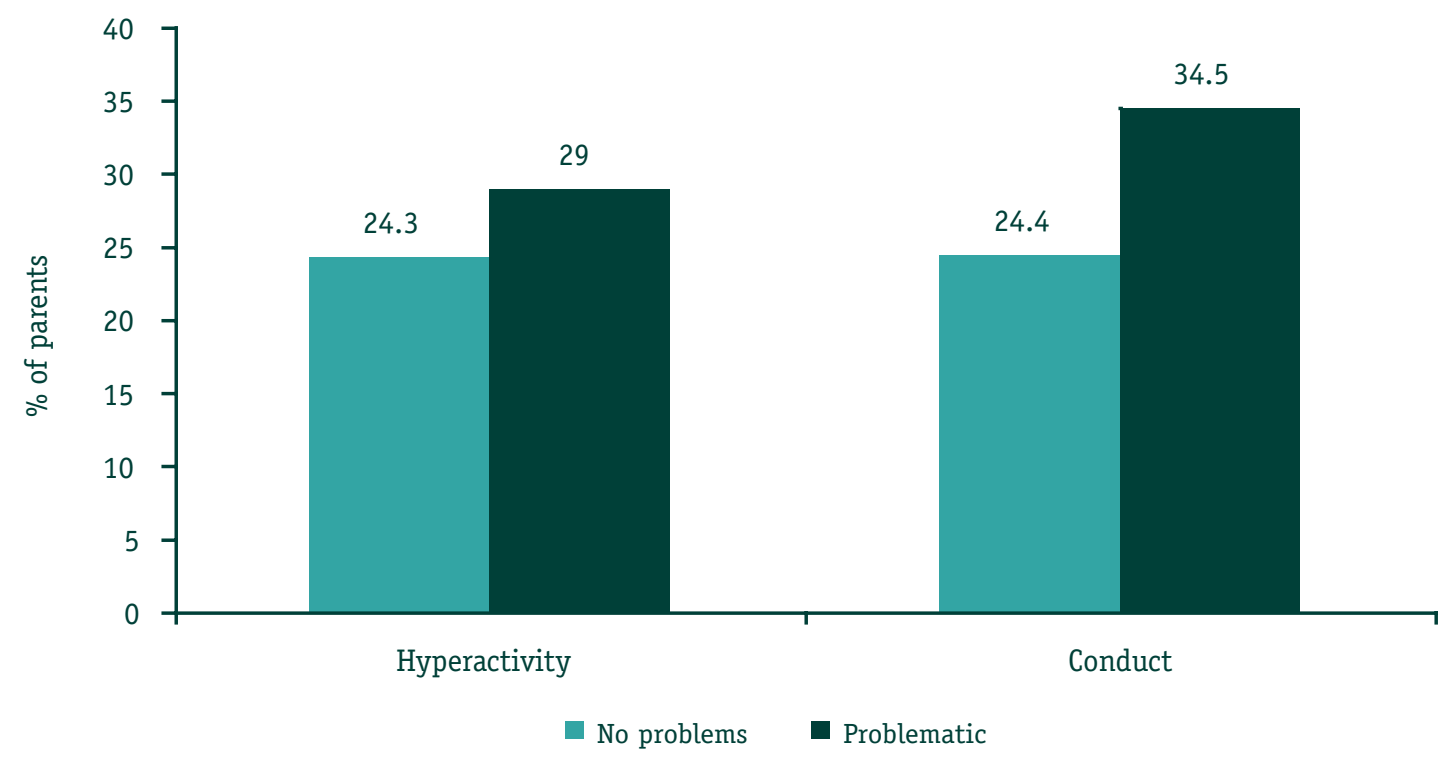

Few differences emerged in the parenting styles between families where children experienced emotional, hyperactivity and conduct problems, and families with no such difficulties. However, verbal hostility was higher among parents whose children were classified as having conduct or emotional problems, but not hyperactivity. Overall, authoritarian scores were also higher within families where children were classified as having conduct difficulties. Democratic participation was lower and corporal punishment higher among parents whose children were classified as having hyperactivity problems.

In summary, there appeared to be some relationship between child behaviour difficulties and parenting behaviours. Parental use of physical punishment was highest in families where children were classified as having hyperactivity or conduct difficulties. Democratic participation was lower among parents whose children had hyperactivity problems. Verbal hostility was also higher in families with children having emotional or conduct difficulties, and parents of children with conduct problems scored higher on the Authoritarian Parenting scale. 
Finally, children's temperament was measured using two scales - the Infant Characteristics Questionnaire (ICQ) for children aged 3 years and under, and the Emotionality, Activity and Sociability (EAS) Questionnaire for children older than 3 years. The ICQ assesses dimensions of fussy/difficultness, adaptability and resistance, while the EAS assesses dimensions of shyness, activity, sociability and emotionality. In terms of parental use of physical punishment in the past year, one significant pattern emerged: for older children, those parents who used physical punishment had children who scored higher on the activity dimension of temperament, which reflected the child's activity levels. A series of correlations was conducted between the scores on the sub-scales of the parenting scales and the scores on the sub-scales of the two temperament scales. One association, characterised as a low correlation, emerged between fussy/difficultness and authoritarian parenting: $11 \%$ of the variation in the score on authoritarian parenting could be accounted for by the score on the fussy/difficultness temperament scale.

\section{Comparison of findings with UK-based studies}

Similar studies of parental attitudes and behaviours related to the discipline of children have been carried out in the UK and it is worthwhile considering key findings on parental reports of the incidence of physical punishment across these studies. Comparison of the reported incidence of physical punishment across these studies in Ireland, England and Scotland is illustrated in Figure 20.

Ghate et al (2003), in a national survey involving 1,250 parents of children aged 0-12 in England, reported a substantially higher incidence level of physical punishment, with $58 \%$ of all parents reporting that they had used this discipline strategy in the past year. Similarly in Scotland, a survey by Anderson et al (2002) of 692 parents found that $51 \%$ of parents reported using physical punishment with children in the past year. As with findings in the present Irish study, the most frequently used types of discipline strategies reported by parents in these UK studies were nonphysical strategies. In addition, trends according to parental recollections of discipline strategies experienced in their own childhood and current practices indicated a decrease in the use of physical punishment over time. Further comparison and discussion of findings across these studies is provided in Chapter 8 of this report.

Figure 20: Comparison of incidence of parental physical punishment across Ireland, England and Scotland (\% of parents)

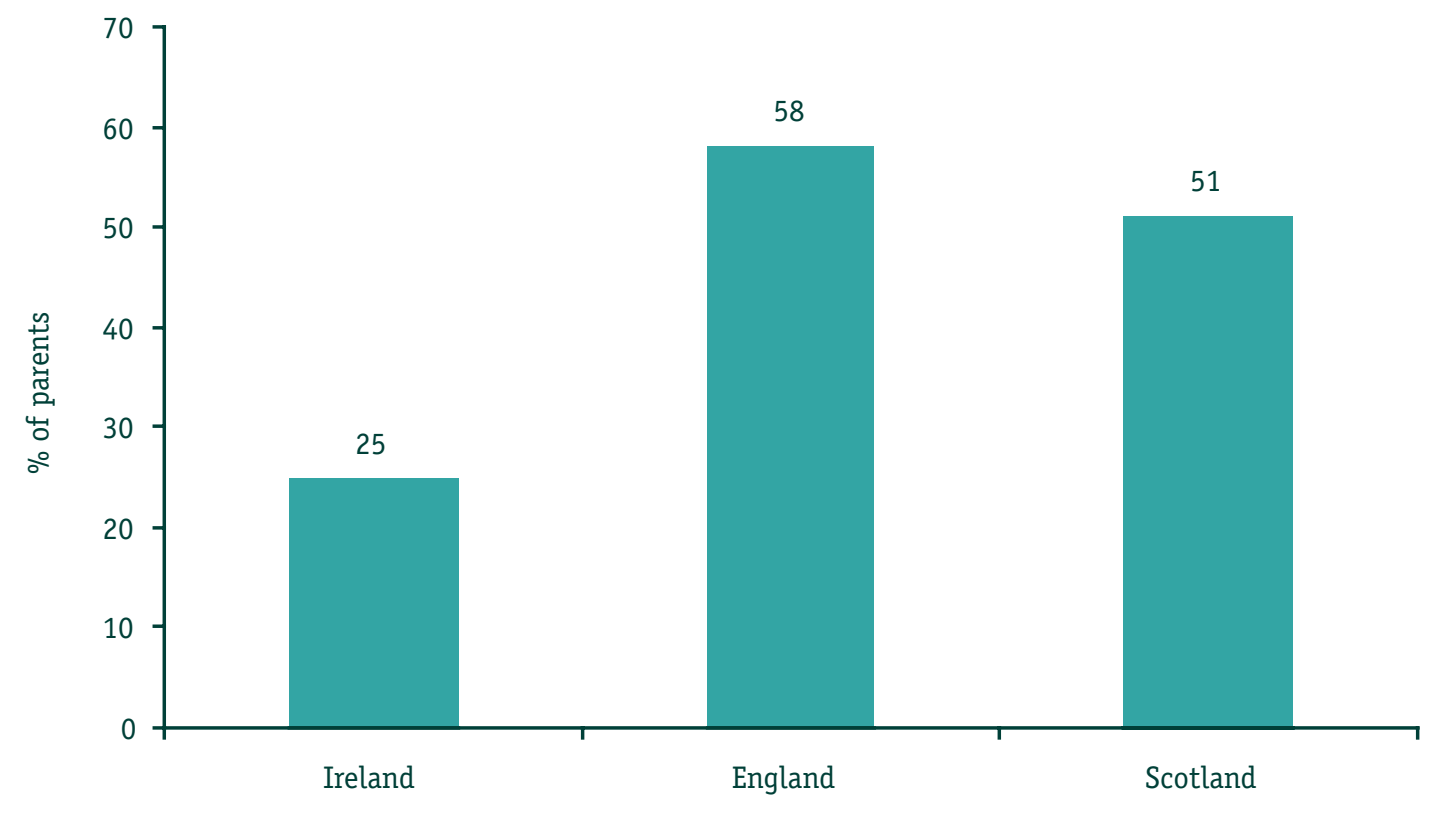




\section{Key findings}

Findings outlined in this chapter provide some indication of the range of discipline strategies currently used by parents in Ireland. These strategies range from inductive, non-aggressive strategies to more coercive strategies, such as physical punishment. Discipline strategies experienced by parents themselves in childhood were also examined and patterns of continuity and discontinuity in parental behaviours over time were explored. Potential influences on these strategies, across parental, child and contextual factors, were also outlined and discussed. In addition to findings on parental discipline strategies, scores relating to the key dimensions of authoritative and authoritarian parenting styles of respondents were also presented. Finally, scores on child behaviour and standardised measures of temperament were outlined and associations with parenting behaviours highlighted.

\section{Key findings are:}

- Parents' self-reports on the incidence of different discipline strategies in the past year suggest that most parents use non-physical discipline strategies with their children. Almost all parents reported using inductive discipline strategies, such as discussing an issue with a child, either frequently or occasionally. Approximately half of parents reported using other non-aggressive discipline strategies, such as making a child take time-out, threatening to ground a child and actually grounding a child. Making a child take time-out and grounding children were used more frequently with children in middle childhood, while giving the child a chore was used with older children in early adolescence.

- Strategies such as threatening to tell someone else and distracting a child in some way were less frequently reported and tended to be used more often with younger children. The least common behaviour reported within non-aggressive discipline strategies was giving a child a chore and this tended to be used more frequently with older children in adolescence.

- Very few parents reported using psychologically aggressive strategies frequently with children. Shouting, yelling or swearing at a child was most commonly used within this category of response, with just under half of parents reporting that they used this strategy in the past year.

- One-quarter of parents reported threatening to smack or hit a child and almost one-fifth of parents reported calling a child stupid or lazy in the past year. Love-withdrawal strategies were the least common behaviours reported by parents within the category of psychologically aggressive responses.

- Approximately one-quarter of all parents reported using physical punishment with their child in the past year. The most common forms of physical punishment reported were slapping a child on the bottom or on the hands, arms or legs, and shaking, grabbing or pushing a child. More severe forms of physical punishment were used by a minority of parents (3\%).

- Child age effects were identified in the use of physical punishment, with children aged 2-9 experiencing physical punishment more frequently than children of other ages. Children in infancy experienced relatively low levels of physical punishment. However, over $10 \%$ of these very young children had experienced physical punishment in the past year according to parents' self-reports.

- Few differences in terms of child or parent age or gender were noted with regard to non-physical or psychologically aggressive discipline strategies.

- Physical punishment was used as an adjunct, rather than as an alternative, to other discipline strategies.

- There was evidence of continuity and discontinuity over time and generations. Parents' recollections of discipline strategies experienced in their own childhood indicated a decrease in psychologically aggressive and physical punishment strategies across generations.

Nevertheless, there was a strong association between current use of physical punishment and past experience of certain physical punishment responses. However, the majority of parents who had experienced physical punishment in childhood did not repeat this behaviour with their own children. 
- Parents scored higher on all aspects of authoritative parenting than authoritarian parenting. Parents also scored higher on warmth and involvement, and induction and reasoning than on democratic participation. Within the authoritarian domain, parents scored higher on verbal hostility and non-reasoning punitive sub-scales than on the corporal punishment sub-scale.

- There were no clear trends in parenting styles according to social class or parental education.

- Parents who had used physical punishment in the past year used significantly lower levels of democratic participation with their children and higher levels of authoritarian parenting than those who had not used physical punishment.

- Older parents were more likely to use democratic participation in their parenting than younger parents, while younger parents were more likely to score higher on corporal punishment.

Similarly, parents of younger children scored lower on democratic participation and induction and reasoning. In contrast, scores on corporal punishment were highest for parents of younger children and lowest for parents of older children. Overall, parents of young children (0-4 years) engaged less frequently in authoritative parenting behaviours than parents of older teenagers (15-17 years).

- There appeared to be some relationship between parenting behaviours and child behaviour difficulties. The proportion of parents who used physical punishment in the past year was highest among families with children classified as having hyperactivity or conduct difficulties. Parents of children with conduct problems engaged more frequently in authoritarian parenting behaviours and levels of verbal hostility were highest in families with children having emotional or conduct problems.

\section{Discussion}

Drawing on the self-report data of parents, the discipline strategies adopted by Irish parents in the present study tapped into three discrete behavioural practices. The first of these was non-aggressive discipline strategies, broadly corresponding to more inductive types of parenting responses. The majority of parents in the present study indicated that this was the most frequently used strategy within their repertoire, consistent with similar studies in the UK (Ghate et al, 2003; Anderson et al, 2002). Not alone did such strategies predominate in current parental practices, but these inductive responses to child discipline were also reported to have increased by comparison with trends generated in parents' accounts of their own experience of discipline in childhood.

Two further categories of discipline response were examined in the present study - psychologically aggressive strategies and physical punishment - broadly corresponding to power-assertive discipline strategies. The incidence of these more coercive discipline responses was relatively low when compared with similar parental reports in recent UK studies. With specific reference to the use of physical punishment by parents, one-quarter of parents in Ireland (25\%) reported using physical punishment with their children in the past year; this compares with $51 \%$ of parents in Scotland (Anderson et al, 2002) and 58\% of parents in England (Ghate et al, 2003).

A key factor associated with higher rates of physical punishment in the present study was child age, with younger children (specifically between the ages of 2 and 9 years) being most likely to be punished physically. These findings are broadly in keeping with previous research findings, which suggest that parents tend to view physical punishment as most appropriate for children of pre-school age and least appropriate for infants (Day et al, 1998; Flynn, 1998). Younger parents were also found to adopt physical punishment as a strategy more frequently and this is consistent with other studies in the UK (Ghate et al, 2003; Anderson et al, 2002). Child gender was not associated with the use of physical punishment in the present study and this is consistent with some previous studies (Woodward and Fergusson, 2002; Holden et al, 1997). In contrast to other studies, however, there was little effect of social class or level of education on parental use of such a discipline response. Nor was there any effect of spousal support and this is most likely explained by the high levels of partner support reported by parents in the present study. Finally, the notion of intergenerational transmission of discipline strategies has been addressed in the literature (Simons et al, 1991; Bower-Russa et al, 2001), with previous research suggesting a link between experiences of harsh discipline and punishment in childhood and the use of these strategies with children in subsequent 
generations. Some support for this concept was provided in the present findings, with patterns of association over time across certain discipline strategies identified. However, the study also found evidence that cycles of intergenerational transmission of parenting behaviours and discipline strategies were altered and patterns of behaviours were not solely determined by past experience.

Findings in the present study also support the notion that discipline strategies co-occur alongside other forms of discipline response. This was particularly the case with regard to the use of physical punishment by parents, which was used in conjunction with other discipline responses such as threats, time-out, withdrawal of privileges and, in many cases, alongside more inductive reasoning strategies. The failure to recognise that physical punishment is often used as an adjunct, rather than as an alternative, to other discipline strategies is a significant shortcoming in much research on the effects of physical punishment. Researchers have drawn attention to the fact that much of the literature exploring the relationship between physical punishment and child outcomes relies on physical punishment as a single disciplinary technique to be examined (Smith et al, 2005; Ritchie, 2002).

The findings in this chapter also present, for the first time in an Irish context, insight into the styles of parenting adopted with children in Ireland. Overall, parents engaged more frequently in behaviours consistent with an authoritative style of parenting and less frequently in behaviours characteristic of an authoritarian style of parenting. This trend resonates well with the relatively low incidence of physical punishment that was found and the tendency for parents to frequently engage in discipline strategies involving induction (such as calm discussion or telling a child their actions made them sad). In contrast to previous research (e.g. Hoff et al, 2002), findings from this study did not reveal patterns in parenting styles according to socio-economic status or level of parental education. 


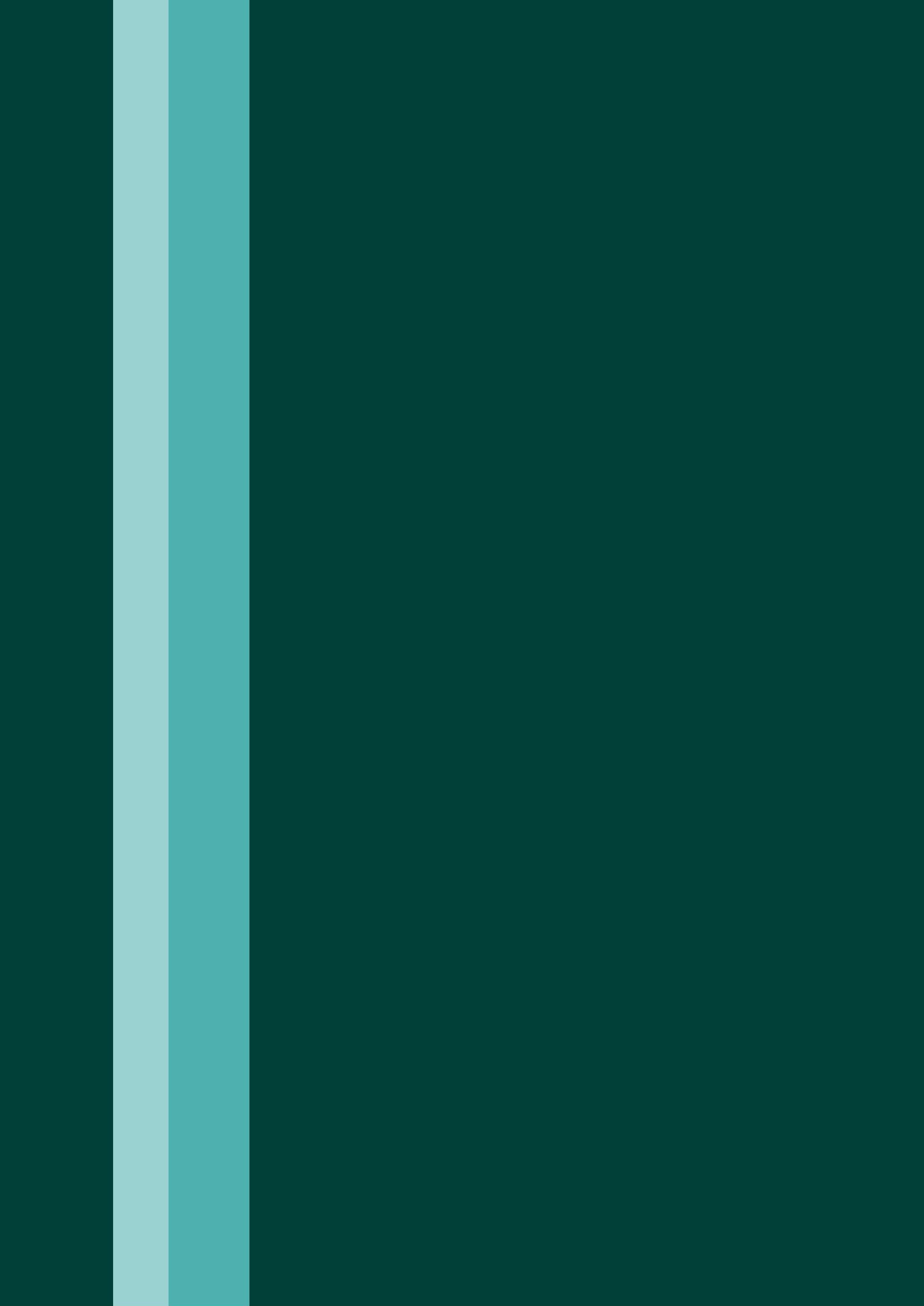


PHYSICAL

PUNISHMENT ATTITUDES, CONTEXT AND RATIONALES 
In this chapter, we focus specifically on parental attitudes and behaviours related to the use of physical punishment of children. The chapter begins by exploring parental attitudes to physical punishment and moves on to outline findings on the possible contexts in which physical punishment is likely to occur. Parental views on the effectiveness of physical punishment are examined and the rationales for its use as a discipline strategy. An exploration of the precise situations in which physical punishment is more likely to be used by parents is followed by an overview of parents' awareness and attitudes to the current legislation on physical punishment in an Irish context.

\section{Attitudes towards smacking}

As part of the Parenting Survey, parental attitudes towards smacking were sought and parents were asked to evaluate a range of contexts in which smacking is most likely to occur. A summary of the findings relating to these parental attitudes is provided in Table 14. Almost two-thirds of parents $(64.5 \%)$ agreed that smacking was not necessary in order to bring up a well-behaved child. However, approximately one-quarter of parents $(23 \%)$ disagreed with this, reflecting the view that smacking may be necessary to bring up a well-behaved child. Almost $70 \%$ of parents indicated that they believed that an occasional smack is not harmful to children, with just one-quarter of parents (24\%) indicating that they disagreed with this view. Almost $30 \%$ of parents believed that smacking is wrong and should never be used, while $58 \%$ disagreed or strongly disagreed that it should never be used. Findings were mixed on the necessity of smacking as a last resort. Almost half of parents (49\%) agreed that smacking is necessary as a last resort, while $40 \%$ disagreed with this statement. Findings were also mixed on the notion that parents who smack can damage their relationship with the child, with $43 \%$ agreeing with this statement and $47 \%$ disagreeing. Just over one-third of parents (38\%) agreed that sometimes a smack is the only way to get the message across, while just over half of parents (52\%) disagreed with this statement. $40 \%$ of parents indicated that children who are smacked are more likely to be aggressive, while half of parents believed that smacking would not result in such an outcome. Finally, more than half of parents $(60 \%)$ believed that parents should have the right to smack their child, while only $26 \%$ believed that parents should not have this right.

Table 14: Parents' attitudes towards smacking (\%)

\begin{tabular}{|l|c|c|}
\hline Attitudes towards smacking & $\begin{array}{c}\text { \% of parents } \\
\text { who agree* }\end{array}$ & $\begin{array}{c}\text { \% of parents } \\
\text { who disagree }\end{array}$ \\
\hline Odd smack does not do a child any harm & 67.1 & 24.1 \\
\hline Not necessary to bring up a well-behaved child & 64.6 & 23.3 \\
\hline Parents have the right to use smacking if they wish & 59.6 & 26.3 \\
\hline Necessary as a last resort & 49.1 & 40.4 \\
\hline Can damage relationship with child & 42.8 & 46.5 \\
\hline Children are likely to be more aggressive & 39.7 & 49.4 \\
\hline Only way to get the message across & 38.3 & 51.6 \\
\hline Wrong and should never be used & 28.4 & 57.9 \\
\hline
\end{tabular}

* Percentage totals may not equal 100 as some parents responded 'Neither agree nor disagree' to each item.

In summary, there was a strong consensus among the majority of parents that, on the one hand, smacking is not necessary to bring up a well-behaved child, but also that an odd smack does not do a child any harm. Over half of parents believed that parents should have the right to use smacking if they so wish. However, there was no clear consensus in terms of the other attitudes explored: approximately half of parents either 'agreed' or 'disagreed' that smacking is necessary as a last resort, that it can damage the parent-child relationship and that it is likely to make children more aggressive.

Further analysis considered whether these attitudes were related to the age or gender of the child and parent, education level of the parent and social class grouping. 


\section{Social class}

A social class dimension to these attitudes emerged (see Figure 21). More parents in the professional/managerial group (39.2\%) and in the other non-manual category $(37.9 \%)$ disagreed that smacking is necessary as a last resort in comparison with the skilled/unskilled manual group $(18.2 \%)$. Over half of parents in the skilled/unskilled manual group (51\%) agreed that smacking is necessary as a last resort.

Figure 21: Percentage of parents who disagree that smacking is necessary as a last resort, by socio-economic classification (\%)

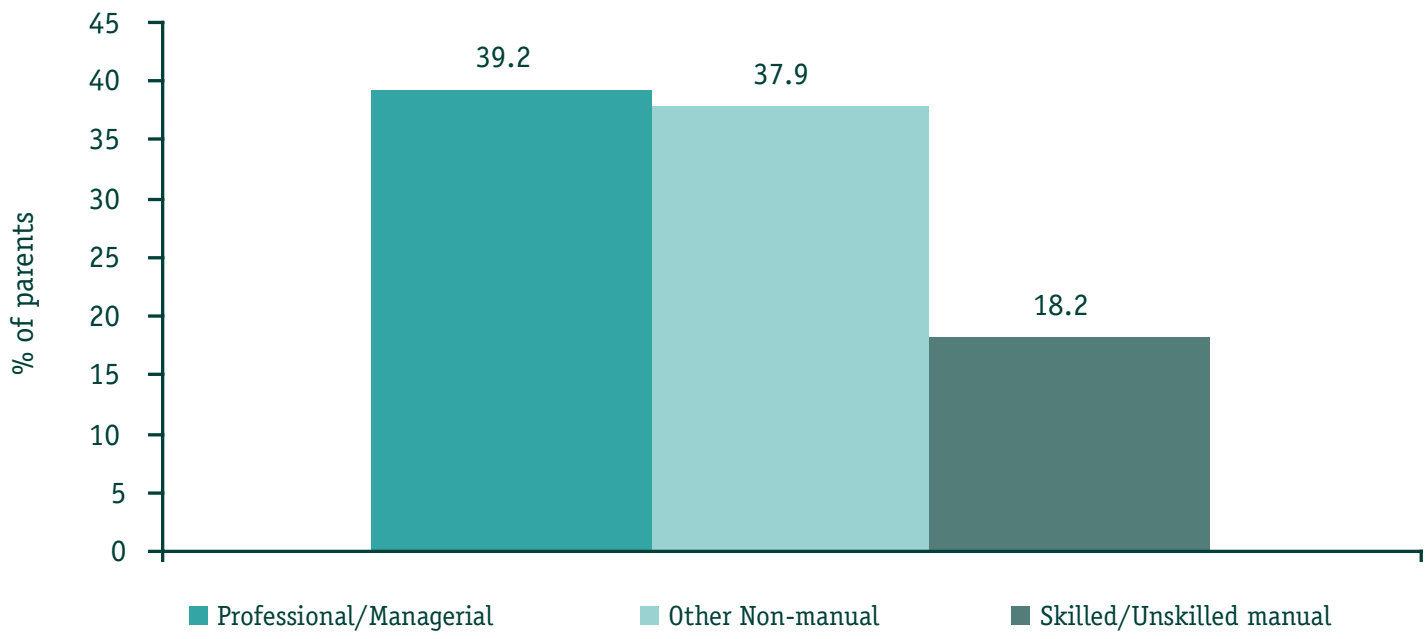

\section{Education level of parent}

Attitudes also appeared to be related to parental education level (see Figure 22). Parents who left school before completing their Leaving Certificate were more likely to strongly agree that parents should have the right to use smacking if they wish, more likely to agree that smacking is necessary as a last resort and less likely to agree that you don't need smacking to bring up a well-behaved child. Conversely, parents who achieved an educational level beyond their Leaving Certificate were more likely to strongly agree that you don't need smacking to bring up a well-behaved child, more likely to agree that parents who smack can damage their relationship with their child, less likely to agree that smacking is necessary as a last resort and also less likely to agree that parents should have the right to use smacking if they wish.

Figure 22: Percentage of parents who disagree that smacking is necessary as a last resort and strongly agree that parents should have the right to use smacking if they wish, by parental education level (\%)

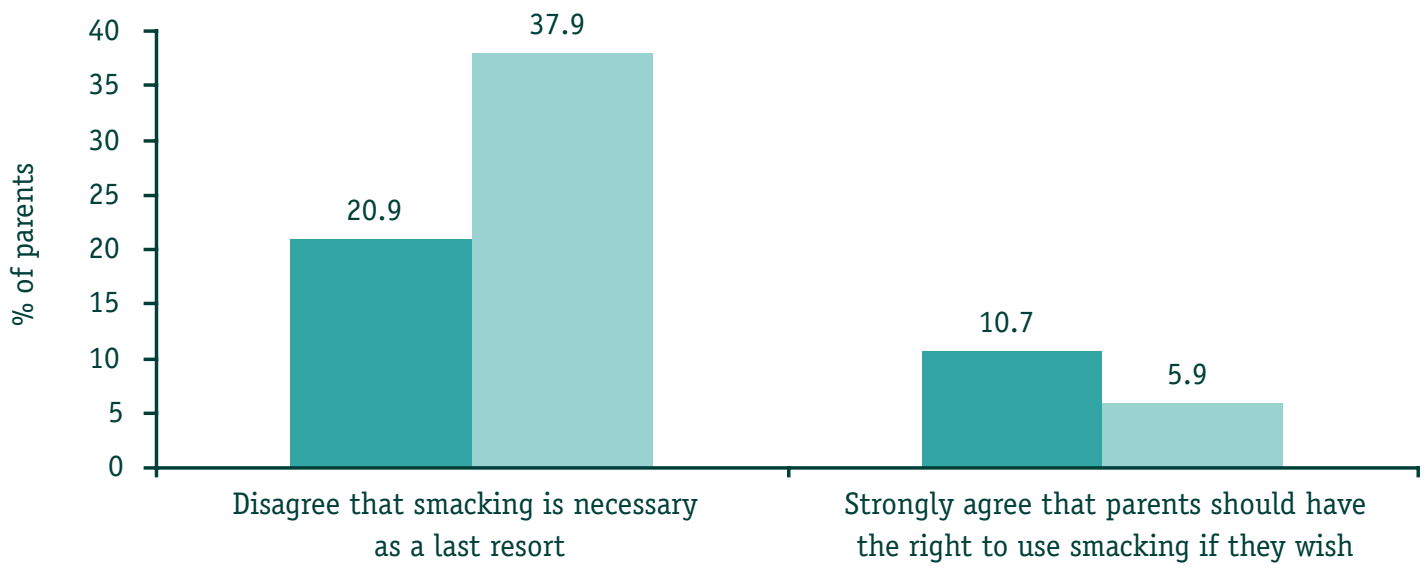




\section{Age of parent}

Attitudes did not emerge as related to the gender or age category of the child, or the gender of the parent. With the exception of the attitude that parents have the right to use smacking if they wish, there were no associations between attitudes and age of the parent. Parents over the age of 45 years were more likely to disagree with the view that parents have the right to use smacking if they wish.

\section{Parental use of physical punishment}

Finally, whether parents agreed or disagreed with the statements was clearly associated with previous use of physical punishment in the past year. Generally, parents who had used physical punishment in the past year were more likely to agree that an odd smack does not do a child any harm, smacking is necessary as a last resort, parents have the right to use smacking if they wish and sometimes a smack is the only way to get the message across. In contrast, those parents who had not used physical punishment were less likely to agree with these statements. Parents who had used physical punishment were more likely to disagree with the view that children who are smacked are likely to be more aggressive, smacking is wrong and should never be used, parents who smack can damage their relationship with their child and smacking is not necessary to bring up a well-behaved child. Again, in contrast, those parents who had not used physical punishment in the past year were more likely to agree with these attitudes.

\section{Effectiveness of smacking}

Parents were asked whether physical punishment was an effective discipline strategy in (1) stopping misbehaviour at the time it is occurring and (2) preventing misbehaviour in future contexts. No clear consensus emerged among parents (see Figure 23). Just over half of parents indicated that smacking was either 'very effective' $(17 \%)$ or 'quite effective' $(40 \%)$ in stopping undesirable behaviours at the time they are occurring. In contrast, just less than half of the respondents were of the view that smacking was 'not very effective' $(30 \%)$ or 'not at all effective $(14 \%)$ in stopping misbehaviour at the time. Similarly, no clear consensus emerged in terms of the perceived effectiveness of smacking in preventing misbehaviour in a later context. Almost $60 \%$ of parents stated that smacking was either 'not very effective' (35\%) or 'not at all effective' (24\%) in preventing later misbehaviour, while just over $40 \%$ believed that smacking was 'very effective' $(12 \%)$ or 'quite effective' $(29 \%)$ in preventing misbehaviour in future contexts.

Figure 23: Perceived effectiveness of smacking in stopping misbehaviour at the time and in a future context (\% of parents)

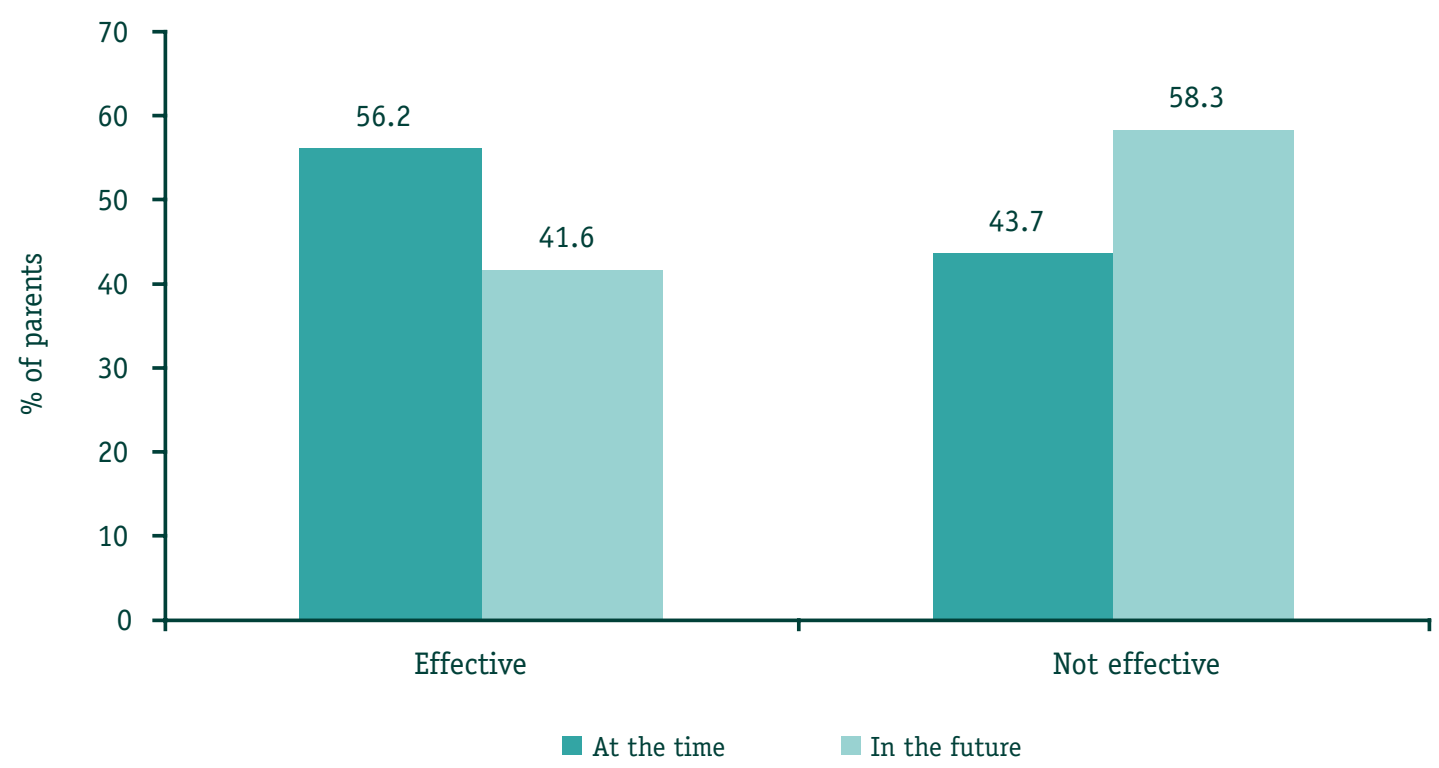


It can be seen from Figure 23 that a higher proportion of parents believe that smacking is effective in stopping misbehaviour at the time compared to preventing misbehaviour in the future. Thus, parents appear to believe that smacking may be effective for achieving immediate compliance, but less effective in achieving long-term goals associated with discipline. Nevertheless, it is clear that a substantial proportion of parents believe that smacking is ineffective in stopping misbehaviour both at the time and in the future.

Beliefs in the effectiveness of physical punishment in both stopping misbehaviour at the time and in preventing later misbehaviour were not associated with social class categorisation, education level, or age or gender of either parent or child. However, a clear association did emerge between beliefs in effectiveness and parental use of physical punishment in the past year (see Table 15). Of those who had used physical punishment in the past year, fewer were of the view that it was 'not very' or 'not at all' effective, while more of this group considered it to be 'quite' or 'very' effective in stopping misbehaviour at the time. More people who had not used physical punishment in the past year stated that it was 'not at all' effective in stopping misbehaviour at the time. In terms of effectiveness in preventing later misbehaviour, fewer parents who had used physical punishment in the past year believed that it was 'not at all' effective in preventing later misbehaviour and more of these parents believed it to be an effective preventative measure.

Table 15: Belief in the effectiveness of physical punishment according to whether parents had used it in the past year (\%)

\begin{tabular}{|l|c|c|}
\hline & \multicolumn{2}{|c|}{ Stopping misbehaviour at the time } \\
\hline & $\begin{array}{c}\text { 'Quite' or 'Very' } \\
\text { effective }\end{array}$ & $\begin{array}{c}\text { 'Not very' or 'Not at all' } \\
\text { effective }\end{array}$ \\
\hline Physical punishment in the past year & 72.4 & 27.6 \\
\hline No physical punishment in the past year & 50.8 & 49.2 \\
\hline \multicolumn{2}{|c|}{} & Preventing misbehaviour in the future \\
\hline & 'Quite' or 'Very' & $\begin{array}{c}\text { 'Not very' or 'Not at all' } \\
\text { effective }\end{array}$ \\
\hline Physical punishment in the past year & 60.4 & 39.6 \\
\hline No physical punishment in the past year & 35.5 & 64.5 \\
\hline
\end{tabular}

Thus, it appears that those who use physical punishment are more likely to believe in its effectiveness, both in stopping misbehaviour at the time and in preventing later misbehaviour, than those who do not use physical punishment.

\section{Rationales for using physical punishment}

In order to gain further insight into the contexts and circumstances in which parents are more likely to use, or to justify using, physical punishment as a discipline strategy, the participants were asked to respond to items describing certain rationales for using such a discipline strategy. A summary of the findings relating to these parental attitudes is provided in Table 16. It was clear that many of the parents did not endorse the majority of rationales for using physical punishment. Over $80 \%$ did not support rationales whose principles suggested coercion or domination in order to achieve desirable outcomes: examples of such rationales were letting a child know who is boss ( $85 \%$ of parents did not support this rationale) and making a child pay for what he/she has done ( $89 \%$ of parents did not endorse this). Neither were parental shortcomings accepted by parents as an appropriate rationale for using physical punishment: at least $90 \%$ of parents indicated that rationales such as parents letting off steam, acting without thinking and using physical punishment as a last resort (can't think of anything else to do) were not acceptable as good reasons for using such coercive discipline strategies. 
The rationale most strongly supported by parents in terms of using physical punishment as a discipline response was to stop the child doing something dangerous, with just over half of parents (52\%) supporting this as a good reason for using physical punishment. Rationales focusing on correcting and teaching children not to behave badly were supported by a substantial minority of parents. Just over one-third (38\%) indicated that using physical punishment to stop bad behaviour quickly was a good reason for its use. Similarly, $38 \%$ of parents were of the view that using physical punishment to underline the seriousness of what the child has done was a good rationale, while just one-quarter of parents supported the rationale of using physical punishment to teach children not to behave badly.

Table 16: Parents' attitudes towards rationales for using physical punishment (\%)

\begin{tabular}{|l|c|c|}
\hline Reasons for using physical punishment & $\begin{array}{c}\text { \% of parents who } \\
\text { think it is } \\
\text { a 'good reason'* }\end{array}$ & $\begin{array}{c}\text { \% of parents who } \\
\text { think it is } \\
\text { a 'bad reason' }\end{array}$ \\
\hline Stop child doing something dangerous & 51.7 & 33.2 \\
\hline Underline seriousness of what child has done & 38.4 & 43.7 \\
\hline Stop bad behaviour quickly & 37.8 & 46.6 \\
\hline Teach child not to behave badly in the future & 25.0 & 58.0 \\
\hline Get child's attention & 11.1 & 81.7 \\
\hline Show the child who is boss & 9.2 & 84.8 \\
\hline Make child pay for what he/she has done & 3.5 & 88.9 \\
\hline Done without thinking & 1.6 & 92.4 \\
\hline Can't think of anything else to do & 2.2 & 96.1 \\
\hline Help the parent let off steam & 2.0 & 96.2 \\
\hline
\end{tabular}

* Percentage totals may not equal 100 as some parents responded 'Neither good nor bad reason' to each item.

It is clear from Table 16 that the most widely endorsed rationale for using physical punishment is in contexts of danger, although approximately one-third of parents did not support this view. It is also clear that many of the parents did not endorse any of the rationales for using physical punishment. Figure 24 illustrates the broad patterns of findings that emerged.

Figure 24: Support or rejection for different rationales for using physical punishment (\% of parents)

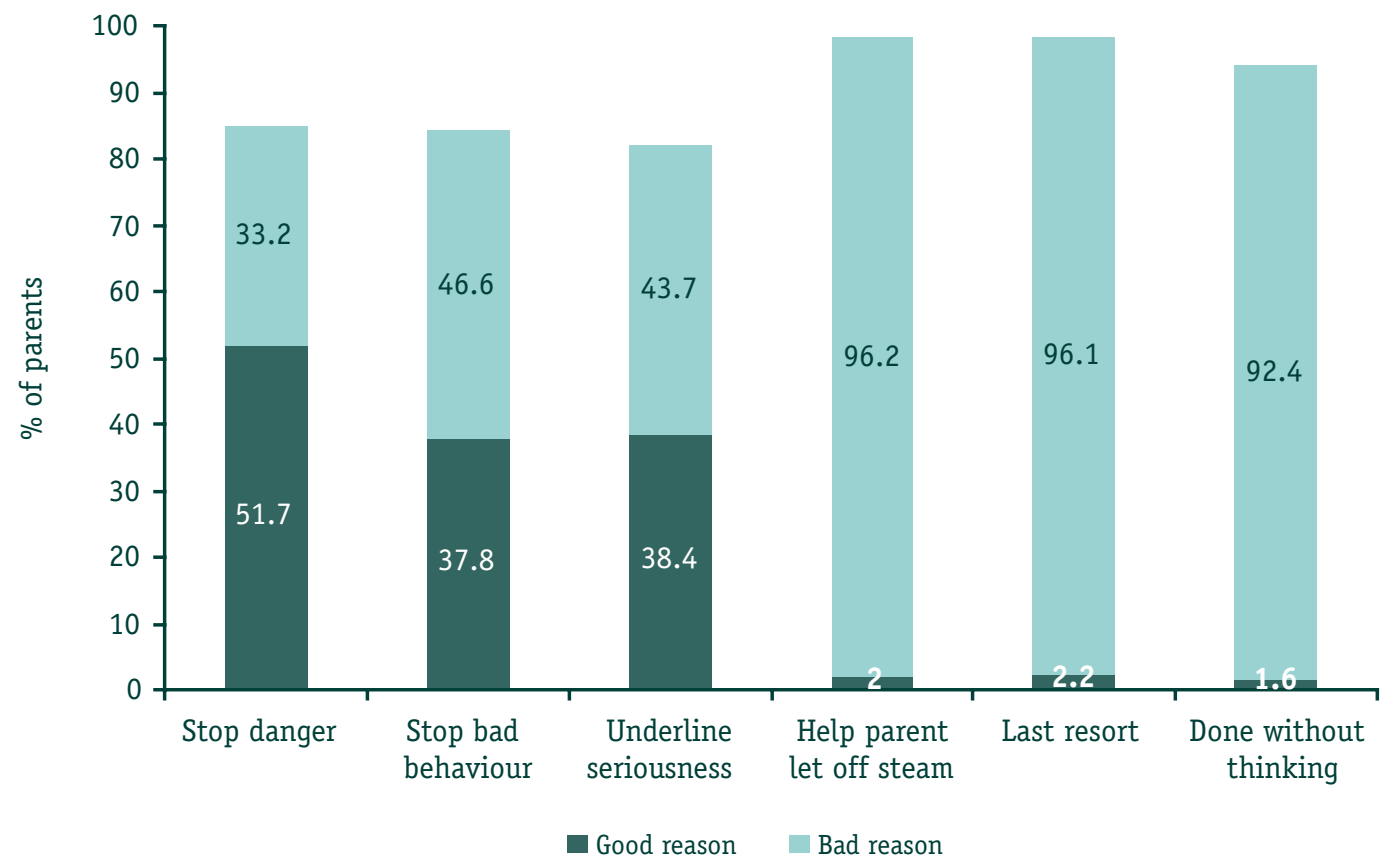


Clear distinctions in attitudes emerged between those parents who had used physical punishment in the past year and those who had not. For example, a greater proportion of parents who had used physical punishment in the past year supported the following rationales for its use: to underline the seriousness of behaviour, to stop bad behaviour quickly, to teach the child not to behave badly, to stop the child doing something dangerous or use as a last resort. In contrast, more of the parents who had not used physical punishment in the past year rejected the following rationales: to underline the seriousness of behaviour, to stop bad behaviour quickly and to stop the child doing something dangerous.

Other patterns emerged according to the education level and gender of the parents, and the age and gender of the child. In relation to education level, those parents who had left school before their Leaving Certificate were more likely to support the rationale of using physical punishment to show the child who is boss. No other differences emerged according to education level. No patterns emerged in terms of the gender of the child, while one pattern emerged in relation to the age of the child: more parents of children aged 15-17 thought that making the child pay for what he/she had done was a good reason for using physical punishment. No patterns emerged in terms of the age of the parent, while two patterns emerged in relation to the gender of the parent: mothers were less likely to say that a good rationale for using physical punishment was to get the child's attention and to show the child who is boss. In contrast, fathers were more likely to cite these as good rationales for using physical punishment. No patterns emerged in terms of social class grouping.

\section{Contexts in which physical punishment occurs}

Parents were asked about a range of factors that might influence the likelihood of their use of physical punishment. Some factors pertained to parental characteristics, such as being tired or worried about the child, while other factors related to children's behaviour, such as child aggression or continuous defiance. Table 17 illustrates that the contexts in which physical punishment is much more likely to occur includes when the child is repeatedly defiant or is aggressive or violent. Other contexts were not particularly likely to induce parental use of physical punishment. For example, in less than $10 \%$ of cases were parents much more likely to use physical punishment when they felt tired or stressed, fearful for or worried about the child, or feeling that they were losing control of the child. However, situational factors do appear to play some role in the propensity of parents to use physical punishment. Thus, between one-quarter and half of the parents in this study reported that they would be either 'much' or 'a bit' more likely to use physical punishment when they themselves were feeling a loss of control over the child or if they were tired, worried, busy or stressed.

Table 17: Likelihood of use of physical punishment in different contexts (\% of parents)

\begin{tabular}{|l|c|c|c|}
\hline Likelihood of using physical punishment & $\begin{array}{c}\text { Much more } \\
\text { likely }\end{array}$ & $\begin{array}{c}\text { A bit more } \\
\text { likely }\end{array}$ & $\begin{array}{c}\text { No more } \\
\text { likely }\end{array}$ \\
\hline When you've had a long, tiring day & 8.2 & 30.6 & 61.3 \\
\hline When you've been worried or scared about the child & 9.2 & 39.6 & 51.2 \\
\hline When the child has been aggressive or violent & 24.8 & 38.9 & 36.3 \\
\hline When you feel you've lost control of the child & 7.1 & 36.9 & 55.5 \\
\hline When you're very busy or pushed for time & 3.9 & 19.8 & 76.3 \\
\hline When you feel things are getting on top of you & 5.4 & 24.9 & 69.5 \\
\hline $\begin{array}{l}\text { When child has been told off repeatedly, but } \\
\text { continues misbehaving }\end{array}$ & 16.8 & 59.1 & 24.1 \\
\hline
\end{tabular}




\section{Child behaviour as a context for physical punishment}

Parents who reported that they had used physical punishment were questioned about the specific contexts in which they were likely to use it as a form of discipline. The main context related to the nature of the child's behaviour. Since behaviours that elicit discipline from parents are likely to vary according to the age of the child, questions were adapted in order to take account of these age differences, with parents of children younger than 5 years (see below) distinguished from parents whose children were 5 years or older (see $p .81$ ).

\section{Children under 5 years of age}

Three types of child behaviours emerged as being most likely to elicit physical punishment responses: dangerous behaviour, aggressive behaviour and non-compliant behaviour (see Figure 25). In keeping with the rationales supported by parents for the use of physical punishment, contexts of danger were most likely to elicit physical punishment as a discipline response according to the views of these parents. Over half of these parents (58.4\%) indicated that they would be likely to smack their child if they were doing something dangerous, while such behaviour might elicit this discipline response for a further $16.6 \%$ of parents.

Children behaving aggressively with intent to hurt parents was also emphasized as significant in terms of possibly eliciting physical punishment as a response. Almost one-third of parents $(30.8 \%)$ reported that they would use physical punishment if a child was hurting or being aggressive towards them, with a further $43 \%$ indicating that they might use physical punishment in response to such behaviour.

Disobedience or non-compliance was also highlighted as a possible situation where parents would be likely to use physical punishment - just over one-quarter of parents $(27.5 \%)$ indicated that they would use this punishment in response to a child refusing to do something he or she was told to do, with a further $32.8 \%$ indicating that they might adopt this discipline strategy. Similarly, situations where children touched or played with objects forbidden to them were highlighted as being likely to elicit physical punishment $-25.5 \%$ of parents reported that they would choose this strategy in response to such behaviour and a further $35.9 \%$ reported that this might lead them to choose such a coercive strategy.

Figure 25: Likelihood of different child behaviours eliciting physical punishment responses by parents, for children younger than 5 years (\% of parents)

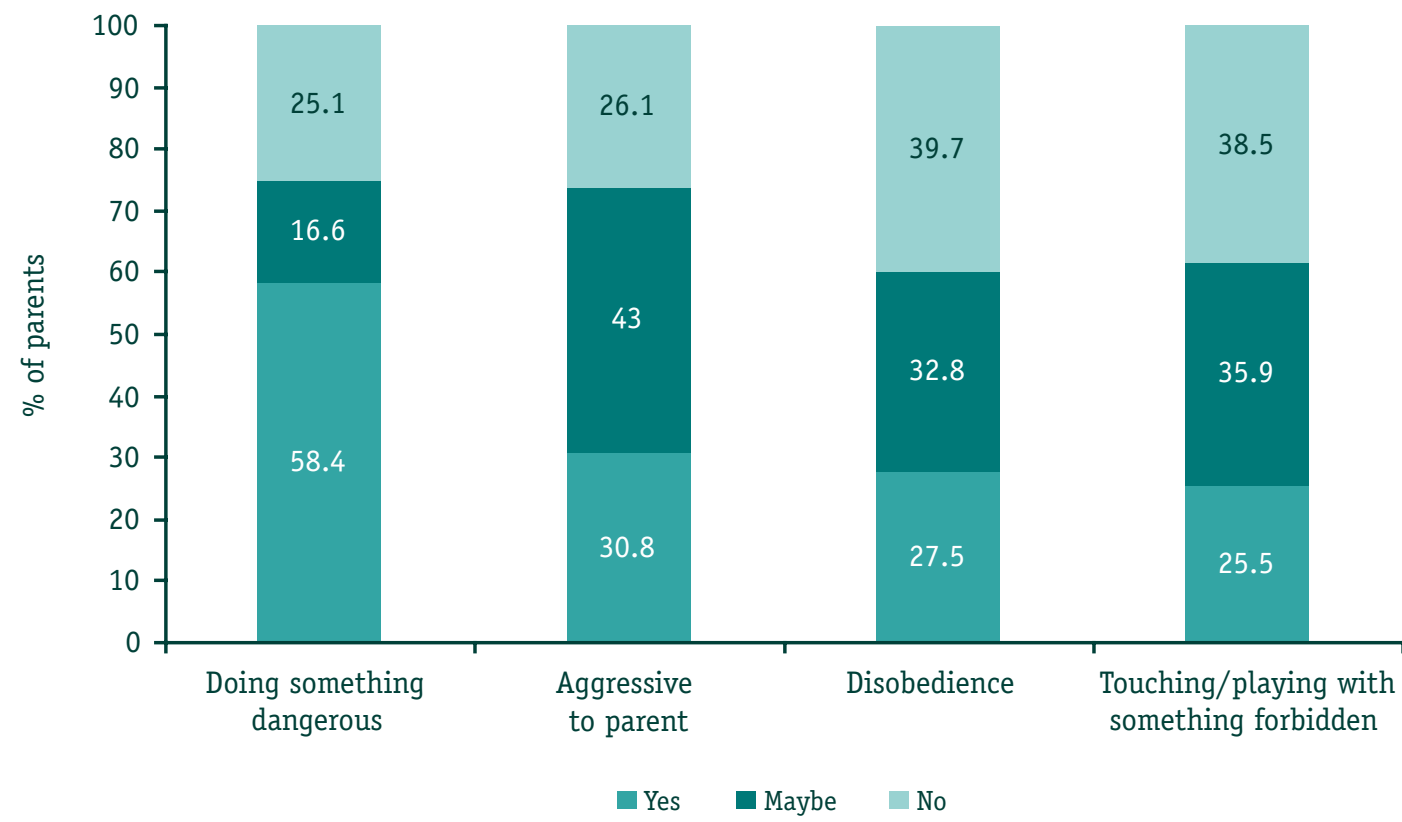


In contrast, behaviours such as crying or whinging, refusing to eat, wetting or soiling himself or herself, being noisy, making a mess or demanding parental attention did not tend to elicit physical punishment responses. Less than $5 \%$ of parents reported that these behaviours would elicit a physical punishment response.

\section{Children aged 5 years and older}

As was the case with children younger than 5, three types of child behaviours emerged as being most likely to elicit physical punishment responses among parents of older children (aged 5 and above): dangerous behaviour, aggressive behaviour and non-compliant behaviour (see Figure 26). For the older age group, the most likely child behaviour to elicit physical punishment as a discipline response was doing something dangerous. Over one-third of parents (34.8\%) indicated that they would be likely to smack their child if they were doing something dangerous, while such behaviour might elicit this discipline response for a further $34.2 \%$ of parents.

Children behaving aggressively towards parents and other children was also emphasized as being likely to elicit physical punishment as a response. Almost one-fifth of parents reported that they would be likely to use physical punishment if a child was hurting or being aggressive towards them $(18.6 \%)$ or another child $(19.3 \%)$. A further $20 \%$ of parents stated that child aggression directed at the parent might elicit a physical punishment response, while $36.7 \%$ indicated that child aggression directed at other children might elicit such a response.

Disobedience or playing with something forbidden also emerged as being likely to elicit a physical punishment response. According to $13.5 \%$ of parents, situations where children were disobedient were likely to elicit physical punishment. A further $42.6 \%$ reported that disobedience might lead them to choose such a coercive strategy. One-quarter of parents (24.7\%) indicated that they would be likely to use this punishment in response to a child playing with something forbidden, while a further $26.5 \%$ indicated that they might adopt this discipline strategy for such an incident.

Figure 26: Likelihood of different child behaviours eliciting physical punishment responses by parents, for children older than 5 years (\% of parents)

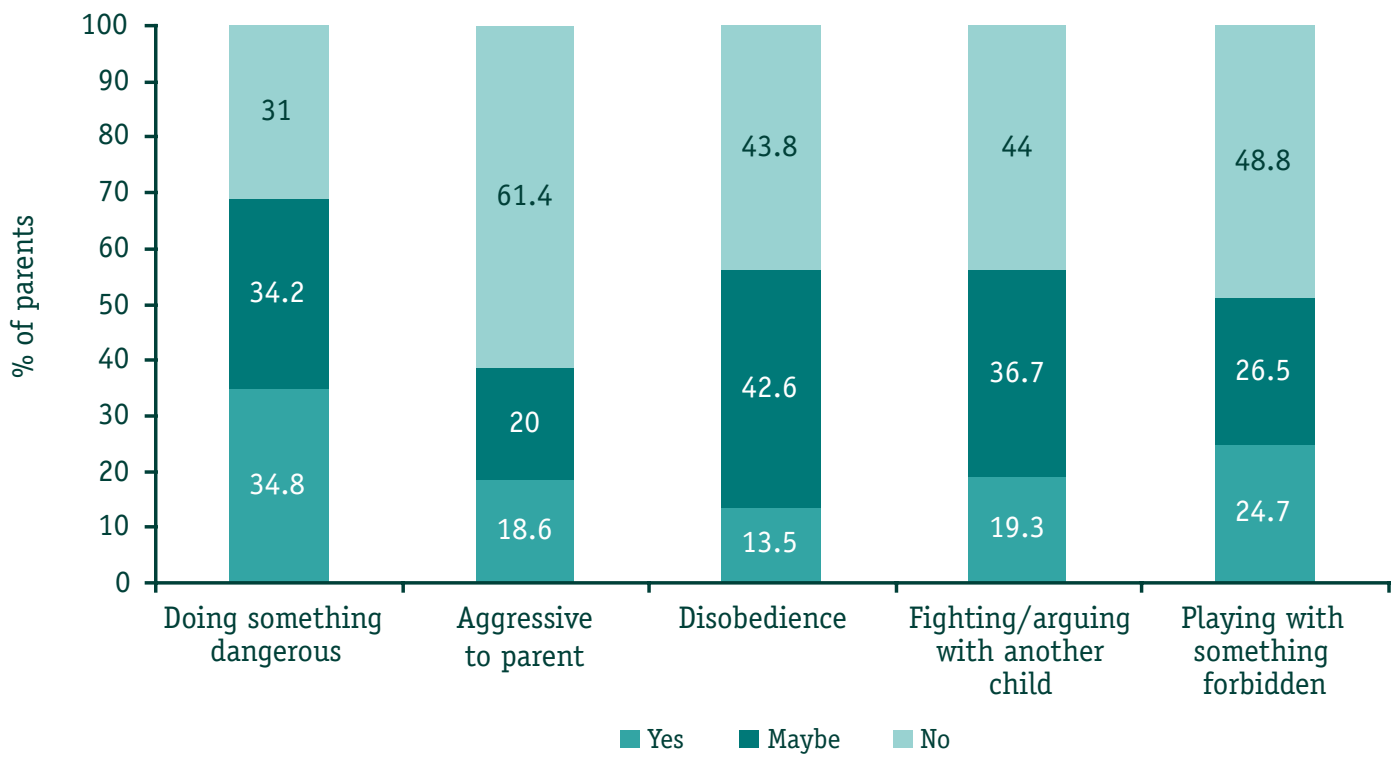

As was the case with parents of children younger than 5, behaviours such as being noisy, making a mess, being careless with things, demanding parental attention, not doing his or her best or trying hard enough were not likely to elicit physical punishment responses from parents. Overall, less than $5 \%$ of parents reported that these behaviours would definitely elicit a physical punishment response. Less than $10 \%$ of parents reported that behaviours such as answering back and getting into trouble with people outside would definitely elicit a physical punishment response. 


\section{Parents' emotional responses following the use of physical punishment}

Parents were asked to reflect on the last time they had smacked their child and how they had felt after doing so (see Figure 27 ). The majority of parents (81\%) reported that they felt sorry or guilty for slapping their child. Furthermore, $42 \%$ of parents felt annoyed at their child for driving them to use physical punishment, while a small minority of parents $(5.5 \%)$ said they felt better after slapping their child.

Figure 27: Parents' feelings following the use of physical punishment with their children (\% of parents)

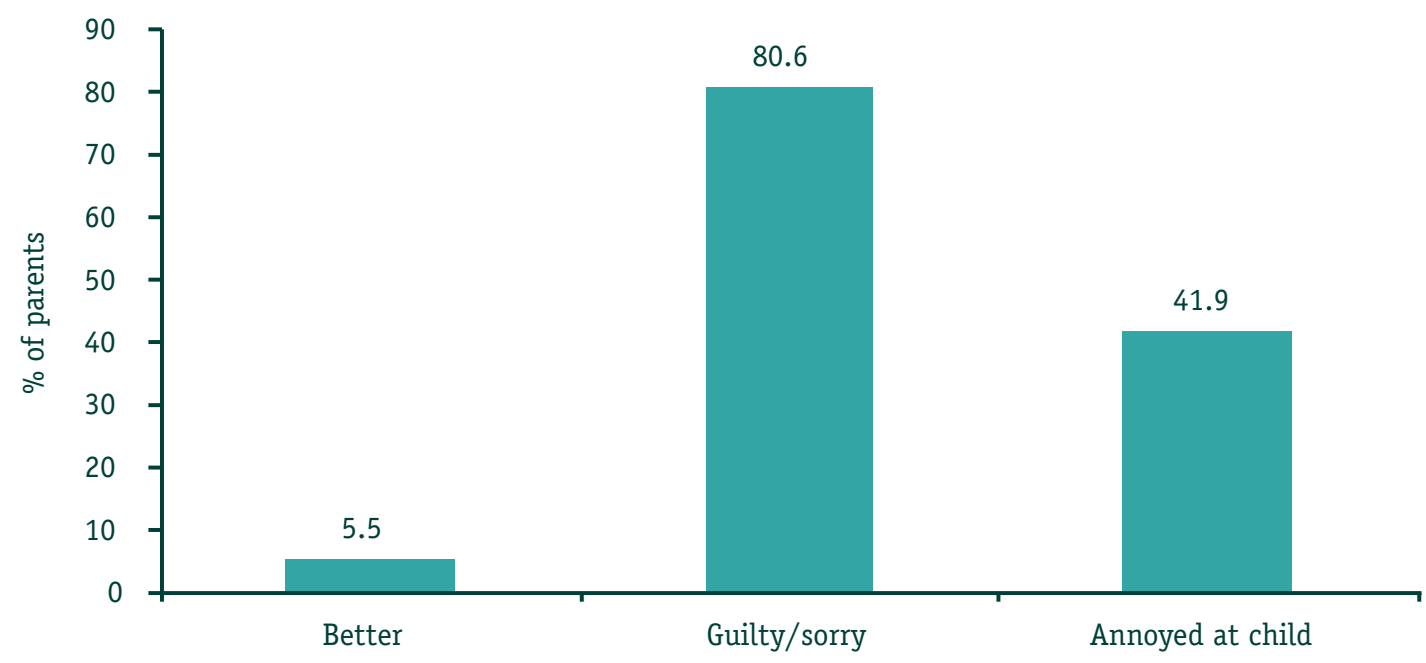

Generally, it appears that most parents are emotionally affected following the use of physical punishment with their children. Moreover, the majority of parents do not feel good following the incident and feelings of guilt or remorse are most common.

\section{Parents' understanding of Irish law in relation to physical punishment}

Parents' attitudes towards legislation on the use of physical punishment were sought. Parents were asked about the extent of their knowledge about the law on physical punishment of children and whether they were aware of any proposed changes to the law. Parents were also asked for their perspectives on how physical punishment by parents should be addressed within legislation (i.e. whether they thought it should be made illegal or not).

In general, findings from the survey indicate that parents lacked clear understanding about Irish law in relation to the physical punishment of children. Over three-quarters of parents admitted that they did not know 'very much' or 'anything at all' about Irish law on physical punishment. Only 16\% of parents stated that they knew 'a great deal' or 'quite a lot' about the law on physical punishment. No social class, education level or age or gender patterns emerged in relation to these findings.

Further evidence of this lack of understanding emerged when parents were asked which of four statements best described the current law in Ireland on smacking children (see Figure 28).

Generally, similar proportions of parents thought that it was not illegal or it was illegal to smack children. One-third of the sample (33\%) stated that they thought it was not illegal to smack a child of any age. In contrast, $28 \%$ thought that it was illegal to smack a child of any age and almost $10 \%$ of parents thought it was illegal to smack a child under a particular age. The remaining $29 \%$ stated that they did not know. 
Figure 28: Statements describing the current law in Ireland on smacking children (\% of parents)

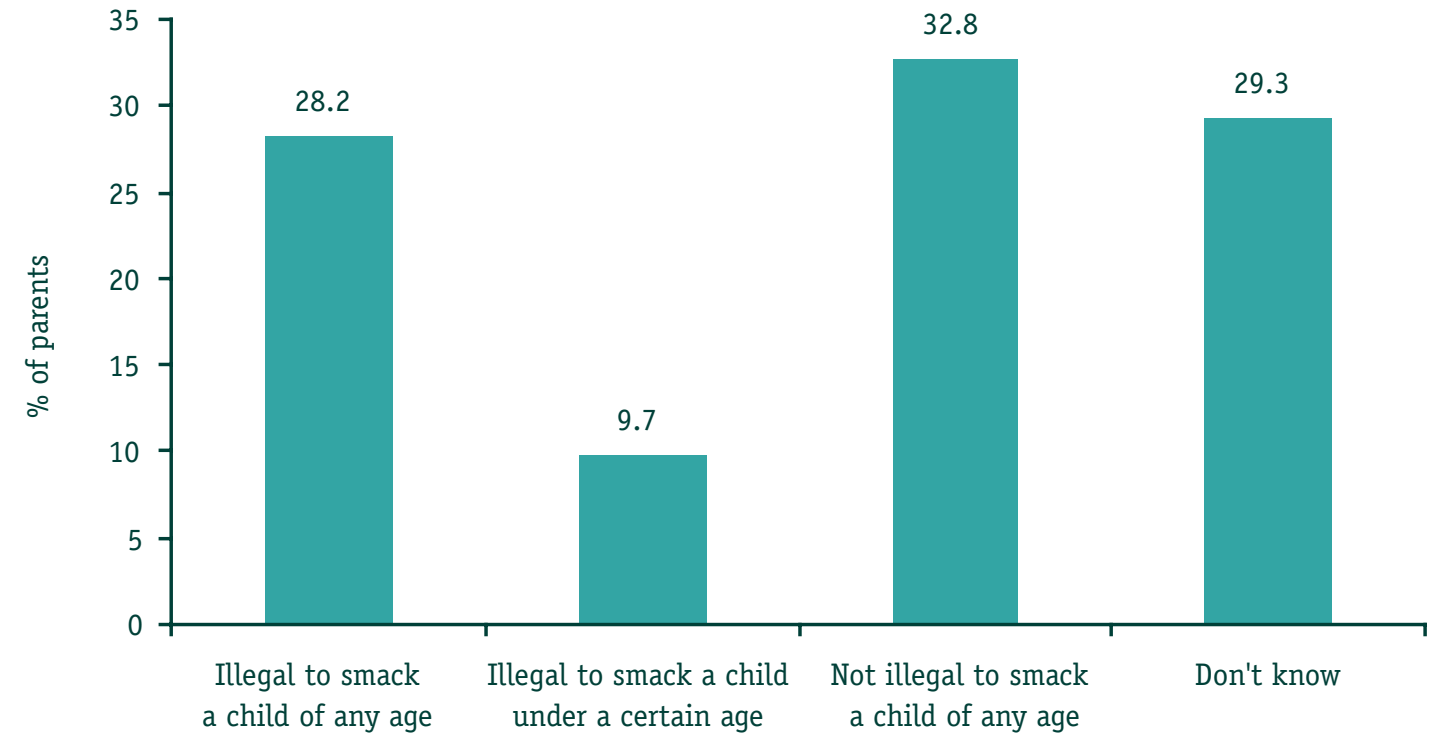

Some differences emerged according to the age of the parent. Younger parents (under 35 years) were more likely to state that they did not know the current law on smacking, while older parents were more likely to state that it is illegal to smack a child of any age. A social class dimension to these attitudes also emerged. Professionals/managers and those who had completed education beyond the Leaving Certificate were more likely to (correctly) believe that it is not illegal to smack a child of any age. However, those parents classified as skilled/unskilled manual and those who had not completed second-level education were more likely to believe that it is illegal to smack a child of any age.

It was clarified to parents that it was currently not illegal in Ireland to smack children, provided excessive force is not used. Parents were then asked whether they were aware of any proposed changes to the law. Overall, $65 \%$ of parents had not heard about proposed changes to the law, $28 \%$ of parents had heard about proposed changes and $6.5 \%$ stated that they did not know. Professionals/managers and those who had completed education beyond the Leaving Certificate were more likely to state that they had heard about proposed changes to the law, while those parents classified as skilled/unskilled manual and those who had left school before completing the Leaving Certificate were less likely to have heard about the proposed changes.

Parents were asked whether they thought it should be made illegal to smack a child. Clear support for an outright ban on physical punishment did not emerge (see Figure 29). Just over one-third of parents $(34 \%)$ felt that smacking should remain legal. Almost one-quarter $(24 \%)$ stated that whether smacking is made illegal should depend on the age of the child, while $42 \%$ said that smacking should be made illegal. Some differences emerged between mothers and fathers: mothers were less likely to state that smacking should remain legal, while fathers were more likely to state that smacking should remain legal. Furthermore, parents who had used physical punishment in the past year were more likely to state that smacking should remain legal. Also, parents who had been smacked themselves in childhood were less likely to state that physical punishment should be made illegal. No education or social class dimensions to these attitudes emerged. 
Figure 29: Responses to whether smacking should be made illegal or remain legal (\% of parents)

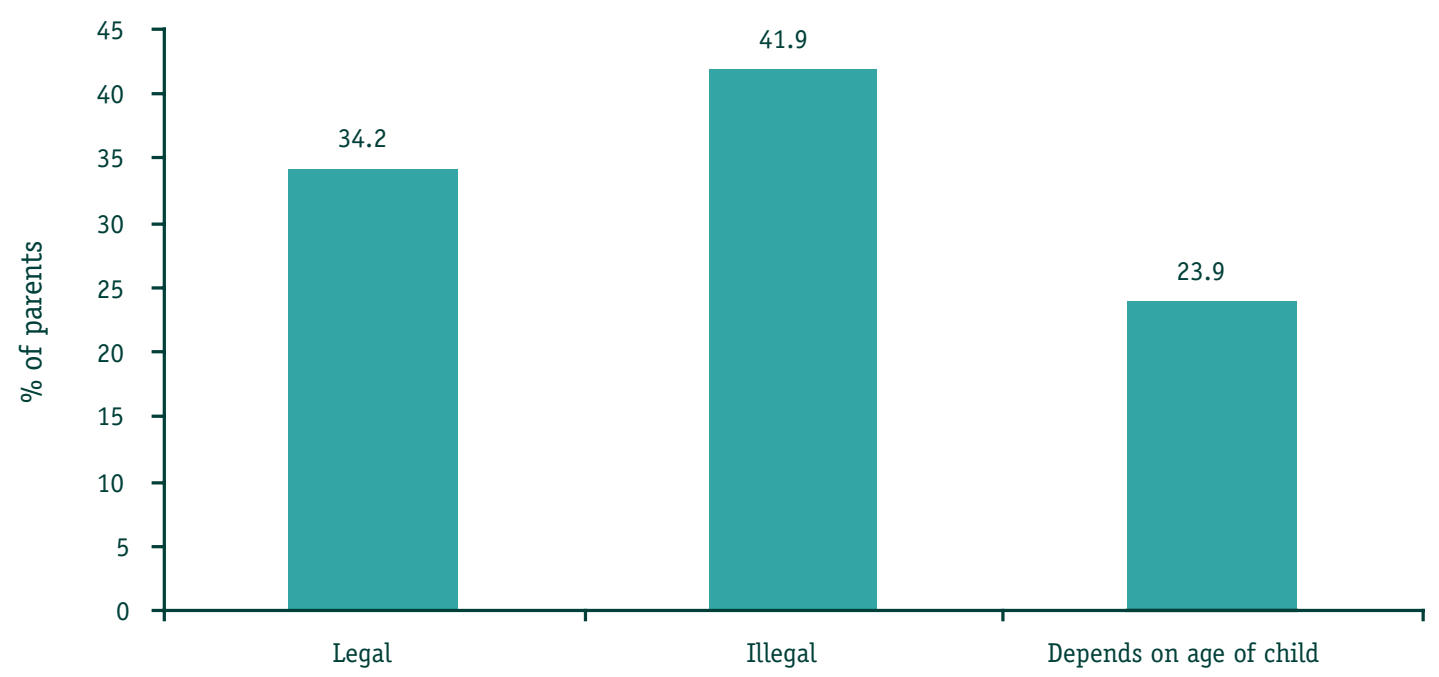

As mentioned above, about one-quarter of parents $(24 \%)$ felt that the law should take account of the age of the child, so that whether smacking is legal or illegal should depend on the age of the child. These parents were further questioned regarding upper or lower age limits at which point it should be made illegal to smack a child. $9 \%$ of these parents felt that there was no lower age limit, while just over $90 \%$ felt that there should be a lower age limit below which it is illegal to smack a child. $86 \%$ of these parents felt that children under 5 were too young to be smacked. The average lower age limit was 3.68 years $(s . d=2.34)$. Figure 30 illustrates the cumulative distribution of lower age limits below which some parents believe smacking should be made illegal.

Figure 30: Cumulative distribution of ages below which parents believe smacking should be made illegal ( $\%$ of parents who believe there should be a lower age limit)

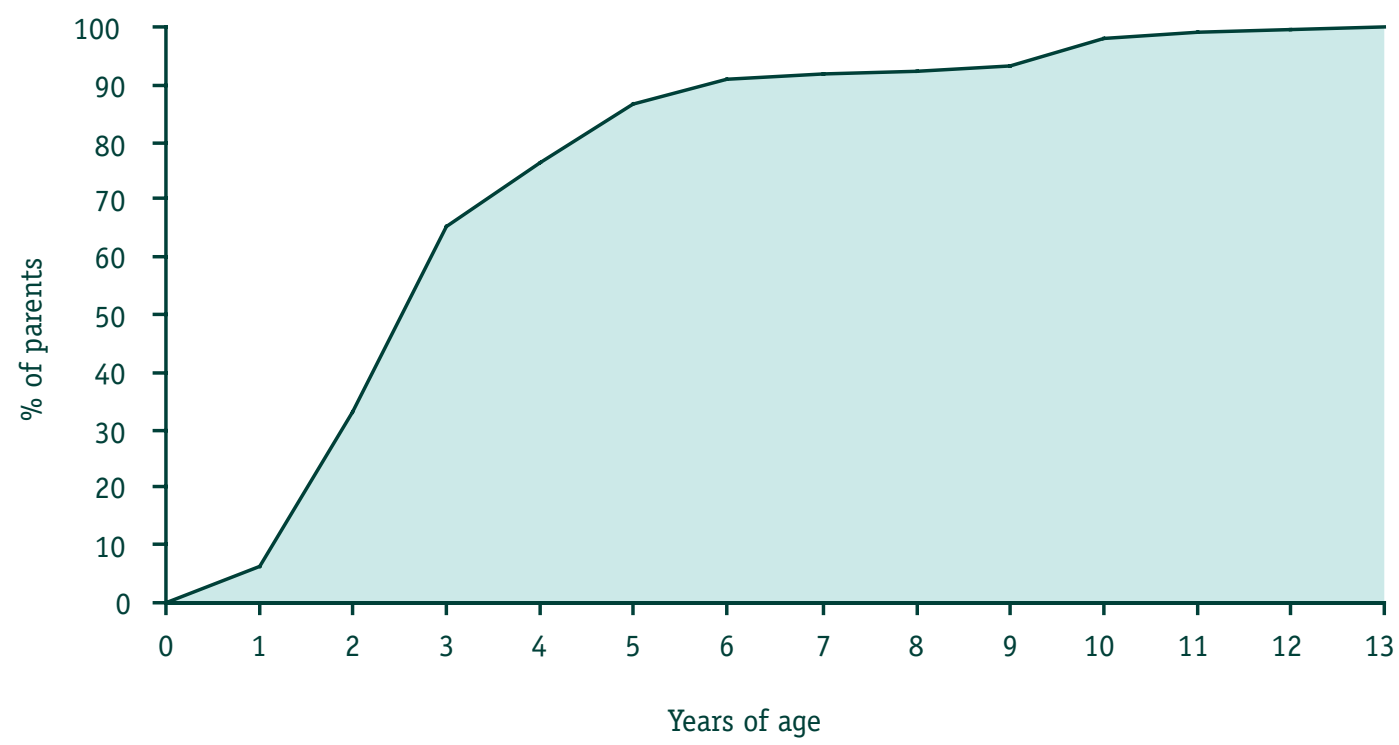

A trend emerged in these lower age limits, where professionals/managers and farmers or those who were self-employed endorsed a significantly younger age limit (3.1 years and 2.9 years respectively) than those classified as skilled/unskilled manual (4.4 years).

In terms of upper age limits, $17 \%$ of parents who believe that the law should take account of the age of the child felt that there should be no upper age limit, while $83 \%$ felt that there should be an upper age limit above which it should be illegal to smack a child. Almost two-thirds of parents $(65 \%)$ felt that children aged 10 and older were too old to be smacked. The average upper age limit 
was 10.28 years (s.d. $=3.45)$. Figure 31 illustrates the cumulative distribution of upper age limits above which parents believe smacking should be made illegal.

Figure 31: Cumulative distribution of ages above which parents believe smacking should be made illegal (\% of parents who believe there should be an upper age limit)

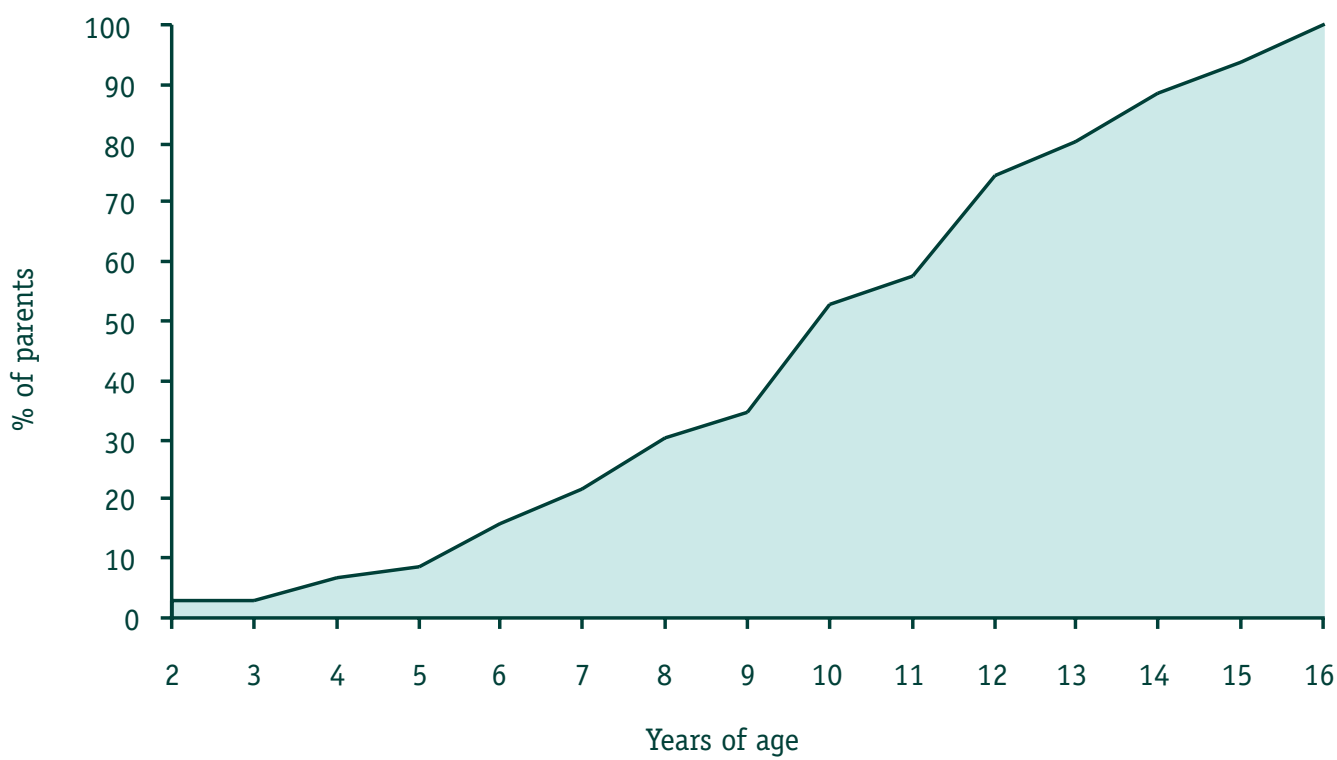

Together, these findings suggest that of those parents who believe that the legality of smacking should depend on the age of the child, the majority reflected that smacking of children younger than 5 and older than 10 should be prohibited.

Finally, it is possible to compare findings from this study based on Irish parents with those of Anderson et al's (2002) similar report on Scottish parents (see Figure 32). It is clear that a smaller proportion of parents in Ireland (34\%) oppose an outright legal ban on physical punishment compared to Scotland $(41 \%)$, while a much higher proportion of parents in Ireland $(42 \%)$ would support the legal prohibition of physical punishment compared to Scotland (14\%).

Figure 32: Comparison of responses to whether smacking should be made illegal or remain legal between Irish and Scottish studies (\% of parents)

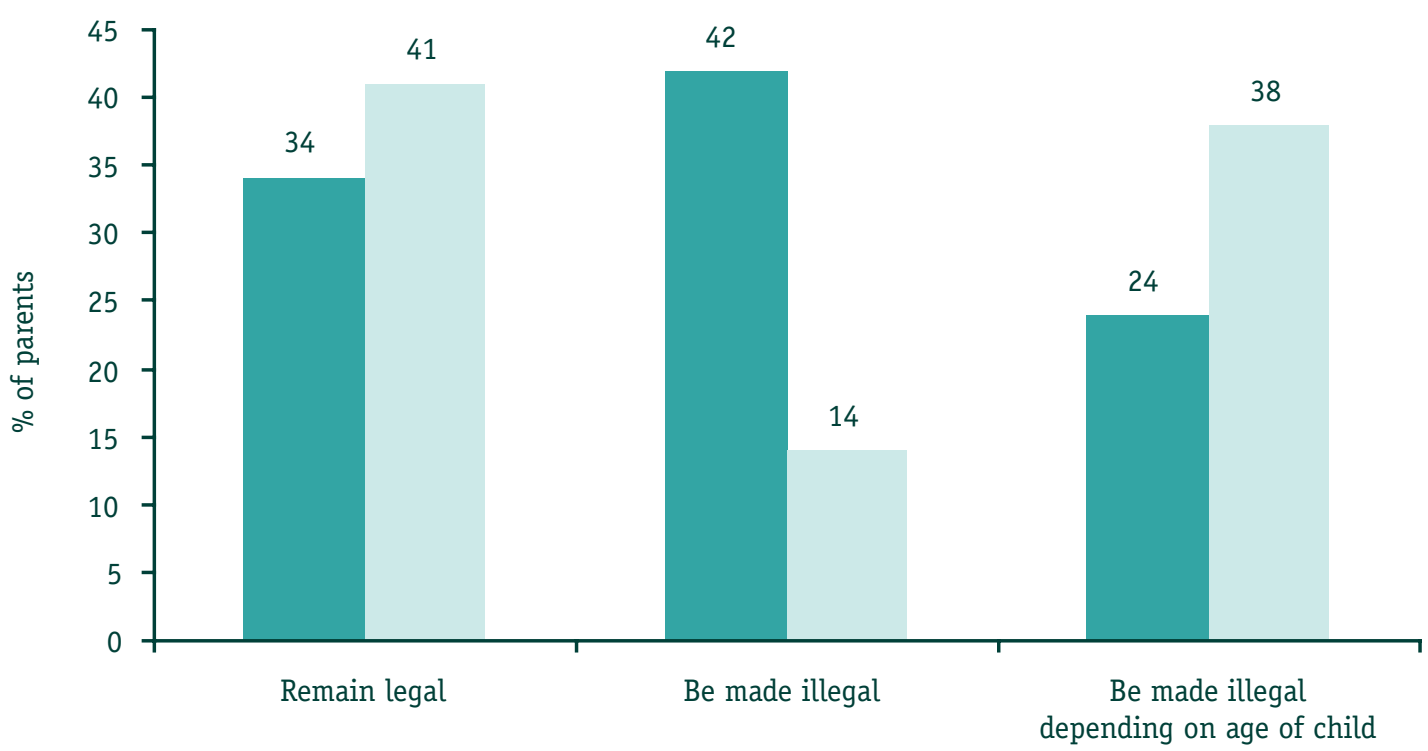

Irish study Scottish study 


\section{Key findings}

Findings presented in this chapter provide an overview of the attitudes relating to physical punishment held by parents in Ireland. Insight is provided into the contexts in which physical punishment is more and less likely to occur, together with the rationales that parents use to endorse their use of physical punishment.

Key findings are:

- No clear consensus emerged in terms of parents' attitudes towards smacking children. On the one hand, the majority of parents believed that the odd smack does not do a child any harm. On the other hand, the majority also believed that it is not necessary to use smacking to bring up a well-behaved child. However, in general, equal proportions of parents agreed and disagreed that smacking can damage the parent-child relationship, that smacking is necessary as a last resort and that children who are smacked are likely to be more aggressive.

- Similarly, there is no clear consensus on the effectiveness of physical punishment as a discipline strategy. Half of parents reflected that physical punishment is effective in stopping misbehaviour at the time, while a slightly lower proportion believed in its effectiveness in preventing future misbehaviour.

- There was a clear association between beliefs in the effectiveness of physical punishment and parental use of physical punishment in the past year. Those who believed in the effectiveness of physical punishment were more likely to have used it as a form of discipline in the past year.

- Clearer patterns of consensus emerged in terms of the justifications for physical punishment that parents rejected or endorsed. The majority of these parents did not endorse rationales underpinned by domination or coercion, such as letting off steam, acting without thinking or letting a child know who is boss. The rationale most strongly endorsed by parents was where a child was perceived to be in danger and, less commonly, to stop bad behaviour quickly or to emphasize the seriousness of what the child had done.

- In support of these findings, contexts most likely to elicit a physical punishment response among parents who use physical punishment included situations where the child was in danger, was being aggressive or was being deliberately defiant or non-compliant.

- It appears that parents were emotionally affected following the administration of physical punishment. Feelings of guilt and remorse were most common and only a minority of parents (5.5\%) professed that they felt better after using physical punishment.

- Parents lacked a clear understanding about Irish law in relation to physical punishment. Similar proportions of parents believed that it was illegal or not illegal to smack a child. Some parents believed that the illegality of smacking depended on the age of the child. The majority of parents believed that children younger than 5 years were too young to be smacked, while almost two-thirds of parents felt that children aged 10 and older were too old to be smacked.

- Clear support for a proposed outright prohibition of physical punishment did not emerge, with similar proportions of parents reflecting that smacking should remain legal or be made illegal. Parents who had used physical punishment in the past year were more likely to reject a proposed legal ban on physical punishment. Fathers were also more likely than mothers to reject such a proposed ban.

\section{Discussion}

One resounding message to emerge from this part of the study is the ambivalence in attitudes towards physical punishment among Irish parents. While the majority of parents agreed that smacking is not necessary to bring up a well-behaved child, over half of parents also reflected the view that an odd smack does not do a child any harm and parents should have the right to use smacking if they wish. Thus, smacking is not deemed to be an essential aspect of effective parenting, yet many parents believe that smacking should be a parent's right. These seemingly opposing viewpoints reflect the complexity of parents' attitudes towards physical punishment. The 
extent to which the lack of consensus in attitudes towards physical punishment among parents in Ireland is influenced by specific features of the Irish context is an important question. A recent review by Gracia and Herrero (2008) found higher levels of acceptability for physical punishment among parents in countries with no legal prohibition against physical punishment and findings from the present study support this trend. Similarly, also in line with this review and other research (e.g. Anderson et al, 2002), social class trends emerged in the present study, with higher levels of acceptability of physical punishment among those from lower socio-economic groups.

Attitudes to physical punishment also appeared to be closely aligned to parents' use of physical punishment. Thus, those parents who reported using physical punishment in the past year were more likely to believe in its effectiveness and more likely to hold attitudes that endorsed physical punishment. Similar findings have emerged from Ghate et al's (2003) study among parents in England. However, given the lower incidence of physical punishment among parents in Ireland (when compared with the incidences reported in recent UK-based studies), the relatively large proportions of parents who display attitudes that do not oppose physical punishment is surprising. Parents' childhood experiences of discipline and physical punishment may play a role in explaining these trends. Findings detailed in Chapter 6 indicated that many more parents experienced physical punishment when they were children than use it now with their own children. Thus, while parents may choose not to use physical punishment, their childhood experiences may lead them to believe that an odd smack does no harm.

Findings pertaining to the contexts in which physical punishment is likely to occur are similar to those emerging from other research. Contexts of danger, as well as behaviours such as aggression and repeated disobedience, were most likely to elicit physical punishment responses from parents. Similarly, Smith et al (2005) reported on studies that found that situations of danger and those that challenge parents' authority were most likely to evoke a physical punishment response from parents. Parents in the present study did not support reasons for using physical punishment that invoked parental emotional responses (such as letting off steam) or lack of control (such as automatic response). Nor did parents support the use of physical punishment when children were not deliberately defiant. However, parents' emotions and attributions did emerge as likely features of physical punishment incidents: parents reported that the likelihood of using physical punishment with their children increased when they were feeling a loss of control of the situation, tired or stressed. Anderson et al (2002) reported similar patterns among Scottish parents.

Findings reported in this chapter reveal a lack of clarity about Irish law in relation to physical punishment of children. Over one-third of parents incorrectly believed that it is illegal to either smack a child under a certain age or to smack a child at all, while one-third of parents correctly believed that smacking is not illegal. No clear patterns in beliefs about legality emerged according to whether parents actually used physical punishment. This suggests that behaviour is not directly linked to understanding about the law. These findings can be compared with those reported by Anderson et al (2002) who asked similar questions of parents in Scotland: a similar proportion of parents in Scotland (about 33\%) also believed that it is not illegal to smack a child, while a higher proportion of parents in Scotland (about 50\%) believed that smacking a child under a particular age, or at all, is illegal.

Exploration of parents' attitudes towards a proposed legal ban on physical punishment in Ireland highlighted that parents did not widely endorse such a prohibition. One-third of parents felt that smacking should remain legal in Ireland. However, $42 \%$ of parents stated that they would support a ban on physical punishment, a much higher proportion than that found in the Scottish study where only $14 \%$ of parents stated that they would support prohibition of smacking children of any age (Anderson et al, 2002). However, the majority of parents in both studies felt that children under the age of 5 are too young to be smacked. 


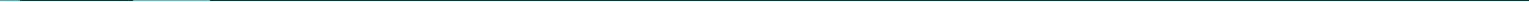




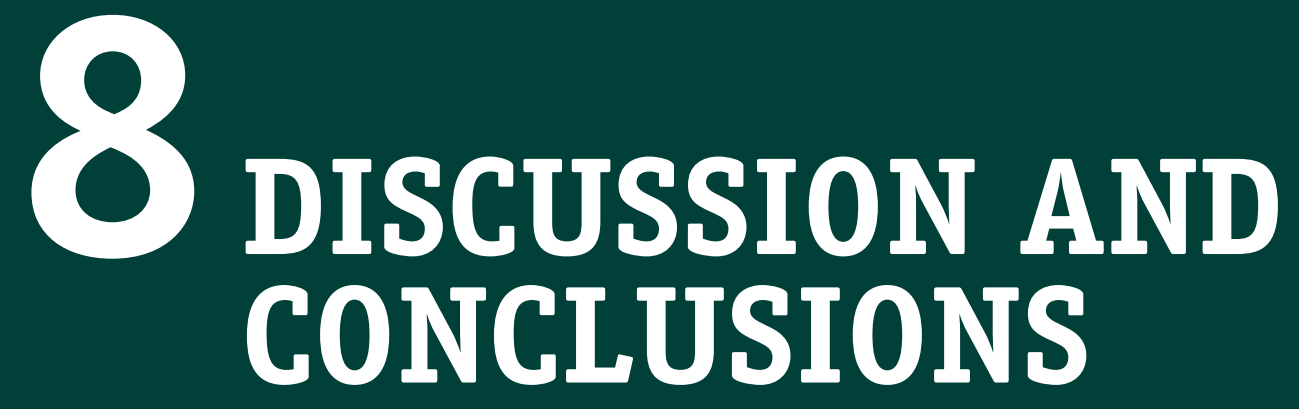


Parenting styles, behaviours and discipline practices have elicited attention, debate and investigation across sociological, socio-legal and psychological disciplines. Parke (2002) highlights the extent to which investigations into the effects of parenting practices involve a particularly challenging domain of study. Key shortcomings identified include weak assessment instruments, lack of knowledge of contextual variables and neglect of child's temperament and difficultness (Collins et al, 2000). Moreover, inherent in much of the prior research on parenting, discipline and physical punishment are simplistic and deterministic views of parental influence, which fail to adequately emphasize the role of child effects on parenting behaviours.

The present study involved a national survey of attitudes and practices related to parenting styles and parental discipline in Ireland, using parental self-report data. Parents' own recollections of discipline experienced in childhood were also explored. Finally, parental attitudes to and rationales for the use of physical punishment were examined, concluding with an investigation into awareness of and attitudes to current and proposed legislation on physical punishment.

\section{Parenting and discipline in context}

As previously outlined, parenting does not occur in a vacuum, but rather evolves within specific social and cultural contexts. To gain insight, therefore, into the complex array of factors influencing parenting styles and discipline responses, it is necessary to be mindful of the influences surrounding these practices and to consider the potential impact of the environment on parent and child behaviours (Grogan-Kaylor and Otis, 2007; Giles-Sims et al, 1995). Bradley and Corwyn (1999) draw attention to the economic, demographic and technological changes that have profoundly altered 'the landscape of parenting' in contemporary society. Determining the significance of any aspect of parenting requires, therefore, some understanding of the broader context in which parenting practices evolve. To this end, contextual information related to parental views on a variety of aspects of contemporary parenting was gathered in the present study, with a particular focus on perceptions of the extent to which parenting has changed, key concerns impacting on the parenting role, child-rearing values and goals of parents, and aspects of parenting experienced as pleasurable by parents.

The majority of parents asserted the view that parenting had changed substantially over the past 20 years. Such a view is broadly in keeping with previous research findings in an Irish context in which parents identified a significant change in the extent to which parental authority and the parental role is supported by society, when compared with parents a generation ago (Daly, 2004). Moreover, balancing family and work commitments represented a more significant pressure on parenting, when compared, for example, with parents in a similar study in Scotland (Anderson et al, 2002). Specifically, almost three-quarters of parents indicated the significance of work-life balance issues compared to just one-third of parents in the Scottish study. Anderson et al (2002) point out that although there is broad consensus that pressures on contemporary parents are greater than in the past, this does not mean that such pressures are experienced in a similar way across different groups, nor even within individual family units. However, little variation in the extent to which pressures were experienced by gender, social and occupational status of parents was noted in the present study. An offset to the perceived pressure on parents reported in the present study was the high level of reported spousal or partner support experienced by parents, in keeping with research which prioritises the role of spousal support in facilitating more positive experiences of parenting (Soriano et al, 2001). Parental perceptions of the increase in pressures on contemporary parenting roles were also counterbalanced with the positive responses generated through an exploration of aspects of parenting considered most enjoyable.

\section{Parenting styles and discipline strategies}

For the first time in an Irish context, the present study gained an insight into the styles of parenting adopted by parents with children in Ireland. The findings clearly point to a dominance of an authoritative style of parenting among parents in Ireland. Less frequently, parents engaged in behaviours that characterise an authoritarian style of parenting. Echoing this trend was the relatively 
Low levels of physical punishment reported by parents, with parents relying more on inductive forms of discipline. In contrast with previous research, no clear trends in parenting styles emerged according to socio-economic status or education level of parents. Generally, the research has found that children from different socio-economic strata experience different parenting. Hoff et al (2002), in their review of a range of studies, found that parental education is positively correlated with authoritative parenting and negatively correlated with authoritarian parenting. The findings from the present study - that no clear differences in parenting style emerged according to parental education or socio-economic status - are somewhat at odds with other research in this area. Hoff et al (2002), however, have suggested that the relationship between socio-economic status (SES) and parenting styles is a complex one and that some aspects of parenting may be more susceptible to the influence of SES than others. Low SES may indeed be a risk factor for less than optimal parenting, but low SES may be neither a necessary nor sufficient cause for poor parenting.

In line with recent theoretical developments in parenting (e.g. Lerner et al, 2002; Teti and Candelaria, 2002), the importance of the characteristics that the child brings to the parenting system was apparent. For example, systematic variation in parenting styles emerged in the present study as a feature of children's age. Parents of younger children engaged in disciplinary strategies that relied less on verbal communication (such as induction and reasoning and verbal hostility) and more on physical action (such as corporal punishment), while the reverse patterns were observed for parents of adolescents. Some associations between parenting behaviour and children's temperament and difficult behaviour also emerged, which supports previous research in this area (Teti and Candelaria, 2002). It is likely, however, that these associations are complex and reflect ongoing transactional effects operating in families (Patterson and Fisher, 2002).

Parenting discipline behaviours reviewed and reported in the present study may best be understood and evaluated within a theoretical framework that emphasizes the particular principles and processes associated with inductive, power-assertive and love-withdrawal discipline strategies. Drawing on the self-report data of parents, the discipline strategies adopted by Irish parents tapped into three discrete behavioural practices among parents - non-aggressive discipline strategies, psychologically aggressive discipline strategies and physical punishment. Non-aggressive discipline strategies broadly correspond to inductive types of parenting responses, implying greater reliance on verbal reasoning and explanation (Hoffman, 2000; Grusec and Goodnow, 1994). On the other hand, psychologically aggressive strategies and physical punishment responses can be likened to power-assertive strategies, which rely to a greater extent on coercive tactics in order to achieve child compliance.

Non-aggressive, inductive discipline strategies were used most frequently by the majority of parents in the present study, with almost all parents reporting the use of such strategies in the past year. These findings resonate with recent UK studies, where specifically $88 \%$ of parents in Scotland indicated that they had used inductive strategies, such as verbal reasoning, with children in the past year (Anderson et al, 2002) and 95\% of parents in England reported non-aggressive discipline strategies as the most common form of discipline response with children (Ghate et al, 2003). Most pervasive across all categories of strategy in the present study was that involving discussion with a child, implying some degree of communication and verbal reasoning in response to disciplinary incidents. Almost all parents reported using this strategy with their child in the past year and this was with reference to all age groups of children, from early childhood through late adolescence. Nevertheless, developmental competencies of children influenced the extent to which verbal reasoning strategies were used, with children under 5 years less likely to be disciplined in this way and children in middle childhood and early adolescence most likely to experience this type of strategy. Allied to the use of verbal reasoning strategies, a relatively high proportion of parents $(60 \%)$ reported telling their child that they had made them sad, a strategy likely to facilitate children's greater understanding of the impact of their behaviour on others (Kerr et al, 2004).

Two issues are worth emphasizing when considering the implications of the predominance of inductive strategies in the present study. First, as outlined in Chapter 2, these inductive styles of discipline have been found to be more effective in promoting children's internalisation 
of moral and social values, and enhancing empathic capacities in children (Kerr et al, 2004; Hoffman, 2002). In particular, discourse and dialogue facilitate the co-construction of meaning between children and their care-givers during disciplinary encounters, thereby influencing the understandings which children internalise about their parents' goals, wishes and intentions (Tomasello, 1999; Smith et al, 2005). Greater use of inductive strategies such as verbal reasoning, as reported by parents in the present study, are associated with greater social and emotional competence in children (Kuczynski and Hildebrandt, 1997). The predominant use of these strategies in the present study is, therefore, worth noting.

A second issue to consider, however, is that any potential effects of these inductive strategies on children's development can only be assessed accurately with reference to more detailed information on their co-occurrence with other inductive and more coercive parental discipline strategies. Such precise information is not available to us in the present study. Further research investigating in greater depth the particular contexts surrounding the use of all discipline strategies would be useful in gaining a more informed insight into the precise effects of these discipline responses.

Other non-aggressive strategies used relatively frequently by parents included time-out and grounding a child, incidences of which were slightly higher than those reported in the Scottish study (Anderson et al, 2002). No gender effects of either parent or child were identified with regard to the use of inductive strategies and responses were also equally distributed across all socio-economic groups.

Psychologically aggressive discipline responses were used relatively infrequently in the present study, with a majority of parents reporting they had never used these strategies with their children in the past year, consistent with findings in the Scottish study (Anderson et al, 2002). These strategies correspond broadly to more coercive, power-assertive discipline techniques, which rely to a greater extent on inducing fear or anxiety in order to achieve compliance. Most prevalent among this category of response in the present study were shouting or yelling at a child and threatening to smack a child (used by $48 \%$ and $27 \%$ of parents respectively). Threats tended to be used more frequently with children in middle childhood, while older adolescents were more likely to be insulted (e.g. being called stupid or lazy), according to parental self-reports. Least commonly reported among psychologically aggressive discipline strategies were love-withdrawal responses, with a very small minority of parents reporting their use. Fathers were also less likely to use certain psychologically aggressive strategies than mothers. No significant effect of social class or educational level was evident.

Implications of these findings for child outcomes again warrant consideration of the individual contexts in which they occur. Broadly speaking, coercive, fear-inducing strategies, such as the psychologically aggressive strategies reported in the present study, are less likely to enhance a child's ability to develop internal attributions for his or her behaviour (Kerr et al, 2004). Nonetheless, some developmental psychologists (Hoffman, 1994; Larzelere, 1996) argue that a combination of power-assertive and inductive disciplinary techniques can encourage moral internalisation. Hoffman argues that discipline should produce an optimal level of arousal in a child, since a low level may result in the child ignoring the parental message. However, it is not possible to accurately assess or even make suggestions regarding the effectiveness of these strategies in the present study. The relatively infrequent use of such power-assertive strategies with children among Irish parents is, nevertheless, worth noting and compares favourably with the reported incidence of psychologically aggressive strategies in the UK (Anderson et al, 2002; Ghate et al, 2003). The notably low incidence of love-withdrawal as a parental discipline strategy in the present study is also worth highlighting, given its association with low self-esteem in children and higher risks of mental health problems as identified by Heaven and Goldstein (2001).

Parental use of physical punishment according to self-reports was relatively low in the present study, with $25 \%$ of Irish parents reporting the use of some form of physical punishment with their children in the past year, compared with $51 \%$ of parents in Scotland (Anderson et al, 2002) and $58 \%$ of parents in England (Ghate et al, 2003). Types of physical punishment examined in the 
study ranged from what some theorists have labelled customary physical punishment (Holden, 2002; Larzelere, 2000) involving slapping or smacking a child, to more severe physical punishment involving hitting a child with an instrument or kicking and knocking over a child. While the overall incidence of physical punishment in the present study was low, parents were more likely to use less severe, customary physical punishment, such as smacking a child on the bottom, hands, arms or legs.

A broad array of factors has been identified as associated with the use of parental physical punishment (Pinderhughes et al, 2000; Kanoy et al, 2003; Dietz, 2000). A key factor associated with higher rates of physical punishment in the present study was child age, with younger children, specifically aged 2-9, most likely to be punished physically. These findings are broadly in keeping with previous research findings, which suggest that parents tend to view physical punishment as most appropriate for children of pre-school age and least appropriate for infants (Day et al, 1998; Flynn, 1998). Similarly, in the present study a substantial majority of parents held the attitude that physical punishment was less appropriate for children under 5 years of age, with almost all parents indicating that it was less appropriate to use with children in infancy. It should, however, be highlighted that despite this finding, $13 \%$ of parents of infants in the present study indicated that they had used physical punishment with their child in infancy in the past year. Child age effects on the use of physical punishment in the study are broadly consistent with studies in the UK (Ghate et al, 2003; Anderson et al, 2002) and Canada (Clement et al, 2000), where parental use of physical punishment as a discipline response is most common among children of toddler and pre-school age. The combination of higher levels of activity and impulsivity attributed to this age range and the more limited understanding of harm and danger displayed by young children (Durrant, 2005) may explain the high frequency of disciplinary incidents using physical punishment reported for this age group. However, it is also worth highlighting that children in middle childhood (aged 5-9) in the present study were only marginally less likely to experience physical punishment than children in early childhood (aged 2-4).

Although a wide range of family and individual characteristics has been found to be associated with the use of physical punishment in previous research (Smith et al, 2005; Gershoff, 2002; GroganKaylor and 0tis, 2007), few significant effects of these characteristics, apart from child age effects, were identified in the present study. Ghate et al (2003) in a similar study in England reports that once overlap between factors is controlled for, a relatively small group of demographic factors are independently associated with different patterns of child discipline. Younger parents in the present study, specifically parents aged under 35, were more likely to adopt physical punishment as a discipline response with their children and this is consistent with other research findings (Ghate et al, 2003; Grogan-Kaylor and 0tis, 2007). One explanation for this may be that increased incidence of the use of physical punishment by younger mothers may be confounded with their lack of experience with children (Culp et al, 1999). Younger parents are more likely to have younger children and the patterns of effects may, therefore, be influenced more by child age than parent age. No effects by gender of parents were reported in the present study, in contrast with other studies where mothers have been reported as being marginally more likely to engage in most discipline strategies (Anderson et al, 2002; Straus and Stewart, 1999). However, the absence of an effect by gender of parents identified in the present study is in keeping with findings across a number of other studies (Hemenway et al, 1994; Murphy-Cowan and Stringer, 1999; Nobes et al, 1999).

Family process variables have also been examined in previous studies and associations between higher levels of inter-parental conflict and physical punishment have been identified (Dadds et al, 1990; Pinderhughes et al, 2000). Related to this, Ghate et al (2003) found that having an unsupportive partner was associated with the use of physical punishment of children among English parents. No effect by support of partner was identified in the present study and this is most likely explained by the high levels of partner support reported by parents in the present study.

As previously outlined, the incidence of physical punishment reported in the present study compares very favourably with previous studies that have attempted to estimate the extent to which parents use physical punishment (Ghate et al, 2003; Anderson et al, 2002). A small-scale 
study carried out in Northern Ireland estimated that $87 \%$ of parents had ever used mild forms of physical punishment with their children (Murphy-Cowan and Stringer, 1999). Studies carried out internationally in Canada and New Zealand also report higher levels of physical punishment than the present Irish study (Clement et al, 2000; Fergusson and Lynskey, 1997). However, the complexities of accurately assessing the incidence of physical punishment and the variety of methodologies adopted to examine this issue make it difficult to compare findings across studies.

As with findings reported for non-aggressive and psychologically aggressive discipline strategies, it is not possible to draw any conclusions with regard to the implications of these findings for child outcomes. Similar to findings from research on psychologically aggressive strategies, physical punishment used as a parental discipline response has been associated with generating higher levels of fear and anxiety in children and providing a model of aggression for child behaviour (Hoffman, 1983 and 2000; Kochanska and Thompson, 1997). Moreover, in contrast to inductive non-aggressive strategies, physical punishment typically promotes children's external attributions for their behaviour and minimises their attributions to internal motivations (Hoffman, 1983; Lepper, 1983). However, the extent to which these effects operate in the present study is dependent on the complex interplay of individual parent-child relationships and the constellation of factors surrounding the disciplinary incidents in which these physical punishment responses occur. Further research to explore these patterns of child-rearing practices in an Irish context would therefore be valuable.

Finally, the findings from the present study are broadly consistent with previous research in this area, with regard to the predominance of inductive non-coercive discipline strategies among parents, the associations between child age and the use of physical punishment, and trends over time and across generations related to the use of physical punishment. However, certain findings are not in keeping with those recorded in previous studies and it is worth considering possible reasons for this disparity. The low incidence of physical punishment in the present study, when compared with similar studies in the UK, may be explained to some extent by the fact that these UK studies were carried out some 7 years ago. Parenting attitudes and behaviours may, therefore, be susceptible to influence and alteration over time, especially given the ongoing public debate in Irish society about issues of child protection and child abuse. Durrant (2006) draws attention to the challenges involved in measuring incidence of physical punishment due to differences in study samples, research instruments and other methodological issues (see Chapter 3 for further detail). Durrant further highlights the importance of cultural, economic or political events (such as unemployment rates, legal reforms, housing shortages) to the incidence and prevalence of physical punishment. It is possible that such factors may contribute in some way to the differences between the findings of the present Irish study and previous research in the UK. In contrast to some previous research, few differences were identified with regard to the use of physical punishment and socio-economic background in the present study, although differences were more apparent with regard to attitudes to physical punishment. As previously outlined, however, while low socio-economic status may be a risk factor for less than optimal parenting, it may not necessarily be a risk factor for parental use of physical punishment. Cultural differences are also worth noting, with extended family involvement in Irish family settings possibly providing the potential for greater support to families parenting under stress.

\section{Intergenerational continuity and change in discipline strategies}

A tendency toward intergenerational transmission of aggression in family relationships is evident, with previous studies indicating a strong tendency for parents who were physically punished to continue the practice with their own children (Holden et al, 1997; Simons et al, 1991). As highlighted in Chapter 6 , it is necessary to be cautious when estimating any association between parental recollections of the prevalence of discipline strategies during their own childhood and the incidence of discipline strategies reported by parents in the past year with their children. Some associations were identified in the present study suggesting the potential influence of childhood experience on current practice of physical punishment with children. For example, parents who had been slapped or hit with an instrument in childhood were more likely to use 
physical punishment currently with their own children. Moreover, childhood experiences of being slapped were associated with greater resistance from parents to prohibiting physical punishment in law. These findings resonate with findings in previous research, where a temporal link between childhood experiences of physical punishment and subsequent endorsement of physical punishment as a discipline strategy was identified (Deater-Deckard et al, 2003; Anderson et al, 2002; BowerRussa et al, 2001). It should be highlighted, however, that the majority of parents in the present study who reported having experienced physical punishment in childhood did not use physical punishment with their own children and this lends support to the notion that cycles of intergenerational transmission of parenting behaviours and discipline strategies can be altered and patterns of behaviour are not solely determined by past experience.

Overall, patterns in findings suggest substantial change over time and across generations in the type and frequency of discipline response adopted by parents in the study. Inductive nonaggressive strategies, specifically parents engaging in verbal reasoning with a child as a discipline response, showed some increase over time, with approximately $25 \%$ more parents now using this strategy with their own children than recalled in childhood experiences. A comparison of childhood and current discipline strategies also indicated changes in the use of psychologically aggressive discipline strategies: these occurred much less frequently in current parenting practices, with the majority of parents interviewed reporting that they had never used these strategies in the past year, even though up to half of them had experienced many of these more coercive discipline responses in their own childhood. Love-withdrawal strategies, such as refusing to speak to a child or telling a child that you did not love them, were also reported substantially less frequently in contemporary parenting practices when compared with parental recollections of discipline practices experienced in the past.

Trends in parental use of physical punishment over time and across generations also denote a shift away from coercive power-assertive discipline responses, with $80 \%$ of parents recalling incidences of being slapped in childhood compared to $15 \%$ of parents reporting slapping their child in the past year. A similar shift away from coercive power-assertive discipline strategies over time and across generations was noted in recent UK studies (Ghate et al, 2003; Anderson et al, 2002). These findings challenge, to some extent, the notion that experience of physical punishment predicts the frequency of its use with children across generations. Consistent, to some extent, with findings in the present study, a previous study carried out in Northern Ireland found that parents who had reported experiencing high frequencies of physical punishment in childhood reported using lower levels of such a discipline response with their own children (Murphy-Cowan and Stringer, 1999). However, these findings were only reported for parents in middle-class families, in contrast to the present study where no effect of social class was evident. Findings in the present study support the argument put forward by Smith et al (2005) who maintain that while the intergenerational transmission of physical punishment use is not determined or pre-ordained, experiencing physical punishment as a child has a powerful impact on the parental use of it as an adult, but the cycle of transmission across generations can be altered.

\section{Physical punishment as an adjunct to other discipline strategies}

Findings in the present study support the notion that discipline strategies do not occur in isolation, but rather co-vary or co-occur alongside other forms of discipline response. This was particularly the case with regard to the use of physical punishment by parents, which was used in conjunction with threats, time-out, withdrawal of privileges and, in many cases, alongside more inductive reasoning strategies. The failure to recognise that physical punishment is often used as an adjunct, rather than as an alternative, to other discipline strategies is a significant shortcoming in much research on the effects of physical punishment (Vissing et al, 1991; Larzelere et al, 1998). Parke (2002, p. 597) further points out that punishment is a 'packaged variable that requires unwrapping to isolate the components that account for its effectiveness'. Wissow (2002) argues that children from families in which physical punishment is used as an exclusive means of discipline may have quite different outcomes than children from families in which it is used as part of a wider range of disciplinary practices. Attention has also been drawn to the fact that much of 
the literature exploring the relationship between physical punishment and child outcomes relies on physical punishment as a single disciplinary technique to be examined (Smith et al, 2005; Ritchie, 2002). Such an imbalance in emphasis may contribute to misleading assumptions regarding the effects of physical punishment, and other non-physical discipline strategies, on children's overall development and well-being.

Consistent with findings in the present study, several studies have reported physical punishment being used as an adjunct to, rather than as an alternative to or replacement for, non-physical strategies (Ghate et al, 2003; Hemenway et al, 1994; Socolar et al, 1999). While it was not within the scope of the present study to examine specific details pertaining to the disciplinary incidents reported in the present study, other studies have highlighted associations between the use of physical punishment and more intense cognitive-emotional responses on the part of parents who adopt these strategies (Pinderhughes et al, 2000). These authors draw attention to the fact that, as a group, discipline strategies may vary in the degree to which they draw on reactive or deliberative processes and that both cognitive-emotional processes and underlying beliefs are related to the use of harsh discipline responses. Some evidence for an association between parent emotions and attributions and physical punishment incidents in the present study were highlighted in Chapter 7. However, future research, to include assessment of the deliberation and reactivity leading to particular discipline responses, including both inductive and power-assertive strategies, would contribute to our further understanding of such processes.

\section{Attitudes, acceptance and behaviours}

One clear message to emerge from the present study is the lack of consensus in attitudes towards physical punishment evident among Irish parents. As discussed in Chapter 7, perceptions about physical punishment are rooted within parents' own experiences of being parented, as well as within broader child-rearing values and attitudes about how children should be treated. These perceptions are closely linked to the social and cultural context in which parents are raising their children. That no clear consensus in attitudes emerged among parents suggests that the Irish context is one where there is an acceptability of physical punishment of children and a belief in its effectiveness. These findings concur with a recent review across 14 EU Member States on the acceptability of physical punishment of children (Gracia and Herrero, 2008): results show that in countries with no legal ban on the use of physical punishment of children, which includes Ireland, there are higher levels of acceptability of physical punishment among parents. The review also revealed a social class and an education level dimension to these attitudes, with the general trend being that those from lower socio-economic groups and those who had achieved lower education levels were more likely to agree with attitudes that endorsed physical punishment and less likely to agree with attitudes that espoused the detriments of physical punishment. Similar social class trends also emerged in the Scottish study by Anderson et al (2002). Unlike the Scottish study, however, the present Irish study did not reveal variations in perceptions of effectiveness by the age of the child.

The present study found that attitudes endorsing physical punishment appeared to be closely aligned with its use, a finding also reported in other research (Ghate et al, 2003; Ateah and Durrant, 2005). Parents who had used physical punishment in the past year were more likely to believe in its effectiveness in both stopping misbehaviour at the time and in preventing later misbehaviour. Furthermore, the attitudes of parents who had used physical punishment revealed higher levels of approval than those who had not used physical punishment. Similarly, Ghate et al (2003) reported that parents in England who believed that physical punishment was acceptable were more likely to use it. of course, the nature of this relationship remains unclear: it may be that parents use physical punishment because they believe it is more effective and acceptable, or they may believe in its effectiveness and acceptability as a justification for their use of it. However, given the low incidence of physical punishment in the past year among parents in the present Irish study, the considerable proportion of parents whose attitudes did not strongly oppose physical punishment is surprising. One explanation for this mismatch between attitudes and 
behaviours may be traced back to parents' own experiences of physical punishment during their childhood. A higher proportion of parents experienced physical punishment as children than use it with their own children. Their childhood experiences may contribute to the attitude that an odd smack does no harm or smacking does not damage the parent-child relationship.

Analysis of the contexts in which physical punishment is likely to occur revealed broadly similar findings to what has emerged in previous research. Parents in Ireland indicated that situational contexts, such as danger to the child and the child's non-compliance and aggression, were most likely to elicit a physical punishment response. In contrast, parents generally did not support justifications for physical punishment that reflected parental emotions or lack of control (e.g. letting off steam, last resort or automatic response) or child behaviours that did not involve deliberate non-compliance (e.g. crying, being noisy or making a mess). These findings are consistent with studies reviewed by Smith et al (2005), which found that the most likely behaviours to be dealt with through physical punishment are those that present a danger to the child or others, and those that challenge parental control. In further support of previous research (Anderson et al, 2002; Socolar et al, 1999; Ateah and Durrant, 2005), between one-quarter and half of the parents in the present study reported that they would be more likely to use physical punishment when they themselves were feeling a loss of control over the child or if they were tired, worried, busy or stressed. Thus, parents' emotions and attributions do play a role in physical punishment incidents.

In terms of the emotional reactions of parents following their use of physical punishment, a high proportion reported feelings of sorrow or guilt, a lesser proportion reported feeling angry at their child, and only a small minority reported feeling better following their use of physical punishment. Generally, these trends are similar to those reported by Anderson et al (2002), although the proportion of parents who felt guilty or sorry was substantially higher in the Irish study $(81 \%$ compared with $53 \%$ in the Scottish study). These findings may also highlight the complexity of parental experiences of physical punishment in that there appears to be a mismatch between how parents feel about physically punishing their children (predominantly negative) and how parents think about physical punishment (belief in its effectiveness).

Findings from the present study indicated misperceptions and lack of clarity among parents in Ireland about Irish law in relation to physical punishment of children. This confusion is broadly similar to what Anderson et al (2002) found in Scotland. Three-quarters of Irish parents and $80 \%$ of parents in Scotland stated that they did not know very much or anything at all about the law on physical punishment. One-third of both samples of parents thought that it was not currently illegal to smack a child of any age. Approximately half of parents in Scotland and 38\% of parents in Ireland incorrectly thought that it was illegal either to smack a child under a certain age or to smack a child at all. Both studies also found that knowledge of the legality or illegality of smacking did not vary according to whether parents had used physical punishment in the past year, suggesting that understanding of the law is not directly linked to behaviour.

Responses to proposed changes in legislation did not highlight widespread support for a ban on physical punishment. Indeed, one-third of parents in Ireland felt that smacking should remain legal - the majority of these parents also reflected the view that parents should have the right to use smacking if they wish. However, it is noteworthy that this proportion is slightly lower than that reported by Anderson et al (2002) in Scotland, where $41 \%$ of parents felt that smacking should remain legal. Other differences emerged between the Irish and Scottish studies: $14 \%$ of parents in Scotland in comparison with $42 \%$ of parents in Ireland endorsed a ban on smacking children of any age, while $24 \%$ of parents in Ireland and $42 \%$ of parents in Scotland felt that the age of the child is important in determining the legality of smacking. Together, these findings suggest that Irish parents were more supportive of a ban on physical punishment than Scottish parents. However, comparison of the proportions in favour or against prohibition of physical punishment in Ireland and Scotland needs to take account of the fact that the studies were conducted some 5 years apart - fieldwork for the Scottish study was conducted in 2002, while data for the Irish study was 
collected in 2007/08. It is possible that in the intervening years, Scottish parents' perspectives may have shifted more in line with what has emerged in the Irish study. Among those endorsing a lower age limit for smacking, a clear consensus emerged from both studies that children younger than 5 are too young to be smacked. Attitudes towards proposed changes to the law also emerged as consistent with parental use of physical punishment: those who use physical punishment are less likely to support a ban on physical punishment. Anderson et al (2002) similarly reported that those who had never used any form of physical punishment were more in favour of an outright ban.

\section{Summary}

The significance of parenting behaviours requires an understanding of the broader context within which parenting occurs. Key findings of the present study within this broader perspective include the perception among Irish parents of increased pressures on the parenting role and difficulties balancing family and work commitments. Findings clearly point to the dominance of an authoritative style of parenting among parents in Ireland. Consistent with recent theoretical developments in parenting, the significance of child characteristics in influencing parenting behaviours is also evident. Three discrete categories of parental discipline responses emerged among Irish parents: non-aggressive discipline strategies, psychologically aggressive discipline strategies and physical punishment. In keeping with findings in recent UK studies, non-aggressive inductive discipline strategies were used most frequently by the majority of parents. Such findings are worth noting in light of the positive associations highlighted between such inductive discipline strategies and children's ability to internalise moral and social values. The relatively infrequent use of psychologically aggressive strategies also compares favourably with reported incidence in similar UK studies. Parental use of physical punishment according to self-reports of Irish parents was low (25\%) when compared with similar reports in Scotland (51\%) and England (58\%). Child age effects were also evident with regard to the use of physical punishment. Specifically, children aged between 2 and 9 years were more likely to experience physical punishment, a finding which is reflected in previous research findings in the UK and Canada, where parental use of physical punishment is most common among children of toddler and pre-school age. Although a wide range of family and individual characteristics has been associated with the use of physical punishment in prior studies, few significant effects of these characteristics, other than child age, emerged in the present study. Trends in parental use of discipline strategies over time and across generations indicate a shift way from coercive power-assertive discipline responses. A key message from this study, therefore, in keeping with studies abroad, is that while experiencing physical punishment as a child can have a significant impact on the use of discipline strategies as an adult, the cycle of transmission across generations can be changed.

No clear consensus emerged with regard to attitudes to physical punishment among Irish parents. In line with previous reviews of attitudes to physical punishment, a social class and an education level dimension were apparent in these attitudes: lower-socio-economic status and lower educational achievement were associated with stronger endorsement of physical punishment. Attitudes endorsing physical punishment also appeared to be closely aligned with its actual use. However, given the low incidence of physical punishment reported by Irish parents in the present study, a surprisingly high proportion of parents did not oppose physical punishment in their reported attitudes. Consistent with previous studies, contexts of danger, non-compliance and aggression were reported as being more likely to elicit physical punishment as a discipline response among Irish parents. Parental feelings of loss of control, stress and anxiety were also associated with the use of physical punishment with children.

With regard to awareness and understanding of the legislative context, lack of clarity in terms of the current status of physical punishment in Irish law was evident among Irish parents, with well over one-third believing that physical punishment was illegal or that the legality depended on the age of the child. Responses to proposed changes in legislation did not highlight widespread support for a ban on physical punishment. While $42 \%$ of Irish parents felt that smacking should be made illegal, the majority of parents believed that they should have the right to use smacking if 
they wish. However, the present study indicates that Irish parents are more supportive of a ban on physical punishment than Scottish parents (14\%), as reported in a similar study in 2002.

\section{Conclusions}

- The incidence of physical punishment among parents in Ireland is low compared to similar UK-based studies. Physical punishment is typically used as an adjunct to other parenting strategies. This means that there is an opportunity to build on parents' existing skills and strengthen the effectiveness of the non-aggressive strategies that parents actually use.

- Discipline strategies need to be considered in the broader context of parenting and the specifics of the disciplinary incident. The propensity for parents to use physical punishment increases when they are stressed, worried about their child's safety or feel that they lack control. Moreover, the use of physical punishment brings with it negative emotional reactions, such as guilt and remorse, for the majority of parents. Parents may use physical punishment as a means to assert their authority and control, but the context of any punishment incident always needs to be considered.

- While the incidence of psychologically aggressive strategies is also low, these strategies may be as harmful to children as physically aggressive strategies. Little emphasis has been placed on the potential negative effects of these psychologically coercive strategies and attention to this issue is warranted.

- Some children are more vulnerable to physical punishment than others - children who are younger and children who display difficult behaviours. Parents of such children may require extra support to reduce their reliance on physical punishment and to enable them to develop alternative discipline strategies.

- There may be a need to challenge the acceptability of physical punishment among parents. Even though the incidence of physical punishment was relatively low, many parents did not see the harm in physical punishment or believed that parents have the right to use it as a discipline strategy. These ambivalent attitudes need to be investigated further and highlight the challenges that a legislative ban on physical punishment would bring to the Irish context. Parents may resist the idea that their behaviour would be subject to external regulation.

- Further research is needed to investigate the use of discipline strategies among ethnic minority parents and parents rearing their children in different family and social contexts in Ireland. Given that parents rarely use one discipline strategy in isolation, future research that considers the effectiveness of different combinations of parental discipline strategies, including inductive and more coercive strategies, would contribute to a more nuanced understanding of these issues. More research on the links between parenting styles and discipline and child outcomes is needed in an Irish context.

- This area of inquiry would also benefit from qualitative research designed to explore a range of issues in-depth, such as how the rights of parents and children are balanced in families, the meaning that discipline has for parenting and for the parent-child relationship, and the ambivalent attitudes that parents have towards physical punishment. 


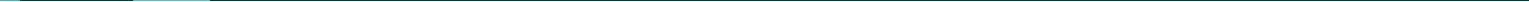


REFERENCES 
Anderson, S., Murray, L. and Brownlie, J. (2002) Disciplining Children: Research with parents in Scotland. Edinburgh: Scottish Executive Central Research Unit.

Ateah, C. and Durrant, J. (2005) 'Maternal use of physical punishment in response to child misbehaviour: Implications for child abuse prevention', Child Abuse and Neglect, Vol. 29, pp. 169-85.

Bandura, A. (1986) Social Foundations of Thought and Action: A Social Cognitive Theory. Englewood Cliffs, NJ: Prentice-Hall.

Barber, B., Stolz, H. and Olsen, J. (2005) 'Parental Support, Psychological Control and Behavioural Control: Assessing relevance across time, culture and method', Monographs of the Society for Research in Child Development, Vol. 70, No. 4.

Bates, J.E., Freeland, C.A. and Lounsbury, M.L. (1979) 'Measurement of infant difficultness', Child Development, Vol. 50, pp. 794-803.

Baumrind, D. (1971) 'Current patterns of parental authority', Developmental Psychology Monographs, Vol. 4, No. 1, Part 2.

Baumrind, D. (1991) 'Does causally relevant research support a blanket injunction against disciplinary spanking by parents?', Invited Address at the 109th Annual Convention of the American Psychological Association, August 2001.

Baumrind, D. (1997) 'Necessary Distinctions', Psychological Inquiry, Vol. 8, pp. 176-82.

Bluestone, C. and Tamis-LeMonda, C.S. (1999) 'Correlates of parenting styles in predominantly working and middle-class African American mothers', Journal of Marriage and the Family, Vol. 61, No. 4, pp. 881-93.

Bornstein, M.H. (ed.) (2002) Handbook of Parenting. Volumes 1-5 (2nd edition). Mahwah, NJ: Lawrence Erlbaum Associates.

Bower-Russa, M.E., Knutson, J.F. and Winebarger, A. (2001) 'Disciplinary history, adult disciplinary attitudes and risk for abusive parenting', Journal of Community Psychology, Vol. 29, pp. 219-40.

Bradley, R.H. and Corwyn, R. (1999) 'Parenting'. In: L. Balter and C. Tamis-LeMonda (eds.), Child Psychology: A Handbook of Contemporary Issues. Philadelphia: Psychology Press, pp. 339-62.

Brody, G.H. and Flor, D.L. (1998) 'Maternal resources, parenting practices and child competence in rural single-parent African American families', Child Development, Vol. 69, pp. 803-16.

Bugental, D.B. and Happaney, K. (2002) 'Parental Attributions'. In: M.H. Bornstein (ed.), Handbook of Parenting. Volume 3: Being and Becoming a Parent (2nd edition). Mahwah, NJ: Lawrence Erlbaum Associates, pp. 509-35.

Bugental, D.B. and Goodnow, J.J. (1998) 'Socialization Processes'. In: W. Damon (Series Ed.) and N. Eisenberg (Volume Ed.), Handbook of Child Psychology. Volume 3: Social, emotional and personality development (5th edition). New York: Wiley, pp. 389-462.

Buss, A.H. and Plomin, R. (1984) Temperament: Early developing personality traits. Mahwah, NJ: Lawrence Erlbaum Associates.

Cawson, P., Wattam, C., Brooker, S. and Kelly, G. (2000) Child Maltreatment in the United Kingdom: A study of the prevalence of abuse and neglect. London: National Society for the Prevention of Cruelty to Children.

Central Statistics Office (2007) Census 2006. Volume 3: Household Composition, Family Units and Fertility. Dublin: The Stationery Office.

Cohen, P. and Brook, J.S. (1995) 'The Reciprocal Influence of Punishment and Child Behaviour Disorder'. In: J. McCord (ed.), Coercion and Punishment in Long-term Perspectives. New York: Cambridge University Press, pp. 154-64.

Clement, M., Bouchard, C., Jette, M. and Laferriere, S. (2000) La Violence Familiale dans la Vie des Enfants du Quebec. Quebec: Institut de la Statistique du Quebec.

Coll, C.T., Meyer, E.C. and Brillon, L. (1995) 'Ethnic and Minority Parenting'. In: M.H. Bornstein (ed.), Handbook of Parenting. Volume 2: Biology and Ecology of Parenting (2nd edition). Mahwah, NJ: Lawrence Erlbaum Associates, pp. 189-209.

Collins, W.A., Maccoby, E.E., Steinberg, L., Hetherington, E.M. and Bornstein, M.H. (2000) 'Contemporary Research on Parenting: The case for nature and nurture', American Psychologist, Vol. 55, pp. 218-32. 
Coplan, R.J., Hastings, P.D., Lagace-Seguin, D. and Moulton, C.E. (2002) 'Authoritative and authoritarian mothers' parenting goals, attributions and emotions across different child-rearing contexts', Parenting, Vol. 2, No. 1, pp. 1-26.

Council of Europe (2007) Views on Positive Parenting and Non-Violent Upbringing. Strasbourg: Council of Europe Publishing.

Council of Europe (2008) Eliminating Corporal Punishment: A Human Rights Imperative for Europe's Children. Strasbourg: Council of Europe Publishing.

Coyl, D.D., Roggman, L.A. and Newland, L.A. (2002) 'Stress, maternal depression and negative mother-infant interactions in relation to infant attachment', Infant Mental Health Journal, Vol. 23, pp. 145-63.

Culp, R.E., Culp, A.M., Dengler, B. and Maisano, P.C. (1999) 'First-time young mothers living in rural communities use corporal punishment with their toddlers', Journal of Community Psychology, Vol. 27, pp. 503-09.

Dadds, M.R., Sheffield, J.K. and Holbeck, J.F. (1990) 'An examination of the differential relationship of marital discord to parents' discipline strategies for boys and girls', Journal of Abnormal Child Psychology, Vol. 18, No. 2, pp. 121-29.

Daly, M. (2004) Families and Family Life in Ireland: Challenges for the Future, Report of Public Consultation Fora. Dublin: Department of Social and Family Affairs.

Daly, M. (2007) (ed.) Parenting in Contemporary Europe: A Positive Approach. Strasbourg: Council of Europe.

Darling, N. and Steinberg, L. (1993) 'Parenting Style as Context: An Integrative Model', Psychological Bulletin, Vol. 113, pp. 487-96.

Day, R.D., Peterson, G.W. and McCracken, C. (1998) 'Predicting spanking of younger and older children by mothers and fathers', Journal of Marriage and the Family, Vol. 60, pp. 79-94.

Deater-Deckard, K. and Dodge, K.A. (1997) 'Externalizing behaviour problems and discipline revisited: Non-linear effects and variation by culture, context and gender', Psychological Inquiry, Vol. 8, pp. 161-75.

Deater-Deckard, K., Lansford, J., Dodge, K., Pettit, G. and Bates, J. (2003) 'The development of attitudes about physical punishment: An 8-year longitudinal study', Journal of Family Psychology, Vol. 17, No. 3, pp. 351-60.

De Leeuw, E.D. and van der Zouwen, J. (1988) 'Data Quality in Telephone and Face-to-Face Surveys: A Comparative Meta-analysis'. In: R.M. Groves, P.P. Biemer and L.E. Lyberg (eds.), Telephone Survey Methodology. New York: John Wiley and Sons.

Department of Education and Science (2006) School Matters: The Report of the Task Force on Student Behaviour in Second-level Schools. Dublin: The Stationery Office.

Department of Health and Children (2000) The National Children's Strategy: Our Children - Their Lives. Dublin: The Stationery Office.

Dietz, T.L. (2000) 'Disciplining Children: Characteristics associated with the use of corporal punishment', Child Abuse and Neglect, Vol. 24, No. 12, pp. 1529-42.

Domjan, M. (2000) The Essentials of Conditioning and Learning (2nd edition). Belmont, CA: Wadsworth.

Durrant, J. (1996) 'The Swedish Ban on Corporal Punishment: Its history and effects'. In: D. Frehesse, W. Horn and K.-D Bussman (eds.), Family Violence against Children: A Challenge for Society. New York: Walter de Gruyter, pp. 19-25.

Durrant, J. (2005) 'Corporal Punishment: Prevalence, predictors and implications for child behaviour and development'. In: S.N. Hart (ed.), Eliminating Corporal Punishment: The Way Forward to Constructive Child Discipline. Paris: UNESC0, pp. 49-90.

Durrant, J. (2006) Researching the Prevalence of Corporal Punishment of Children: A Working Paper (unpublished manuscript). Winnipeg: University of Manitoba, Department of Family Social Sciences. 
Durrant, J., Broberg, A. and Rose-Krasnor, L. (1999) 'Predicting maternal use of physical punishment from maternal characteristics in Sweden and Canada'. In: P.D. Hastings and C.C. Piotrowski (eds.), New Directions in Child Development: Conflict as a context for understanding maternal beliefs about child-rearing and children's misbehaviour. San Francisco: Jossey-Bass, pp. 25-41.

Eamon, M.K. and Zuehl, R.M. (2001) 'Maternal depression and physical punishment as mediators of the effect of poverty on socio-emotional problems of children in single-mother families', American Journal of Orthopsychiatry, Vol. 71, pp, 218-26.

Eisenberg, N. and Valiente, C. (2002) 'Parenting and Children's Prosocial and Moral Development'. In: M.H. Bornstein (ed.), Handbook of Parenting. Volume 5: Practical Issues in Parenting (2nd edition). Mahwah, NJ: Lawrence Erlbaum Associates, pp. 111-42.

Eisenberg, N., Losoya, S. and Fabes, R.A. (2001) 'Parental socialization of children's dysregulated expression of emotion and externalizing problems', Journal of Family Psychology, Vol. 15, pp. 183-205.

Ellison, C., Bartowski, J. and Segal, M. (1996) 'Conservative Protestantism and the parental use of corporal punishment', Social Forces, Vol. 74, pp. 1003-28.

European Court of Human Rights (1998) Judgment on A v. United Kingdom, 23 September 1998 (Paragraphs 10 and 22-24).

Fergusson, D.M. and Lynskey, M.T. (1997) 'Physical punishment/maltreatment during childhood and adjustment in young adulthood', Child Abuse and Neglect, Vol. 21, pp. 617-30.

Fisher, P.A. and Fagot, B.I. (1993) 'Negative Discipline in Families: A multi-dimensional risk model', Journal of Family Psychology, Vol. 7, No. 2, pp. 250-54.

Flynn, C.P. (1998) 'To Spank or Not to Spank: The effect of situation and age of child on support for corporal punishment', Journal of Family Violence, Vol. 13, pp. 21-37.

Freeman, M. (1999) 'Children are unbeatable', Children and Society, Vol. 13, pp. 130-41.

Gershoff, E. (2002) 'Parental Corporal Punishment and Associated Child Behaviours and Experiences: A Meta-Analytic and Theoretical Review', Psychological Bulletin, Vol. 128, pp. 539-79.

Gershoff, E., Miller, P. and Holden, G. (1999) 'Parenting Influences from the Pulpit: Religious affiliation as a determinant of parental corporal punishment', Journal of Family Psychology, Vol. 13, pp. 307-20.

Ghate, D., Hazel, N., Creighton, S., Finch, S. and Field, J. (2003) The National Study of Parents, Children and Discipline in Britain. London: Policy Research Bureau.

Giles-Sims, J., Straus, M.A. and Sugarman, D.B. (1995) 'Child, maternal and family characteristics associated with spanking', Family Relations, Vol. 44, No. 2, pp. 170-76.

Goodman, R. (1997) 'The Strengths and Difficulties Questionnaire: A Research Note', Journal of Child Psychology, Psychiatry and Allied Disciplines, Vol. 38, No. 5, pp. 581-86.

Goodnow, J. and Collins, W. (1990) Development according to Parents: The nurture, sources and consequences of parents' ideas. Hillsdale, NJ: Erlbaum.

Gracia, E. and Herrero, J. (2008) 'Is it considered violence? The acceptability of physical punishment of children in Europe', Journal of Marriage and the Family, Vol. 70, pp. 210-17.

Graziano, A.M. (1994) 'Why we should study sub-abusive violence against children', Journal of Interpersonal Violence, Vol. 9, pp. 412-19.

Graziano, A.M. and Namaste, K.A. (1990) 'Parental use of physical force in child discipline', Journal of Interpersonal Violence, Vol. 5, pp. 449-63.

Greene, S. (1994) 'Why do parents smack their children?', Journal of Child Centred Practice, Vol. 1, No. 1, pp. 27-38.

Grogan-Kaylor, A. and Otis, M. (2007) 'The predictors of parental use of physical punishment', Family Relations, Vol. 56, pp. 80-91.

Grusec, J.E. and Goodnow, J.J. (1994) 'Impact of parental discipline methods on the child's internalisation of values: A reconceptualisation of current points of view', Developmental Psychology, Vol. 30, pp. 4-19. 
Hagekull, B., Bohlin, G. and Hammaberg, A. (2004) 'The Role of Perceived Control in Child Development: A Longitudinal Study', International Journal of Behavioural Development, Vol. 25, No. 5, pp. 429-37.

Hart, C.H., DeWolf, D.M., Wozniak, P. and Burts, D.C. (1992) 'Maternal and paternal disciplinary styles: Relations with pre-schoolers' playground behavioural orientations and peer status', Child Development, Vol. 63, pp. 879-92.

Heaven, P.C. and Goldstein, M. (2001) 'Parental influences and mental health among some Australian youth: Cross-cultural analysis', Australian Journal of Psychology, Vol. 53, No. 3, pp. 170-75.

Hemenway, D., Solnick, S. and Carter, J. (1994) 'Child-rearing Violence', Child Abuse and Neglect, Vol. 18, No. 12, pp. 1011-20.

Hoff, E., Laursen, B. and Tardif, T. (2002) 'Socio-economic Status and Parenting'. In: M.H. Bornstein (ed.), Handbook of Parenting. Volume 2: Biology and Ecology of Parenting (2nd edition). Mahwah, NJ: Lawrence Erlbaum Associates, pp. 231-52.

Hoffman, M.L. (1970) 'Moral Development'. In: P.H. Mussen (ed.), Carmichael's Manual of Child Psychology, Volume 2. New York: Wiley, pp. 261-360.

Hoffman, M.L. (1983) 'Affective and Cognitive Processes in Moral Internalisation'. In: E.T. Higgins, D. Ruble and W. Hartup (eds.), Social Cognition and Social Development: A Socio-Cultural Perspective. Cambridge: Cambridge University Press, pp. 236-74.

Hoffman, M.L. (1994) 'Discipline and Internalisation', Developmental Psychology, Vol. 30, No. 1, pp. 26-28.

Hoffman, M.L. (2000) Empathy and Moral Development: Implications for caring and justice. Cambridge: Cambridge University Press.

Holbrook, A.L., Green, M.C. and Krosnick, J.C. (2003) 'Telephone vs. face-to-face interviewing of national probability samples with long questionnaires: Comparisons of respondent satisficing and social desirability response bias', Public Opinion Quarterly, Vol. 67, pp. 69-125.

Holden, G.W. (2002) 'Perspectives on the effects of corporal punishment: Comment on Gershoff (2002)', Psychological Bulletin, Vol. 128, No. 4, pp. 590-95.

Holden, G.W., Coleman, S.M. and Schmidt, K.L. (1995) 'Why 3-year-old children get spanked: Parent and child determinants as reported by college-educated mothers', Merrill-Palmer Quarterly, Vol. 41, pp. 431-52.

Holden, G.W., Thompson, E.E., Zambarano, R.J. and Marshall, L.A. (1997) 'Child effects as a source of change in maternal attitudes towards corporal punishment', Journal of Social and Personal Relationships, Vol. 14, pp. 481-90.

Holden, G.W., Miller, P. and Harris, S. (1999) 'The instrumental side of corporal punishment: Parents' reported practices and outcomes', Journal of Marriage and the Family, Vol. 61, pp. 908-19.

Humphreys, P., Fleming, S. and O'Donnell, 0. (2000) Balancing Work and Family Life: The role of flexible working arrangements. Dublin: Department of Social and Family Affairs.

James, A. and Prout, A. (1997) Constructing and Reconstructing Childhood: Contemporary issues in the sociological study of childhood. London: Falmer.

Kalb, L.M. and Loeber, R. (2003) 'Child Disobedience and Non-Compliance: A Review', Pediatrics, Vol. 111, pp. 641-52.

Kanoy, K., Ulku-Steiner, B., Cox, M. and Burchinal, M. (2003) 'Marital relationship and individual psychological characteristics that predict physical punishment of children', Journal of Family Psychology, Vol. 17, No. 1, pp. 20-28.

Kendler, K.S. (1996) 'Parenting: A Genetic-Epidemiologic Perspective', American Journal of Psychiatry, Vol. 153, pp. 11-20.

Kent, D. and Peplar, D. (2003) 'The Aggressive Child as Agent in Coercive Family Processes'. In: L. Kuczynski (ed.), Handbook of Dynamics in Parent-Child Relations. Thousand Oaks, CA: Sage, pp. 131-44.

Kerr, D., Lopez, N., Olson, S. and Sameroff, J. (2004) 'Parental discipline and externalizing behaviour problems in early childhood: The roles of moral regulation and child gender', Journal of Abnormal Child Psychology, Vol. 32, No. 4, pp. 369-83. 
Kochanska, G., Coy, K.C. and Murray, K.T. (2001) 'The development of self-regulation in the first four years of life', Child Development, Vol. 72, pp. 1091-1111.

Kochanska, G. and Thompson, R.A. (1997) 'The emergence and development of conscience in toddlerhood and early childhood'. In: J.E. Grusec and L. Kuczynski (eds.), Parenting and Children's Internalization of Values: A Handbook of Contemporary Theory. New York: Wiley, pp. 53-77.

Kuczynski, L. and Hildebrandt, N. (1997) 'Models of conformity and resistance in socialization theory'. In: J.E. Grusec and L. Kuczynski (eds.), Parenting and children's internalization of values: A Handbook of Contemporary Theory. New York: Wiley, pp. 227-56.

Larzelere, R.E. (1993) 'Response to Oosterhuis - Empirically justified uses of spanking: Towards a discriminating view of corporal punishment', Journal of Psychology and Theology, Vol. 21, pp. 142-47.

Larzelere, R.E. (1996) 'A Review of the Outcomes of Parental Use of Non-abusive or Customary Physical Punishment', Pediatrics, Vol. 98. No. 4, pp. 824-28.

Larzelere, R.E. (2000) 'Child Outcomes of Non-abusive and Customary Physical Punishment by Parents: An Updated Literature Review', Clinical Child and Family Psychology Review, Vol. 3, pp. 199-221.

Larzelere, R.E., Sather, P.R., Schneider, W.N., Larson, D.B. and Pike, P.L. (1998) 'Punishment enhances reasoning's effectiveness as a disciplinary response to toddlers', Journal of Marriage and the Family, Vol. 60, pp. 388-403.

Layte, R., McGee, H., Quail, A., Rundle, K., Cousins, G., Donnelly, C., Mulcahy, F. and Conroy, R. (2006) The Irish Study of Sexual Health and Relationships. Dublin: Crisis Pregnancy Agency.

Lepper, M.R. (1983) 'Social Control Processes and the Internalization of Social Values: An attributional perspective'. In: E.T. Higgins, D.N. Ruble and W.W. Hartup (eds.), Social Cognition and Social Development. New York: Cambridge University Press, pp. 294-330.

Lerner, R.M., Rothbaum, F., Boulos, S. and Castellino, D.R. (2002) ‘Developmental Systems Perspective on Parenting'. In: M.H. Bornstein (ed.), Handbook of Parenting. Volume 2: Biology and Ecology of Parenting (2nd edition). Mahwah, NJ: Lawrence Erlbaum Associates, pp. 315-44.

Locke, L.M. and Prinz, R.J. (2002) 'Measurement of Parental Discipline and Nurturance', Clinical Psychology Review, Vol. 22, pp. 895-930.

Maccoby, E.E. and Martin, J.A. (1983) 'Socialization in the context of the family: Parent-child interaction'. In: P.H. Mussen (Series Ed.) and E.M. Hetherington (Volume Ed.), Handbook of Child Psychology. Volume 4: Socialization, personality and social development (4th edition). New York: Wiley, pp. 1-101.

MacKinnon, C.E., Lewis, C., Lamb, C.E., Arbuckle. B., Baradaran, L.P. and Volling, B.L. (1992) 'The relationship between biased maternal and filial attributions and the aggressiveness of their interactions', Developmental Psychopathology, Vol. 4, pp. 403-15.

McGee, H., Garavan, R., deBarra, M., Byrne, J. and Conroy, R. (2002) The SAVI Report: Sexual Abuse and Violence in Ireland. Dublin: The Liffey Press.

Miller, S.A. (1995) 'Parents' attributions for their children's behaviour', Child Development, Vol. 66, pp. 1557-84.

Mulvaney, M.K. and Mebert, C.J. (2007) 'Parental corporal punishment predicts behaviour problems in early childhood', Journal of Family Psychology, Vol. 21, pp. 389-97.

Murphy-Cowan, T. and Stringer, M. (1999) 'Physical Punishment and the Parenting Cycle: A Survey of Northern Irish Parents', Journal of Community and Applied Social Psychology, Vol. 9, pp. 61-71.

Newsom, C., Flavell, J.E. and Rincover, A. (1983) 'The Side Effects of Punishment'. In: S. Axelrod and J. Apsche (eds.), The Effects of Punishment on Human Behaviour. New York: Academic Press, pp. 285-316.

Nobes, G. and Smith, M. (2002) 'Family structure and the physical punishment of children', Journal of Family Issues, Vol. 23, No. 3, pp. 349-73.

Nobes, G., Smith, M., Upton, P. and Heverin, A. (1999) 'Physical punishment by mothers and fathers in British homes', Journal of Interpersonal Violence, Vol. 14, No. 8, pp. 887-902. 
One Family (2004) Meeting the needs of asylum-seeking and refugee one-parent families: One family and the effects of a changing clientele. Dublin: One Family.

Park, M.S. (2001) 'The factors of child physical abuse in Korean immigrant families', Child Abuse and Neglect, Vol. 25, pp. 945-58.

Parke, R.D. (2002) 'Punishment revisited - Science, values and the right question: Comment on Gershoff (2002)', Psychological Bulletin, Vol. 128, pp. 596-601.

Patterson, G.R. (1982) Coercive Family Processes. Eugene, OR: Castalia.

Patterson, G.R. and Fisher, P.A. (2002) 'Recent developments in our understanding of parenting: Bidirectional effects, causal models and the search for parsimony'. In: M.H. Bornstein (ed.), Handbook of Parenting. Volume 5: Practical Issues in Parenting (2nd edition). Mahwah, NJ: Lawrence Erlbaum Associates, pp. 59-88.

Pecnic, N. (2007) 'Towards a Vision of Parenting in the Best Interests of the Child'. In: M. Daly (ed.), Parenting in Contemporary Europe: A Positive Approach. Strasbourg: Council of Europe.

Pinderhughes, E., Dodge, K., Bates, J., Pettit, G. and Zelli, A. (2000) 'Discipline Responses: Influences of parents' socio-economic status, ethnicity, beliefs about parenting, stress and cognitive-emotional processes', Journal of Family Psychology, Vol. 14, No. 3, pp. 380-400.

Pinheiro, P.S. (2006) World Report on Violence against Children: United Nations Secretary-General's Study on Violence against Children. Geneva: United Nations.

Ritchie, J. (2002) 'Parents: Discipline, punishment and child abuse. A four-decade study of child-rearing attitudes and practices', The New Zealand Psychological Society Bulletin, Vol. 100, pp. 30-33.

Robinson, C.C., Mandleco, B., Olsen, S.F. and Hart, C.H. (2001) 'The Parenting Styles and Dimensions Questionnaire (PSDQ)'. In: B.F. Perlmutter, J. Touliatos and G.W. Holden (eds.), Handbook of Family Measurement Techniques. Volume 3: Instruments and Index. Thousand Oaks, CA: Sage, pp. 319-21.

Shannon, G. (2005) Child Law. Dublin: Thomson Round Hall.

Shumow, L., Vandell, D.L. and Posner, J.K. (1998) 'Harsh, firm and permissive parenting in lowincome families: Relation to children's academic achievement and behavioural adjustment', Journal of Family Issues, Vol. 19, pp. 483-507.

Simons, R.L., Whitbeck, L.B., Conger, R.D. and Chyi-In, W. (1991) 'Intergenerational transmission of harsh parenting', Developmental Psychology, Vol. 27, No. 1, pp. 159-71.

Smetana, J.G. (1997) 'Parenting and the development of social knowledge reconceptualized: A social domain analysis'. In: J.E. Grusec and L. Kuczynski (eds.), Parenting and Children's Internalization of Values: A Handbook of Contemporary Theory. New York: Wiley, pp. 162-92.

Smith, A.B., Gollop, M., Taylor, N.J. and Marshall, K. (2005) The Discipline and Guidance of Children: A Summary of Research. Dunedin and Wellington, NZ: Children's Issues Centre and Office of the Children's Commissioner.

Smith, J.R. and Brooks-Gunn, J. (1997) 'Correlates and consequences of harsh discipline for young children', Archives of Pediatrics and Adolescent Medicine, Vol. 151, No. 8, pp. 777-86.

Socolar, R.R.S., Winsor, J., Hunter, W.M., Catellier, D. and Kotch, J.B. (1999) 'Maternal disciplinary practices in an at-risk population', Archives of Pediatrics and Adolescent Medicine, Vol. 153, No. 9, pp. 927-34.

Soriano, G., Weston, R. and Kolar, V. (2001) 'Meeting the Challenges of Parenting: Factors that enhance and hinder the role of parents', Family Matters, No. 58. Melbourne: Australian Institute of Family Studies.

Straus, M.A. (1991) 'Discipline and Deviance: Physical punishment of children and violence and other crime in adulthood', Social Problems, Vol. 38, pp. 133-54.

Straus, M.A. and Stewart, J.H. (1999) 'Corporal Punishment by American Parents: National data on prevalence, chronicity, severity and duration in relation to child and family characteristics', Clinical Child and Family Psychology Review, Vol. 2, No. 2, pp. 55-70.

Teti, D. and Candelaria, M.A. (2002) 'Parenting Competence'. In: M.H. Bornstein (ed.), Handbook of Parenting. Volume 4: Social Conditions and Applied Parenting (2nd edition). Mahwah, NJ: Lawrence Erlbaum Associates, pp. 149-80. 
Timur, S. (2000) 'Changing trends and major issues in international migration: An overview of UNESCO programmes', International Social Science Journal, Vol. 52, No. 165, pp. 255-68.

Tomasello, M. (1999) The Cultural Origins of Human Cognition. Cambridge, MA: Harvard University Press.

Tulviste, T. and Ahtonen, M. (2007) 'Child-rearing values of Estonian and Finnish mothers and fathers', Journal of Cross-Cultural Psychology, Vol. 38, No. 2, pp. 137-55.

UN (1989) United Nations Convention on the Rights of the Child. Geneva: United Nations. Available at: www2.ohchr.org/english/law/crc.htm (accessed September 2009)

Vasta, R. (1982) 'Physical Child Abuse: A Dual Component Analysis', Developmental Review, Vol. 2, pp. $125-49$.

Vissing, Y.M., Straus, M.A., Gelles, R.J. and Harrop, J.W. (1991) 'Verbal aggression by parents and psychosocial problems of children', Child Abuse and Neglect, Vol. 15, No. 3, pp. 223-38.

Watson, D. and Parsons, S. (2005) Domestic Abuse of Women and Men in Ireland: Report on the National Study of Domestic Abuse. Dublin: The Stationery Office.

Weisberg, H.F. (2005) The Total Survey Error Approach: A Guide to the New Science of Survey Research. Chicago: University of Chicago Press.

Weir, L., Etelson, D. and Brand, D. (2006) 'Parents perceptions of neighbourhood safety and children's physical activity', Preventive Medicine, Vol. 43, No. 3, pp. 212-17.

Wilson, C.M., Wilson, L.C. and Fox, C.A. (2002) 'Structural and personal contexts of discipline orientations of Guyanese parents: Theoretic and empirical considerations', Journal of Comparative Family Studies, Vol. 33, pp. 1-13.

Wissow, L.S. (2001) 'Ethnicity, income and parenting contexts of physical punishment in a national sample of families with young children', Child Maltreatment, Vol. 6, pp. 118-29.

Wissow, L.S. (2002) 'Child Discipline in the First Three Years of Life'. In: N. Halfon, K.T. McLearn and M.A. Schuster (eds.), Child-rearing in America: Challenges facing parents with young children. New York: Cambridge University Press, pp. 146-77.

Woodward, L.J. and Fergusson, D.M. (2002) 'Parent, child and contextual predictors of childhood physical punishment', Infant and Child Development, Vol. 11, No. 3, pp. 213-36.

Wolfner, G.D. and Gelles, R.J. (1993) 'A Profile of Violence towards Children: A National Study', Child Abuse and Neglect, Vol. 17, No. 2, pp. 197-212.

Wu, P., Robinson, C.C., Yang, C., Hart, C.H., Olsen, S.F., Porter, C., Jin, S., Wo, J. and Wu, X. (2002) 'Similarities and differences in mothers' parenting of pre-schoolers in China and the United States', International Journal of Behavioural Development, Vol. 26, pp. 481-91. 


\section{APPENDIX: CHILD PROTECTION PROTOCOL}




\section{Background}

While this project is not dealing directly with abuse of children, an interviewer may become aware, during the course of the interview, that children living in a household are being abused. We define 'abuse' as behaviour that causes, or is likely to cause, significant physical or emotional harm to the child. It is important, therefore, that we outline clearly what the responsibilities of the interviewer are in this situation.

First, it is worth noting that there is no legal requirement to report child abuse. However, most professional organisations that deal with families, children or people who have been abused have developed strict guidelines whereby any abuse of children must be reported. In such cases, the client is always informed in advance that if the professional (social worker, counsellor, etc) becomes aware that children are being abused, he or she will be obliged to report it. An agreement of the client to this condition is obtained before the professional begins to work with him or her.

Our situation [the Parenting Survey] is quite different. First, we do not know the full identity of the people who are being interviewed in this project. The telephone numbers are generated at random by a computer and we have no way of looking up the name and address associated with the number. Second, we have approached the respondents for help, not the other way around. We have given respondents an absolute guarantee that the information they provide will be treated in confidence. Third, if we were to begin the interview with a statement to the effect that we will report all instances of (suspected) child abuse, it would seriously discourage participation in the survey. This, in turn, would damage our ability to collect information that is vital to understanding the circumstances around physical disciplining of children.

On the other hand, if we become aware that children are at risk, we have a moral obligation to make every effort to ensure that they receive help. The following is the course of action we will adopt.

\section{Is a child at risk of abuse in this household?}

The first question is whether there are grounds to be concerned that a child may be at risk in the household where the interview is being conducted. The following would be grounds for such a concern:

1. The respondent says that he/she has physically or sexually abused children.

2. The respondent says that his/her partner has physically or sexually abused children.

\section{Course of action}

1. Where you feel that a child is at risk, you should say the following to the respondent at the end of the interview:

'As you know, I do not know your full name or your address. However, I am concerned that, given what you have told me, children [as well as yourself] may be at risk in your present situation. I would like to strongly encourage you to seek help, for their sakes [as well as for your own]. Would you be willing to take the telephone number of Parentline or of someone in your health board area whom you could contact to get help?'

2. If the respondent is willing, provide the number of Parentline [1890 927 277] and of the HSE Child Care Service.

3. Note on the follow-up sheet to ask them about this during call-back.

By the end of the interview, the interviewer should have built up a good rapport with the respondent so that the chances of their taking on board a suggestion to take the matter further are increased.

In all cases where you have a concern regarding children in the household, be sure to discuss the interview with the fieldwork manager [name provided] or the project leaders [names provided]. 


\section{The call-back}

1. On call-back, you can check whether the respondent has thought further about seeking help. If they have not taken action, the following suggestion should be made:

'As you know, I do not know your full name or your address. However, as I mentioned the last time we talked, I am concerned that, given what you have told me, children [as well as yourself] may be at risk in your present situation. If you were to give me your name and address, I could contact your local health board office on your behalf. Would you like me to do this for you?'

2. If the respondent is willing to let you do this, check for the relevant area and county on the list of Child Protection and Social Work Services provided. These services tend to follow normal office hours. 
